\title{
A REVISION OF THE ARHOPALA GROUP OF ORIENTAL LYCAENIDAE (LEPIDOPTERA : RHOPALOCERA)
}

\author{
By W. H. EVANS \\ Honorary Associate British Museum (Natural History)
}

CONTENTS

\begin{tabular}{|c|c|c|c|c|c|c|c|c|c|c|c|c|}
\hline & & & & & & & & & & & & PAGE \\
\hline INTRODUCTION & . & . & . & . & . & . & . & . & . & . & . & 85 \\
\hline General Key & To & GenerA & AND & Grot & PS & . & . & . & . & . & . & 87 \\
\hline Keys $\mathrm{A}$ To $\mathrm{P}$ & FOR & EACH & ROUP & AND & Genu & & . & . & . & . & . & 88 \\
\hline ApPENDIX & . & . & . & . & . & . & . & . & . & . & . & I33 \\
\hline REFERENCES & . & . & . & . & . & . & . & . & . & . & . & 136 \\
\hline INDEX & . & . & . & . & . & . & . & . & . & . & . & I38 \\
\hline
\end{tabular}

INTRODUCTION

THE Arhopala group of genera was first constituted as such by De Nicéville (I89o). A revision of the group, which he called the Amblypodia group (see Appendix I), was published by Bethune-Baker (I903). Swinhoe (I9I0) elevated the group to subfamily rank, Amblypodiinae. Evans (I925, I932) reverted to the name Amblypodia including in the group the genera Iraota, Horsfieldia, Thaduka, Mahathala and Amblypodia (=Arhopala). But in this review I intend to deal only with the last of these genera : no review is needed for the rest of the group. Corbet (I940, see Appendix I) was the first author to demonstrate clearly that Arhopala, as currently used, and not Amblypodia, is the correct generic name for the I87 species included in this review, though, as will appear later, I have found it necessary to restrict the application of that name.

Doherty (I889) remarked that Arhopala was a cumbrous genus and that every opportunity should be taken of dividing it. This is easier said than done in a convincing manner. Moore for instance created a number of genera, which were not accepted by subsequent authors. What is the definition of a genus ? Long ago I put that question to Professor W. T. M. Forbes : he replied that you want two characters, one of which must be structural. I put the same question to the late Lord Walter Rothschild: he replied that a species was a nature-made entity, but that a genus was a man-made conception created for his own convenience. It is no easy matter to decide whether a particular character difference is of generic value. One should bear in mind that the golden rule is that there is no golden rule and that one cannot modify nature, but that one can adapt one's conceptions to the 
circumstances of any particular case. I have described and named I24 genera and have tried to keep within the limits, which may be regarded on one hand as Rothschild's abstention from dividing up Papilio in his work on that genus, and on the other the division by B. C. S. Warren and others of the well-beloved and wellknown genus Argynnis into numerous genera based on minor differences in the genitalia.

In my Hesperiid work I found that the genitalia always furnished excellent clues to identification and classification. In the Arhopala group the genitalia give very little assistance. But the long ovipositor of Panchala and the spiked uncus of Flos serve to define these genera, while in certain species (BII to I4) identification is difficult without a genitalia examination. There is very little variation in venation except in respect of the hind wing cell. Its abnormal shape defines the genus Arhopala and its great length separates the new genus Aurea. No further structural differences of generic value could be found. One hundred and fifty-eight species remain to be placed in the genus Narathura, which has been divided into I2 groups lettered $A$ to $L$, the other 4 genera continuing as $M$ to $P$ for facility of Index reference. The larger groups have been divided into sub-groups.

The general key and the keys for each group and genus have been framed in accordance with the system introduced in my Identification of Indian Butterflies. I have also used the same simple abbreviations adopted in that work, viz.: $\mathrm{F}=$ fore wing, $\mathrm{H}=$ hind wing : upf = upperside of fore wing : unh = underside of hind wing, etc., because these, like the keys, have proved both convenient and easy to operate.

Following the year of publication after the author's name, I have given the type locality and the location of the type, if known ; and a list of the material in the British Museum (Natural History). The early, artist-made illustrations, often badly reproduced, are generally unsatisfactory as it was not recognized that identification is dependent primarily on the disposition of the underside markings. Corbet published good photographs of the undersides in I946 and of the genitalia in I94I of the Malayan species. These have been cited, " $\mathrm{g}$ " being added for the genitalia figures. For other species the best available figure has been cited (generally from Seitz).

The treatment of the species in the keys may appear uneven. When identification is dependent on a single easily-recognized character, there is no need to say more. Where identification is difficult, as much assistance as is available has been given. In some cases, such as further information about Panchala in addition to the genitalia character, any description would have to be lengthy and probably would nevertheless be unsatisfactory. It is assumed that students and collectors will have available some book containing illustrations, such as Seitz.

Subspecies have been arranged from west to east. Generally the differences are "geographical" and are well marked, but in certain cases (e.g. muta B4 and philander Hro) several sub-species appear to fly together, due perhaps to some ecological cause or to " invasions" from other areas.

The Appendix contains details of various nomenclature difficulties and is referred to in the keys. 
I have to thank Lt.-Col. J. N. Eliot for a great deal of useful advice and for checking my work: he has saved me from many blunders. Major C. F. Cowan, Lt.-Col. Eliot, Mr. J. A. Hislop, M.C., and Prof. R. C. R. Morrell placed their collections at my disposal and Brigadier A. W. G. Wildey furnished me with a great deal of information about Malaya. Dr. Diakonoff of the Leiden Museum very kindly allowed me to examine the type of Panchala weelii Piepers. Mr. H. K. Clench of the Carnegie Museum, Pittsburg, sent me paratypes of species described by Holland. Dr. E. M. Hering as usual was very helpful regarding material in German Museums, Mr. N. D. Riley, C.B.E., and Mr. W. H. Tams assisted me to resolve nomenclature difficulties.

\section{GENERAL KEY TO GENERA AND GROUPS}

$A \quad(\mathrm{P}) . \quad \delta^{t}$ genitalia, sides of uncus at dorsal end rounded.

Aa $(\mathrm{O})$. o ovipositor short and blunt.

$\mathrm{Ab}(\mathrm{N})$. $\mathrm{H}$ end cell angled, lower part parallel to termen, upper part inclined to midway between the central and outer spots in space 7 .

Ac (M). $\quad \mathrm{H}$ cell not longer than half the wing.

Genus Narathura Moore 1878 : type hypomuta Hewitson, fixed by author. One hundred and fifty-eight species in 12 groups.

Synonyms Nilasera Morre I88I: type centaurus Fabricius, fixed by author. Satadra Moore 1884: type atrax Hewitson, fixed by author. Darasana Moore 1884: type perimuta Moore, fixed by author.

Ad (L). Markings more or less complete.

Ae (C). Unh discal spots in spaces 7, 6, 5 macular and with their centres in line.

Af (B). Tailed.

Anthelus group. Twenty-three species.

$B$ (Af). Not tailed.

Epimuta Group. Twenty-five species.

C (Ae). Not as in Ae.

$\mathrm{Ca}(\mathrm{K}) . \quad \mathrm{H}$ tornus more or less produced and angled; termen tailed or dentate.

$\mathrm{Cb}(\mathrm{J})$. F termen even, not conspicuously falcate or crenulate. $\mathrm{H}$ outer half of dorsum not conspicuously excavate.

Cc (G). Unh discal band completely dislocated at vein 2 . Tailed at end of vein $2 \mathrm{H}$.

Cd (D). $\mathrm{H}$ with an additional white-tipped tail at end of vein 3 .

Abseus group. Three species.

$D$ (Cd). $\mathrm{H}$ no tail at end of vein 3 .

$\mathrm{Da}(\mathrm{E})$. Unh with a white streak at base of space 8 .

Theba group. Four species.

E (Da). Unh with the usual spot at base of space 8 .

$\mathrm{Ea}(\mathrm{F})$. Unh discal band unbroken from costa to vein 2. $\mathrm{H}$ with conspicuously projecting tornal lobe.

Hercules group. Two species.

F (Ea). Unh discal band broken at vein 6 as usual.

Democritus group. Twenty-eight species.

$G \quad(\mathrm{Cc})$. Unh discal band not completely dislocated at vein 2.

$\mathrm{Ga}(\mathrm{H})$. Unf discal band broken at vein 4 and the upper part is directed to the termen.

Eumolphus group. Twenty-two species. 
$H$ (Ga). Unf discal band unbroken, or only slightly dislocated at vein 4 and the upper part is directed to the dorsum.

Ha (I). $\mathrm{H}$ with long tail, ciliate throughout on its dorsal side.

Centaurus group. Fifteen species.

I (Ha). $\mathrm{H}$ tail filamentous, a tooth or absent.

Vihara group. Eighteen species.

$J \quad(\mathrm{Cb})$. F termen conspicuously falcate or crenulate. $\mathrm{H}$ outer half of dorsum conspicuously excavate.

Rama group. Six species.

$K$ (Ca). $\mathrm{H}$ tornus rounded, dorsum and costa sub-equal : termen not tailed or dentate.

Perimuta group. Seven species.

$L$ (Ad). Below, markings more or less incomplete. Unf no basal spot in cell. $\mathrm{H}$ termen dentate.

Fulla group. Four species.

$M$ (Ac). $\mathrm{H}$ cell longer than half wing: tail short and stout. ot above, green.

Genus Aurea nov. : type Arhopala aurea Hewitson ; fixed by author. Four species.

$N \quad(\mathrm{Ab})$. H end cell straight and inclined, directed to the central spot in space 7 .

Genus Arhopala Boisduval 1832: type phryxus Boisduval, fixed by Scudder r87o. Five species. Synonym Iois Doherty I 889 , undescribed, placed as synonym by De Nicéville I890.

$O$ (Aa). + ovipositor long, tapered, bent down at tip.

Genus Panchala Moore 1882 : type ganesa Moore, fixed by author. Eight species.

Synonym Acesina Moore 1884 ; type paraganesa De Nicéville, fixed by author.

$P$ (A). $\delta$ genitalia, sides of uncus at dorsal end produced and pointed. Markings of a different type.

Genus Flos Doherty I889: type apidanus Cramer, fixed by author. Thirteen species.

Synonym Amblypodia Auctorum nec Horsfield (see Appendix r).

\section{Genus NARATHURA Moore 1878}

$A$. Anthelus Group of Narathura

1a (9a). Unf with a spot at base of space ro.

\section{Anthelus Sub-group}

Ib (6a). Unf I or more spots in space II.

I (2a). Unh 2 spots at base of space 8 ; unf 3 spots in space II.

anthelus. Nine sub-species. Fig. Corbet 3 and $3 \mathrm{~g}$.

(a) ot $\mathrm{F}$ 30 $\mathrm{mm}$., shining blue, border $2 \frac{1}{2} \mathrm{~mm}$. at apex to $\frac{1}{2} \mathrm{~mm}$. at dorsum. of paler blue, upf border $8 \mathrm{~mm}$. at apex to 2 at dorsum.

Sub-sp. anthelus Doubleday \& Hewitson I852: ơ Moulmein; type B.M. 20 đ., 18 ㅇ Ataran, Burma.

(b) Above and below much darker. Unh all markings prominent.

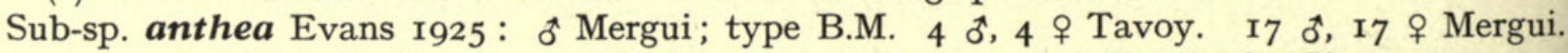

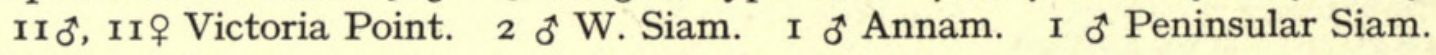

(c) Intermediate to anunda. क o more purple.

Sub-sp. grahami Corbet I94I : o Malaya ; type B.M. 6 o, 5 오 Malaya.

(d) Darker. ot upf border a thread. क purple, border ro $\mathrm{mm}$. at apex to $5 \mathrm{~mm}$. at dorsum. Below as anthelus.

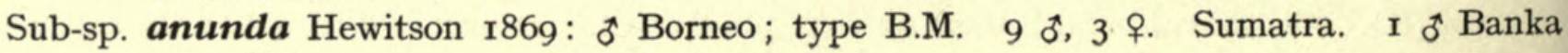
II 0,3 우 Borneo. 
(e) Above as anunda. Below, looking very different; uniform, rather dark brown, markings all equally prominent, instead of the subcostal markings unh being more prominent than the rest: no whitish subcostal area.

Sub-sp. majestatis Fruhstorfer r913: 'o Nias ; type B.M. 5 đo, 6 o Nias.

$(f)$ o above, pale shining blue, border as in anthelus. Unh markings faint except at costa.

Sub-sp. jabadia Fruhstorfer I913: ơ Java; type B.M. 6 o Java.

(g) More like anunda, but rather bluer.

Sub-sp. saturatior Staudinger 1889 : Palawan. 7 \$, 6 ㅇ Palawan.

(h) ot above blue as jabadia, border as anunda. Unh much darker, all markings equally conspicuous, subcostal whitish area present. $\uparrow$ above brown, darker apically, no blue area.

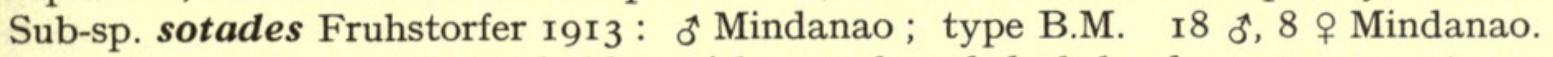

(c) As sotades, but + purple-blue with very broad dark borders, $12 \mathrm{~mm}$. at apex to 9 at dorsum; uph $5 \mathrm{~mm}$. mid-termen and veins 2, 3, 4 darkened.

Sub-sp. impar nov. : ㅇ Mindoro; type B.M. Io ઈ, 2 ㅇ Mindoro.

2a (I). Unh not more than I spot at base of space 8 .

2 (3a). Unf 2 spots in space II.

auxesia. Two sub-species. Fig. Seitz, Pl. I50 B $d$.

(a) 우 F $24 \mathrm{~mm}$. Above, very pale blue, whitish mid F and a dark spot end cell; border $5 \mathrm{~mm}$. at apex $\mathrm{F}$ to $2 \mathrm{~mm}$. at dorsum; veins darkened.

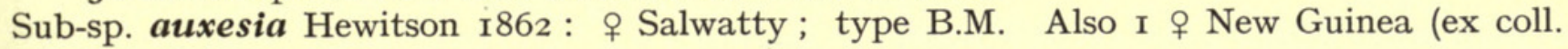
Hewitson).

(b) ㅇ purple-blue, with whitish bordered dark spot at end of cell. ot dark purple-blue, border I mm.

Sub-sp. salvia nov.: \& Salwatty (ex coll. Hewitson); type B.M. Also 2 ㅇ Dutch New Guinea. 2 đึ, 5 아 Mefor Is., Geelvink Bay.

3a (2). Unf I spot in space II.

3 (4a). Unh costa broadly darkened, followed by a white fascia from base to termen. ơ F $23 \mathrm{~mm}$. : pale blue, border $4 \mathrm{~mm}$. at apex to $\frac{1}{2} \mathrm{~mm}$. at termen. Fig. Corbet I and I g.

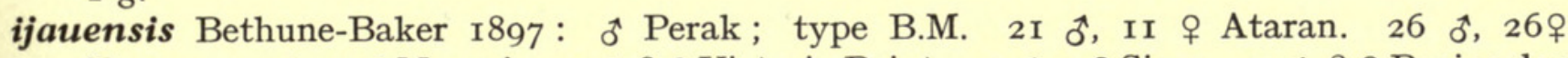

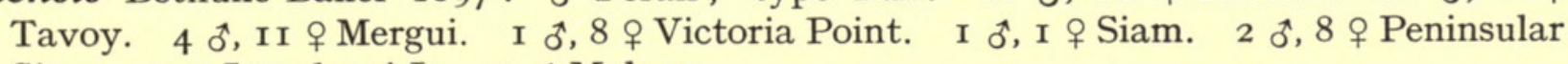
Siam. 2 ơ Langkawi Is. 3 ô Malaya.

Synonyms subfasciata Moore I883: ơ Tavoy, type B.M. Homonym of subfasciata Moore I88I (L.4).

simonea Corbet I94I : o Tavoy ; type B.M.

4a (3). Unh uniform.

4 (5). Unf spots in spaces 4 to 6 as a band, spot in 7 out of line.

eridanus. Five sub-species. Fig. Seitz $148 a$.

(a) As eridanus, but unf spots in spaces 7, Io, II are much larger and more conspicuous.

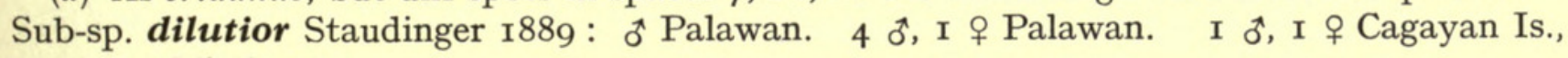
near Mindanao.

(b) ot F $27 \mathrm{~mm}$., border a thread. क above generally all brown.

Sub-sp. lewara Ribbe r926: ot Celebes. 2 ot, 3 우 Celebes.

Synonym itama Ribbe r926: 아 Celebes ; all brown form.

(c) of F $25 \mathrm{~mm}$., border $3 \mathrm{~mm}$. at apex to $\frac{1}{2} \mathrm{~mm}$. at dorsum. \& brown with some blue scaling at bases $\mathrm{F}$ and $\mathrm{H}$.

Sub-sp. elfeta Hewitson I869: 오 Sula Mangoli ; type B.M. I2 ㅎ, 5 오 Sula Mangoli.

Synonym viola Röber 1887: đ̊ Bangkei (see Appendix 2).

(d) of F $27 \mathrm{~mm}$., as lewara. \& pale blue basally, outwardly whitening, border $\mathrm{F} 9 \mathrm{~mm}$. at apex, bearing small blue spots in spaces 4, 5; at dorsum $4 \mathrm{~mm}$.; dark spot end cell ; border ro $\mathrm{mm}$. on $\mathrm{H}$. 
Sub-sp. padus Felder I865: $\delta^{*}$ Halmaheira ; type B.M. 18 ऽ, 3 ㅇ Halmaheira.

(e) ot F $20 \mathrm{~mm}$., border a thread. o as for padus, but seems to be very variable.

Sub-sp. eridanus Felder I860: $ᄋ$ Amboina ; type B.M. I of, 3 ㅇ Amboina. I + Ceram. Synonym polita Röber I887: đ̛ Ceram.

5 (4). Unf spots in spaces 4 to 7 on a regular curve.

anarte. Two sub-species. Fig. Corbet 4 and $5 \mathrm{~g}$.

(a) of $\mathrm{F}$ 30 $\mathrm{mm}$. : shining blue, turning violet apically on $\mathrm{F}$, border $\mathrm{I} \frac{1}{2}$ to $\frac{1}{2} \mathrm{~mm}$. : क purple blue with broad borders.

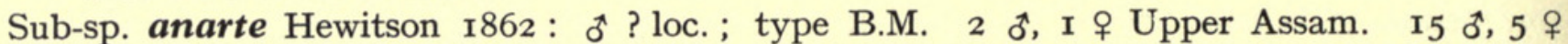

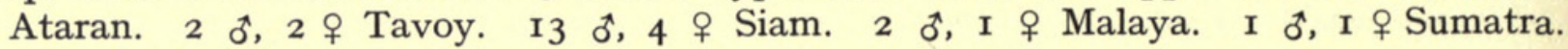
I ơ Borneo.

Synonym morphicolor Corbet I94I : ot Malaya ; type B.M.

(b) Below, all markings darker. Unf costal spots in spaces 7 and ro rectangular, overlapping. Unh a more or less conspicuous white streak from base to termen over vein 6 . Sub-sp. auzea De Nicéville I896: đ̃ Java. Fig. Corbet 4 g. I đo Java.

6a (Ib). Unf no spot in space II.

6 (7a). Unf no costal spot in space ro. Large, ơ F $34 \mathrm{~mm}$. Generally like anthelus auzea.

trionoea Semper I89o: đo Mindanao. I ơ Luzon.

7a (6). Unf with a costal spot in space ro.

7 (8). Below, purple washed, markings conspicuous. Unh costal area broadly paler. ơ F $22 \mathrm{~mm}$., dark blue, border $\frac{1}{2} \mathrm{~mm}$. Fig. Corbet 2 and $2 \mathrm{~g}$.

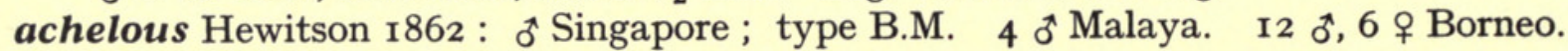

8 (7). Below, uniform brown, markings inconspicuous, hardly darker than ground, no purple wash nor a paler subcostal area unh. Above as achelous.

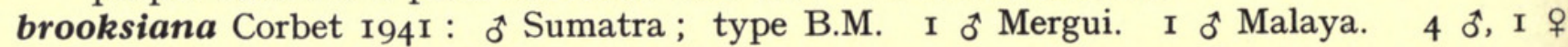
Sumatra. I $₫$ Batoe Is.

Synonym malu Corbet I946 : ơ Mergui ; type B.M.

9a (га). Unf no spot at base of space ro.

9b (18a). Unf discal markings macular.

\section{Camdeo Sub-group}

9 (Iоa). Unf with a spot at base of space 7 . 0 F $18 \mathrm{~mm}$., entirely dark brown, except for basal blue scaling. o pale blue with broad dark borders. Fig. Seitz $\mathrm{I}_{4} 8 b$.

annulata Felder I860: ot Amboina; type B.M. 2 đ Palawan. I $q$ Philippines. I $\sigma^{\star}$ Celebes. I 4 ơ, 3 ㅇ Amboina. I o Buru.

Synonyms tristis Röber I887: क Bangkei.

evebina Staudinger I889: o Palawan.

10a (9). Unf no spot at base of space 7 .

ro (I Ia). Unf no discal spot in space 7 .

johoreana. Two sub-species. Fig. Corbet ro.

(a) \& $\mathrm{F} 20 \mathrm{~mm}$. Above purple-blue, border $5 \mathrm{~mm}$. at apex to 2 at dorsum: $\mathrm{H}_{4} \mathrm{~mm}$. and veins broadly darkened.

Sub-sp. johoreana Corbet I94I : $q$ Malaya ; type B.M. 2 \& Malaya.

(b) o $18 \mathrm{~mm}$., sexes alike, blue, not purple, border $4 \mathrm{~mm}$. at apex to $2 \mathrm{~mm}$. at dorsum: H $3 \mathrm{~mm}$., veins not darkened.

Sub-sp. kalima nov. : ơ Nias ; type B.M. 4 ठ, I 9 Nias. 
11a (10). Unf with a discal spot in space 7 .

II (I2a). Unf the spot in space 7 in continuation of those in spaces 4 to 6 . o $\mathrm{F} 2 \mathrm{I} \mathrm{mm}$., pale silvery metallic blue, border I mm. at apex, vanishing at dorsum. $q$ bluish-white with broad border and dark spot at end cell. Unh whitish below costa inside the discal band.

varro Fruhstorfer 1913: + Karen Hills. Fig. Corbet 7 and $13 \mathrm{~g}$ as kavennia. 3 of, 3 우 Karens. I \& Ataran.

Synonym karennia Evans I925: đ Karens ; type B.M.

12a (II). Unf spot in space 7 detached from rest of band.

I2b (I4a). Unf lower part of end-cell spot expanded and the central spot in space Ib elongate.

I 2 (13). Below, markings conspicuously white-edged.

dispar. Four sub-species. Fig. Corbet 8 and I I g.

(a) of F $26 \mathrm{~mm}$., plain blue, border a thread. क much darker blue than dispar and borders broader, $7 \mathrm{~mm}$. F and ro $\mathrm{mm}$. $\mathrm{H}$; a black spot at end of cell $\mathrm{F}$. Below as dispar.

Sub-sp. diluta Evans 1932: ơ Maymyo; type B.M. 26 đ, 26 우 N. Shan States. Fig. Corbet $12 \mathrm{~g}$.

(b) ô upf with a dark spot end cell surrounded by a whitish area. Unf discal band broad. o above, pale blue with $2 \frac{1}{2} \mathrm{~mm}$. border $\mathrm{F}$ and $\mathrm{I} \mathrm{mm}$. $\mathrm{H}$.

Sub-sp. dispar Riley \& Godfrey I92I : $₫$ N. Siam ; type B.M. Also I 0,3 ㅇ S. Shan States, Burma.

(c) Above, as diluta: below no white areas, markings large. + bluish-purple with broad borders.

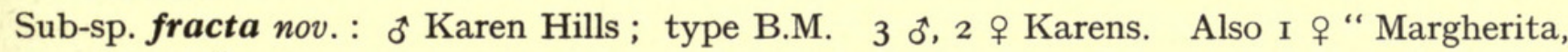
Assam ".

(d) of F $22 \mathrm{~mm}$. Above as diluta, but the second specimen has a dark spot at end of cell upf and a whitish area around it. Below, as dispar, but markings smaller.

Sub-sp. chota nov. : ot Ataran, Burma; type B.M. 2 ot Ataran.

(e) F $25 \mathrm{~mm}$. Above, broadly white about a black spot at end of cell. Below mostly white with reduced markings. Fig. Corbet 9 . Unique.

Sub-sp. pendleburyi Corbet I94I : † Malaya; type B.M.

13 (I2). Below, markings inconspicuous, edged pale brown.

semperi. Two sub-species.

(a) ô pale purple, border a thread. ㅇ purple, no whitish area beyond end cell. Fig. Corbet 6 and $9 \mathrm{~g}$.

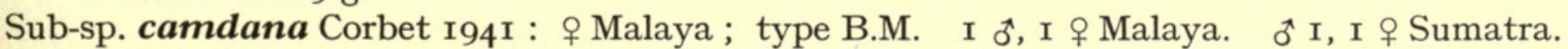

(b) of $\mathrm{F} 25 \mathrm{~mm}$., purple, border $\mathrm{I} \frac{1}{2} \mathrm{~mm}$. at apex to I at dorsum : conspicuous black spot at end cell. क purple, whitish about end cell upf, border $5 \mathrm{~mm}$.

Sub-sp. semperi Bethune-Baker I896: o Borneo; type B.M. 2 đ, I 우 Borneo.

Synonym panthera Corbet I946: 우 Borneo; type B.M.

14a (12b). Unh lower part end-cell spot not expanded and central spot in space rb not elongate.

I4b (I7). Unf discal spots in spaces 2, 3 not smaller than those in spaces 4 to 6 .

I4C (I6). Below, grey, markings black, conspicuous.

I4 (I5). Below pale grey. ot $\mathrm{F}>25 \mathrm{~mm}$.

camdeo. Two sub-species. Fig. Seitz I49d.

(a) o F $29 \mathrm{~mm}$., pale violet-blue with a discal white area, border a thread, usually a prominent end-cell spot.

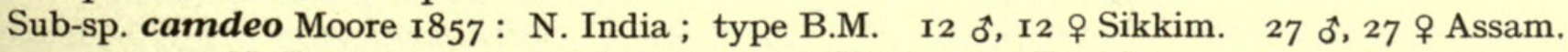
I $\delta^{\star}, 2$ o N. Burma. 2 ot, 2 o Ataran. I to Siam. 3 t Tonkin. 
(b) Smaller, of F $25 \mathrm{~mm}$. ㅇ without the double spot beyond end cell upf. Below, markings not so black and rather larger.

Sub-sp. sebonga Tytler I926: क Manipur ; type B.M. 5 t Manipur. I of, 2 o N. Burma.

15 (I4). Below dark grey. ơ $\mathrm{F}<25 \mathrm{~mm}$.

opalina. Two sub-species. Fig. Corbet 5 and $8 \mathrm{~g}$.

(a) Like camdeo, but much smaller, ơ F $19 \mathrm{~mm}$.

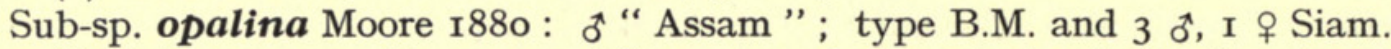

(b) o $^{\mathrm{F}} 22 \mathrm{~mm}$. Above, no white area or dark spot at end of cell upf. क generally all blue above and small white area may be present beyond end of cell.

Sub-sp. fruhstorferi Röber I897: + “ Java "; type B.M. ; figured by Piepers \& Snellen I9I 8, Rhop. Java, Pl. 24, fig. I08 as aedias but unknown to authors : probably from Burma.

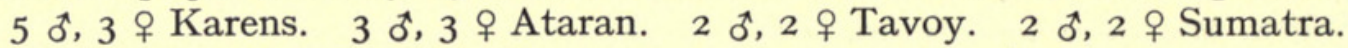

Synonym sphendale Fruhstorfer 19I4: ô Annam; type lost.

16 (I4c). Below, brown, markings inconspicuous. o $\mathrm{F} 24 \mathrm{~mm}$., above pale blue, border a thread. $q$ uniform pale purple blue, border $\mathrm{F}$ tapering from $4 \mathrm{~mm}$. at apex to $2 \mathrm{~mm}$. at dorsum : spot at end cell, but no spot beyond it as in opalina. Fig. Corbet II and Io g.

azata De Nicéville I895: o Perak. The figures in Rhop. Java are of aedias. I o Victoria Point, S. Burma. 5 t Malaya. 2 ot, I + Sumatra.

17 (I4b). Unf discal spots in spaces 2, 3 smaller than those in spaces 4 to 6 . of $\mathrm{F} 28 \mathrm{~mm}$., shining purple-blue, border a thread; like aedias. Unf narrow white bar across middle of space $\mathrm{Ib}$ : rarely spots at bases of spaces io and 7 .

hellada. Two sub-species. Fig. Corbet $\mathrm{I} 3$ and $7 \mathrm{~g}$.

(a) Generally markings below fainter.

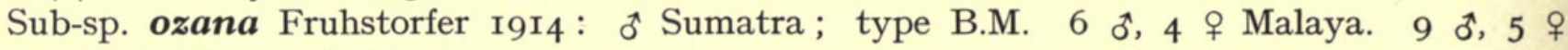
Sumatra. I o Borneo.

(b) Below, markings darker.

Sub-sp. hellada Fruhstorfer I9I4: đ Nias ; type B.M. 9 đ, I 우 Nias.

18a (9b). Unf discal markings banded, including spots in spaces 2 and 3 .

\section{Aedias Sub-group}

I 8 (I9a). Unf discal spot in space 7 out of line with those in spaces 4 to 6 ; no white bordered dark area in the basal half of space $\mathrm{Ib}$, as in the very similar hellada.

aedias. Five sub-species. Fig. Corbet $\mathrm{I}_{4}$ and $\mathrm{I}_{4} \mathrm{~g}$ as agnis.

(a) of F 24 to $29 \mathrm{~mm}$., pale shining blue, turning violet at apex. + with 2 forms, typically blue, border as at apex $8 \mathrm{~mm}$., tapering to $\mathrm{I} \mathrm{mm}$. at dorsum, $3 \mathrm{~mm}$. on $\mathrm{H}$; second form Io $\mathrm{mm}$. at apex, $4 \mathrm{~mm}$. at dorsum and $8 \mathrm{~mm}$. on $\mathrm{H}$.

Sub-sp. yendava Grose-Smith I887: 우 Yendaw Valley, Burma; type B.M. Io o, 2 우 Karens. I7 ô, 3 ㅇ Ataran.

Synonym pallida Evans I932: $\delta$ Karens ; type B.M.

(b) Intermediate: $ᄋ$ generally blue as in yendava.

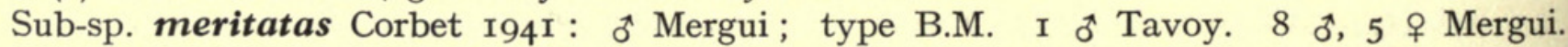
2 아 Victoria Point, S. Burma.

(c) of 20 to $30 \mathrm{~mm}$., dark shining blue border a thread. o purple, border 3 to Io $\mathrm{mm}$. on $\mathrm{F}$ and $\mathrm{H}$, variable. Unf discal markings variable, spots in spaces 4 and 7 are usually out of line with those in spaces 2, 3; may be a costal spot in space ro, rarely a spot at base of space ro and more rarely a spot in space Ir.

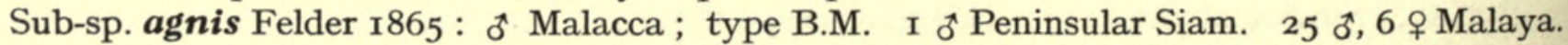

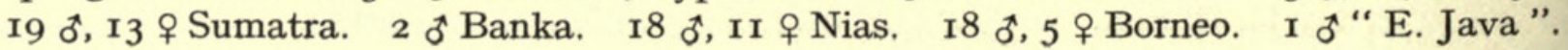


Synonyms soter Fruhstorfer I9I3: ot Sumatra ; type B.M.

sphetys Fruhstorfer 1913: ot Nias ; type B.M.

hagius Fruhstorfer I9I3; ơ " E. Java” ; type B.M.

(d) of F $23 \mathrm{~mm}$., pale shining blue, no purple or violet tinge. क still paler, border $5 \mathrm{~mm}$. Fig. Corbet I5 g.

Sub-sp. aedias Hewitson I862: ㅇ Java ; type B.M. 8 o, I + Java. In Rhop. Java fig. of aedias is fruhstorferi and azata is aedias.

Synonym pangeran Fruhstorfer I9I4: ot W. Java ; type B.M.

(e) Only differs from agnis in being smaller and less variable on the underside.

Sub-sp. oenotria Hewitson r869: ot Mindanao. i 8 o Mindanao.

19a (18). Unf discal spot in space 7 in line with those in spaces 4 to 6 .

rgb (23). Unf discal spot in space 4 in line with those in spaces 5 to 7 .

I9c (22). Unf discal band broken at vein 4 .

I9 (20a). Unh lower part of end-cell spot expanded.

myrzala. Three sub-species. Fig. Corbet $\mathrm{I} 2$ and $6 \mathrm{~g}$ as lammas.

(a) Unh in space 7, white edges to central and discal spots looped together. of $\mathrm{F} 2 \mathrm{I} \mathrm{mm}$., dark violet blue, border I mm. o blue.

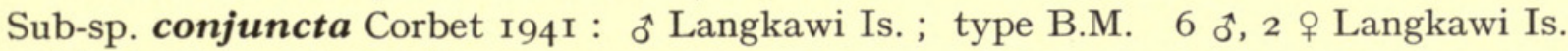

(b) ơ duller. o purple.

Sub-sp. lammas Corbet I94I : ơ Malaya; type B.M. 5 o Malaya. 5 of, 3 우 Borneo.

(c) Unh in space 7 the entire space between the central and discal spots filled by a conspicuous white spot.

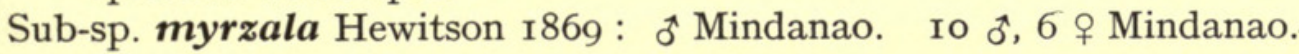

20a (I9). Unh lower part of end-cell spot not expanded.

20 (2I). Unf discal band continued into space $\mathrm{Ib}$. के $\mathrm{F} 2 \mathrm{I} \mathrm{mm}$., dark purple-blue, border

$3 \mathrm{~mm}$. o paler, border $5 \mathrm{~mm}$.; on $\mathrm{H}$ blue colouring very restricted. Fig. Seitz $\mathrm{I}_{4} 8 d$.

dohertyi Bethune-Baker I903: ơ Celebes; type B.M. 23 ơ, I4 우 Celebes.

21 (20). Unf discal band not continued into space $\mathrm{Ib}$. of $\mathrm{F} 20 \mathrm{~mm}$., dark violet-blue, border

$\frac{3}{4} \mathrm{~mm}$. Fig. Corbet $\mathrm{I}_{5}$ and $\mathrm{I}_{7} \mathrm{~g}$ as pseudomuta (see Appendix 5).

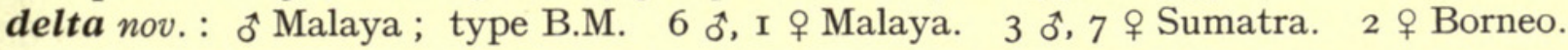

22 (I9c). Unf discal band not broken at vein 4.

allata. Five sub-species. Fig. Corbet $\mathrm{I} 6$ and $\mathrm{I} 8 \mathrm{~g}$ as pandora.

(a) i purple. Below suffused purple. ot $\mathrm{F} 22 \mathrm{~mm}$.

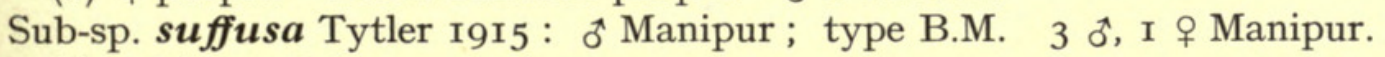

(b) 우 blue. Below as suffusa.

Sub-sp. atarana Tytler I926: † Ataran ; type B.M. I ㅇ N. Burma. I ơ N. Shan States.

I o S. Shan States. 4 ơ, 4 ㅇ Ataran.

(c) Below, not suffused purple. of $\mathrm{F}$ border $\mathrm{I} \frac{1}{2} \mathrm{~mm}$. क $\mathrm{blue}$.

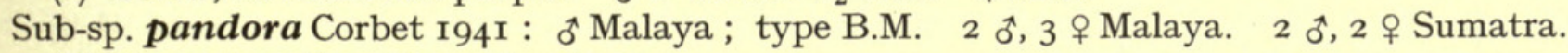

(d) o purple, otherwise as pandora.

Sub-sp. evandra Corbet I94I : ơ Borneo ; type B.M. 2 đo, 2 ㅇ Borneo.

(e) Larger, ơ $\mathrm{F} 24 \mathrm{~mm}$., border I to $2 \mathrm{~mm}$. क purple.

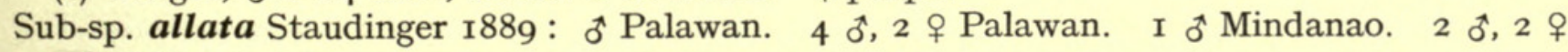
Mindanao.

$23(\mathrm{I} 9 b)$. Unf discal spot in space 4 out of line with the spots in spaces 5 to 7 . ot $\mathrm{F} 22 \mathrm{~mm}$., upf with a discal area of modified scảles, as in epimuta.

atosia. Five sub-species. Fig. Corbet 17 and $\mathrm{I} 6 \mathrm{~g}$ as malayana.

(a) ot above, pale silvery blue, shading to violet: + pale blue. 


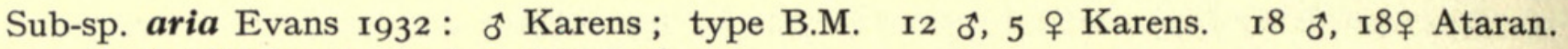

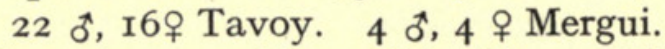

(b) ơ above, uniform violet-blue ; + blue.

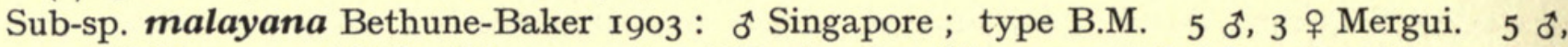

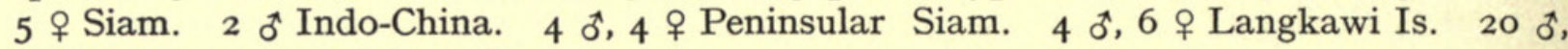
I6 + Malaya. I ㅇ " Java”.

Synonyms jahara Corbet I94I : ơ Mergui ; type B.M.

udapa Corbet I94I : ơ Malaya : type B.M.

(c) ô uniform violet-blue. क purple.

Sub-sp. atosia Hewitson 1863 : đo Sumatra ; type B.M. I5 đ, 6 o Sumatra. 6 o, 9 o Banka. I6 ơ, I3 9 Borneo. 4 ơ Pulo Laut.

(d) Like aria, but borders rather broader.

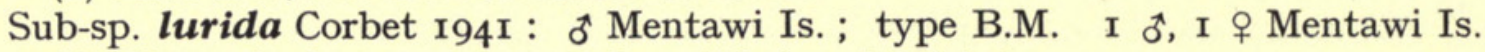

(e) Like aria, but ô upf area of modified scales faint.

Sub-sp. aricia Staudinger I889: o Palawan. None in B.M.

\section{B. Epimuta Group of Narathura}

1a (23a). Unf no spots between cell and costa.

Ib (2ra). Unf end-cell spot of uniform width throughout.

Ic (I Ia). Unh discal band dislocated at vein 2 completely or so that the spots on either side do not overlap more than the the extent of the inner edge of the spot in space 2 being in line with the outer edge of the spot in space Ic.

\section{Epimuta Sub-group}

Id (3a). Unf discal spot in 4 not in line with those in spaces 5,6 .

I (2). Unf discal spot in space 4 out of line with those in spaces 3, 2. of upf $22 \mathrm{~mm}$. with discal area of modified scales as in atosia.

epimuta. Three sub-species. Fig. Corbet 20 and $20 \mathrm{~g}$.

(a) ot shining pale blue, turning violet towards apex $\mathrm{F}$, border $2 \mathrm{~mm}$. at apex, tapering to I $\mathrm{mm}$. at dorsum and $\frac{1}{2} \mathrm{~mm}$. on $\mathrm{H}$. क o shining blue, border $7 \mathrm{~mm}$. at apex tapering to $2 \mathrm{~mm}$. at dorsum and $\frac{1}{2} \mathrm{~mm}$. on $\mathrm{H}$. Smaller.

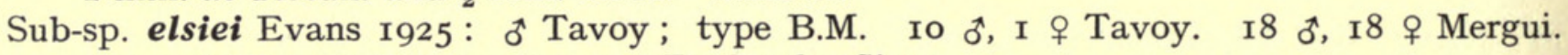
$7 \delta^{\star}, \mathrm{I}$ ㅇ Victoria Point. $3 \delta^{\star}, \mathrm{I}$ ㅇ Peninsular Siam.

(b) Intermediate. ot as epimuta. o blue rather than purple.

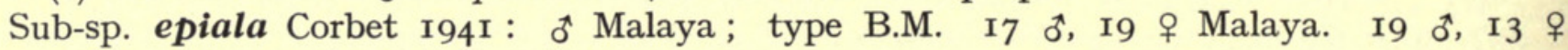
Sumatra. 5 ơ, I $q$ “Java”.

(c) 0 uniform shining blue, border a thread. क purple with broad borders.

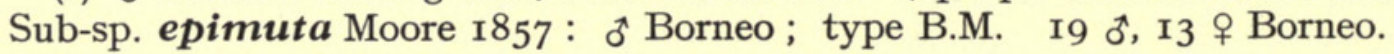

2 (I). Unf discal spot in space 4 more or less in line with those in spaces 3, 2 . $\delta$ upf no area of modified scales.

hypomuta. Two sub-species. Fig. Corbet 23 and $19 \mathrm{~g}$.

(a) of F I4 to $20 \mathrm{~mm}$., shining dark purple-blue, border a thread. o shining deep blue, border $2 \frac{1}{2} \mathrm{~mm}$.

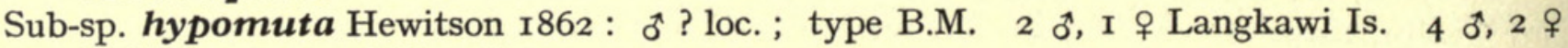
Malaya. I ơ, 2 우 Sumatra.

(b) ㅇ $\mathrm{F}$ border $4 \mathrm{~mm}$.

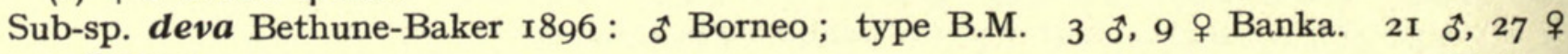
Borneo.

Synonym shelfordi Moulton r9I I : ㅇ Borneo; type B.M. 
3a (Id). Unf discal spot in space 4 in line with those in spaces 5,6 .

$3 \mathrm{~b}$ (5a). Unf discal band conspicuously angled mid-space 4 and continuous from spot in space 6 to spot in space 3 .

3 (4). Unf discal spots in spaces 2, 3 in line.

metamuta. Two sub-species. Fig. Corbet 22 and $22 \mathrm{~g}$.

(a) ô F I $8 \mathrm{~mm}$., upf dark purple-blue, uph shining light blue, very strongly contrasting, border $\mathrm{I} \frac{1}{2} \mathrm{~mm}$. ㅇ blue, border $3 \mathrm{~mm}$.

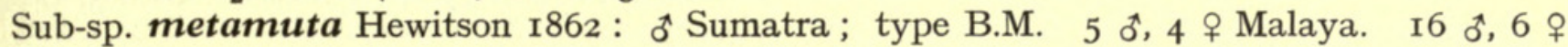
Sumatra.

Synonym gunongensis Bethune-Baker I897: ơ Perak; type B.M.

(b) Uph darker shining blue in $\sigma^{t}$ and upf border $\frac{3}{4} \mathrm{~mm}$.

Sub-sp. hilda nov. : ơ Borneo ; type B.M. 4 ô, I 9 Borneo.

4 (3). Unf discal spot in space 2 out of line, nearer termen.

muta. Nine sub-species. Fig. Corbet $24 \mathrm{~g}$. At either end of its range muta is constant, but from Malaya to Borneo there appear to be several forms flying together. They were regarded as species by Corbet (I94I), but are now believed to be sub-species.

(a) $\delta^{\text {I }} \mathrm{I} 8$ to $20 \mathrm{~mm}$., shining metallic blue, completely overlaid violet on $\mathrm{F}$, border $\mathrm{I} \frac{1}{2} \mathrm{~mm}$. o pale blue to violet, border $7 \mathrm{~mm}$. at apex to $2 \mathrm{~mm}$. at dorsum. (The metamuta of Evans 1932.)

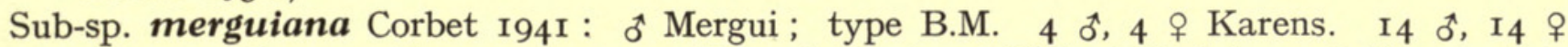

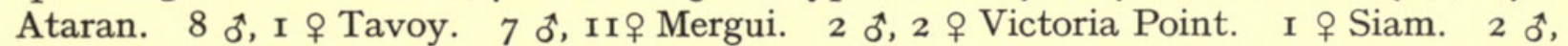
I ㅇ Peninsular Siam.

(b) ô F I9 mm. uph shining blue contrasting with the violet upf, but not so greatly as in merguiana. Fig. Corbet $25 \mathrm{~g}$.

Sub-sp. maranda Corbet I94I : o Malaya; type B.M. I 2 ot, I3 우 Malaya.

(c) $\delta \mathrm{F}^{\mathrm{F}} 3$ to $\mathrm{I} 8 \mathrm{~mm}$., plain shining blue, border $\mathrm{I} \frac{1}{2} \mathrm{~mm}$. क darker and smaller than maranda. Fig. Corbet $25 \mathrm{~g}$.

Sub-sp. tropaea Corbet I94I: ot Johore; type B.M. I5 $\delta^{\star}, 8$ 우 Malaya.

Synonyms busa Corbet I94I : ơ Malaya ; type B.M. Fig. Corbet 25 g. santava Corbet I94I : o Singapore ; type B.M.

(d) Grades from merguiana to waterstradti.

Sub-sp. trima Corbet I94I : o Sumatra ; type B.M. 27 đิ, 27 오 Sumatra.

(e) Smaller, of F $\mathrm{I} 7 \mathrm{~mm}$., uniform blue, borders broad, $\mathrm{I} \frac{1}{2}$ to $2 \mathrm{~mm}$. क क border up to $5 \mathrm{~mm}$. Fig. Corbet 25 and $26 \mathrm{~g}$.

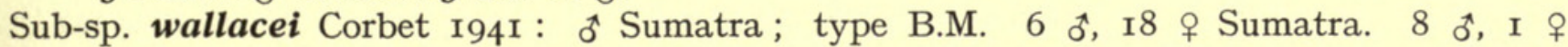
Banka.

(f) Almost exactly as merguiana $\delta^{*}$, smaller, o* $\mathrm{F}$ I $8 \mathrm{~mm}$., border $\mathrm{I} \frac{1}{2} \mathrm{~mm}$. Below, very much darker ochreous-brown.

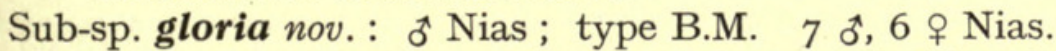

(g) Large, ot F $20 \mathrm{~mm}$., bright shining purple-blue, border $2 \mathrm{~mm}$., F and $\mathrm{H}$. क s shining blue, border $6 \mathrm{~mm}$. at apex to $3 \mathrm{~mm}$. H.

Sub-sp. waterstradti Bethune-Baker I896: ơ Kina Balu. 23 ô, 24 ㅇ Kina Balu, Borneo.

(h) Smaller and duller, border generally broader on $\mathrm{H}$. क क purple rather than blue, borders $4 \mathrm{~mm}$. F and $\mathrm{H}$.

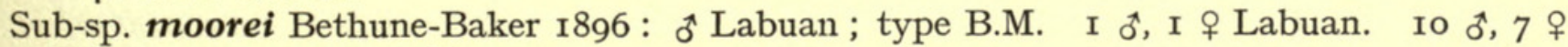

Pulo Laut. 20 đิ, 2 우 Borneo.

Synonym daganda Corbet I94I : o Borneo ; type B.M.

(i) $\sigma^{7} \mathrm{~F} 20 \mathrm{~mm}$., very pale shining blue, violet tinge on $\mathrm{F}$, border $\frac{3}{4} \mathrm{~mm}$. + very pale blue, border $3 \mathrm{~mm}$. at apex to I $\mathrm{mm}$. at dorsum.

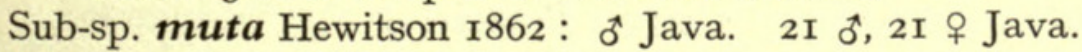

$5 \mathrm{a}(3 \mathrm{~b})$. Unf discal band not angled mid space 4 , but more or less broken at vein 4 .

5b (9a). Unf markings well defined. of F I7 to $20 \mathrm{~mm}$. 
$5 \mathrm{c}(7 \mathrm{a})$. Unh spots mid-cell and mid-space Ic enlarged and approximate.

5 (6). Unf discal spot in space 3 elongate, out of line and longer than the rest. of $\mathrm{F} 20 \mathrm{~mm}$., very dark blue, border a thread. Fig. Corbet 24 and $27 \mathrm{~g}$.

kurzi Distant I885: ơ Malacca. I4 ô, 7 아 Malaya.

6 (5). Unf discal spot in space 3 as rest of band, which is broader than usual. of $\mathrm{F} \mathrm{I} 9 \mathrm{~mm}$., dark purple-blue, border $\frac{1}{2} \mathrm{~mm}$. Below, dull brown, markings rather darker than ground. sceva Bethune-Baker 1903: ơ Sumatra. 2 ơ Sumatra.

7a (5c). Unh spots mid-cell and mid-space ic small, rounded and wide apart.

7 (8). Unf in space Ib an outwardly white-edged dark spot under the central cell spot and a tiny brown dot between the discal and the basal spots in space 2 . of $\mathrm{F} 20 \mathrm{~mm}$., purple-blue, border I mm. F produced and below, plain brown as in kurzi. क purple, borders $6 \mathrm{~mm}$.

indra nov. : ơ Borneo ; type B.M. 6 đ。, 2 ㅇ Borneo.

8 (7). Unf no such markings in space $\mathrm{rb}$. क $\mathrm{F} 20 \mathrm{~mm}$. Like baluensis but wings more produced and termen straighter. Below markings broad, as in kurzi and sceva.

siabra Corbet I94I : ơ Pulo Laut ; type B.M. 2 ơ Pulo Laut.

9a (5b). Unh markings faint, ill defined. Small.

9 (Io). Above, very dark purple-blue, border a thread. ot F I7 mm. o purple, border 4 to $3 \mathrm{~mm}$.

alica nov. : ơ Borneo: type B.M. 3 ठ, I 우 Borneo.

10 (9). Above, bright shining purple-blue, border $\mathrm{I} \frac{1}{2} \mathrm{~mm}$. $\sigma^{\star} \mathrm{F} \mathrm{I} 6 \mathrm{~mm}$. क ำ bluer, border $4 \mathrm{~mm}$. at apex $\mathrm{F}$ to $2 \mathrm{~mm}$. at dorsum.

avathina. Two sub-species. Fig. Corbet $23 \mathrm{~g}$.

(a) Above, bluer.

Sub-sp. avathina Corbet I94I : ơ Malaya ; type B.M. 4 ô, 4 오 Malaya.

(b) Above, more purple.

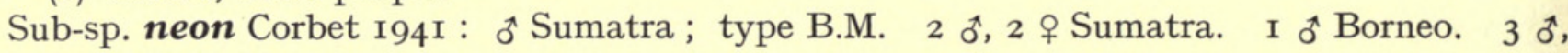
I 우 Pulo Laut.

Synonym xenon Corbet I94I : ô Pulo Laut; type B.M.

11a (Ic). Unh discal band incompletely dislocated at vein 2, more or less overlapping.

\section{Amphimuta Sub-group}

I I b (I8a). Unh discal band irregular, due to spot in space 3 being out of line.

I Ic (I6a). ot uph space 6 not entirely blue.

IId (I4a). ô clasp undivided.

I I (I2a). ot clasp hourglass-shape. ô $\mathrm{F} 20 \mathrm{~mm}$., varying from blue to very dark purpleblue, border broad, 2 to $\mathrm{I} \frac{1}{2} \mathrm{~mm}$.

agesilaus. Three sub-species. Fig. Corbet 69 and $3^{\mathrm{I}} \mathrm{g}$ as gesa.

(a) ot above much brighter blue. क also bluer.

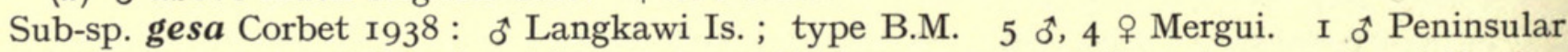

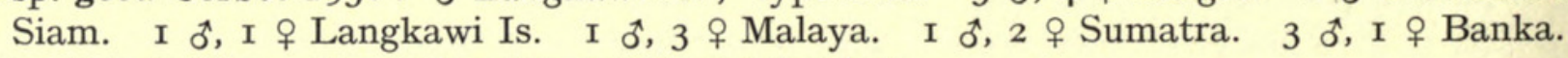

(b) ot dark blue. + purple with very broad borders.

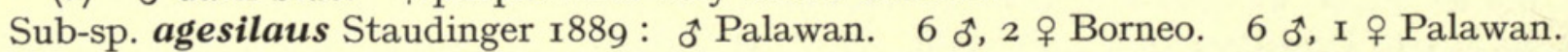

(c) ơ F I $8 \mathrm{~mm}$., very dark blue, border $2 \mathrm{~mm}$. F, $4 \mathrm{~mm}$. $\mathrm{H}$. o border $4 \mathrm{~mm}$. F and $\mathrm{H}$ all brown except some blue scaling in the cell.

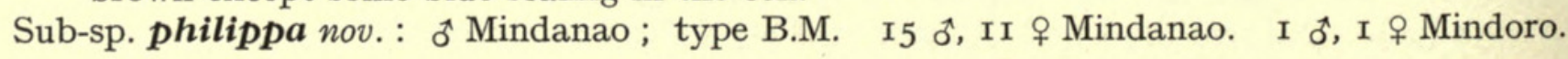


12a (II). ỡ clasp not hourglass-shape.

I2 (13). of F I8 to $19 \mathrm{~mm}$., wings more rounded. ot dark blue border $\frac{1}{2} \mathrm{~mm}$. क shining purple-blue, border $3 \mathrm{~mm}$. at apex to I or $2 \mathrm{~mm}$. at dorsum and on $\mathrm{H}$. Below markings smaller and more macular. End of clasp rounded.

baluensis Bethune-Baker I904 : ot Kina Balu ; type B.M. Fig. Corbet 30 and 34 g. 27 đ, 8 o Borneo. I ot Pulo Laut.

13 (I2). o $\mathrm{F} 2 \mathrm{I}$ mm., termen straight. o lighter blue, borders broad. End of clasp tapered. major Two sub-species. Fig. Corbet 28 and $32 \mathrm{~g}$.

(a) ơ $\mathrm{F} 2 \mathrm{I} \mathrm{mm}$., bright shining blue, border $3 \mathrm{~mm}$. at apex to $2 \mathrm{~mm}$. at dorsum and on $\mathrm{H}$.

o blue. Looks very different from major and agesilaus gesa.

Sub-sp. norda nov. : ơ Langkawi Is. ; type B.M. 2 ô, 3 † Langkawi Is.

(b) Rather darker and with broader borders.

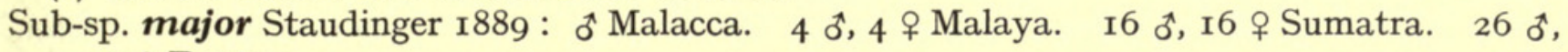
37 우 Borneo.

14a (I Id). Clasp divided.

I4 (I5). ôt rather bright purple-blue, border broad. Like major and agesilaus, difficult to separate without examining the genitalia clasp.

catori. Two sub-species.

(a) ơ F $21 \mathrm{~mm}$., border I mm.

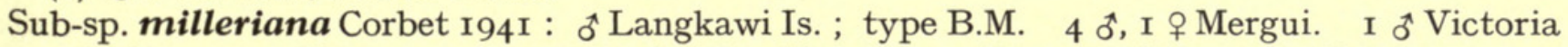

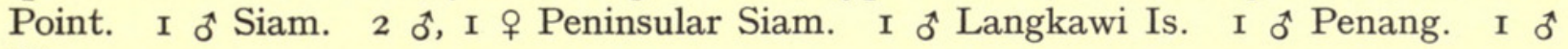
Nias.

(b) of $\mathrm{F}$ border broader, 2 to $5 \mathrm{~mm}$. Very variable unh, where the costal markings are often absent.

Sub-sp. catori Bethune-Baker I903: ot Borneo ; type B.M. Genitalia of type checked : Bethune-Baker's genitalia fig. is from a specimen of major. I ot Peninsular Siam.

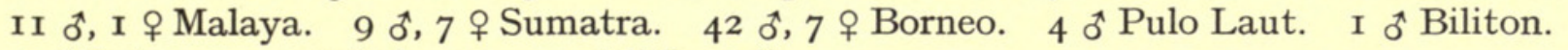
3 ơ Labuan. I oै Palawan. 3 o “ Java ".

15 (I4). ô very dark blue, border narrow, $\frac{1}{2} \mathrm{~mm}$. क bright violet-blue with broad borders.

amphimuta. Two sub-species. Fig. Corbet 29 and $33 \mathrm{~g}$.

(a) ơ 2 I mm. : upf no modified scales.

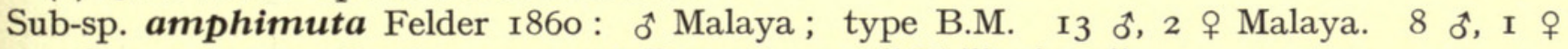

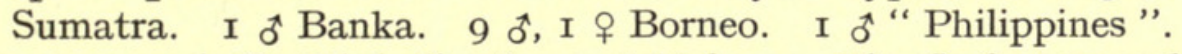

Synonym asia De Nicéville I893: ơ Malaya. Fig. Corbet 3I and $35 \mathrm{~g}$.

(b) Genitalia and general appearance do not differ, but upf with a central area of modified scales as in epimuta. Unf discal band unbroken. Unh with a strong purple gloss.

Sub-sp. quadra nov. : ot Java ; type B.M. Unique.

16a (IIc). ơ uph space 6 all blue : $\widehat{\star} \mathrm{F} 20 \mathrm{~mm}$., border a thread.

I6 (I7). Below markings faint.

moolaiana. Four sub-species. Fig. Corbet 27 and $30 \mathrm{~g}$.

(a) ot above, brilliant shining pale blue, turning to violet on apical half $\mathrm{F}$. \& pale blue, border $7 \mathrm{~mm}$. at apex to $3 \mathrm{~mm}$. at dorsum, $\mathrm{I} \frac{1}{2} \mathrm{~mm}$. on $\mathrm{H}$.

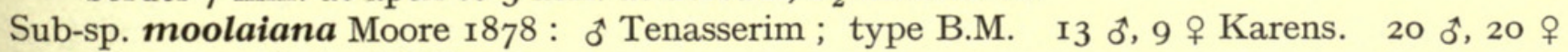
Ataran. 18 ơ, 18 ㅇ Tavoy.

Synonyms pastorella Doherty I889: ot Tavoy; type B.M. pagaiensis Ollenbach I92I : ot Tavoy; type B.M.

(b) ot uniform shining blue. क darker, borders narrower and traces of a dark spot beyond end cell upf.

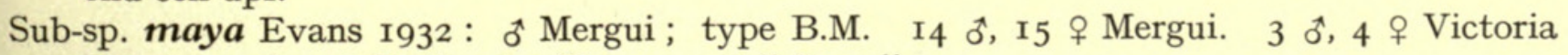
Point. 2 ô, 2 i Peninsular Siam. I to "Java ". 
(c) ô uniform purple-blue. क purple-blue.

Sub-sp. yajuna Corbet I94I : ơ Malaya; type B.M. 9 ô, 5 우 Malaya. 9 ơ Sumatra. II $\mathrm{O}^{*}, 2$ 우 Borneo.

(d) of F $18 \mathrm{~mm}$., as maya. o pale blue with very broad border, $9 \mathrm{~mm}$. at apex to $4 \mathrm{~mm}$. at dorsum $\mathrm{F}$ and on $\mathrm{H}$.

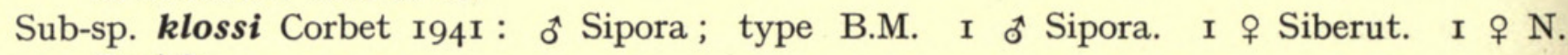
Pagi Is.

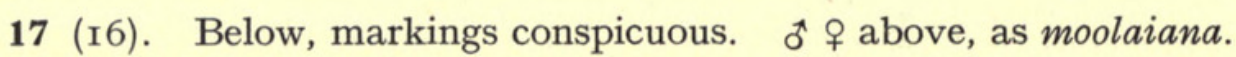

hesba Hewitson 1869 : ô Mindanao. io $\delta^{t}, 1$ ㅇ Mindanao.

18a (I Ib). Unh discal band regular from space 2 to space 7 , spot in space 3 in line. I8 (I9a). Below, markings very faint. of $\mathrm{F}$ I $7 \mathrm{~mm}$., purple-blue, border I $\mathrm{mm}$.

zylda. Two sub-species. Fig. Corbet 33 and 29 g.

(a) Small, ô I6 mm., bright shining blue, o paler blue, border $5 \mathrm{~mm}$. at apex to $2 \mathrm{~mm}$. at dorsum F. Fig. Corbet 34 .

Sub-sp. elioti Corbet I94I : ơ Malaya; type B.M. I ô, 2 ㅇ Malaya.

(b) ô darker blue. क unknown.

Sub-sp. zylda Corbet 194I : ơ Sumatra ; type B.M. 5 ơ Sumatra.

19a (I8). Below, markings conspicuous. ot above, very dark blue, border $\frac{1}{2} \mathrm{~mm}$.

I9 (20). Unf discal band broken. of $\mathrm{F} 2 \mathrm{I}$ to $25 \mathrm{~mm}$. क purple, border $3 \mathrm{~mm}$. Fig. Corbet 32 and $36 \mathrm{~g}$.

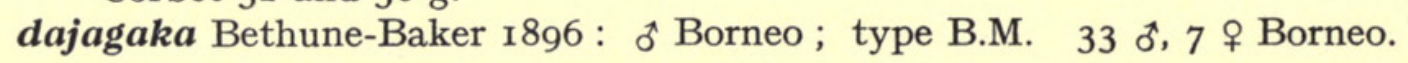

20 (I9). Unf discal band unbroken. o $^{2} 23 \mathrm{~mm}$. Fig. Corbet $38 \mathrm{~g}$.

anamuta Semper 1890: ot Mindanao. 3 ơ Mindanao. I to Mindoro.

21a (Ib). Unf lower part of end-cell spot enlarged.

\section{Belphoebe Sub-group}

2I (22). Unh no white spot mid space 7 . 0 F I $8 \mathrm{~mm}$., rather pale violet blue, border 5 $\mathrm{mm}$. at apex to $2 \mathrm{~mm}$. at dorsum and on $\mathrm{H}$. Below markings conspicuous. Fig. Corbet 35 and $37 \mathrm{~g}$.

belphoebe Doherty I889: o Tavoy; type B.M. I $\star$ A Assam. I $₫$ Tavoy. I $\star$ Malaya. Synonym cowani Corbet I94I : đ Malaya ; type B.M. Fig. Corbet 92.

22 (2I). Unh with a conspicuous white spot mid space 7 . ơ F I5 mm., shining blue, border $4 \mathrm{~mm}$. at apex to $\mathrm{I} \frac{1}{2} \mathrm{~mm}$. at dorsum and on $\mathrm{H}$. Below, purple washed; markings white edged. Fig. Corbet 36 and $4 \mathrm{I}$ g.

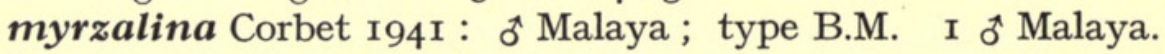

23a (га). Unf with spots between cell and costa. of $\mathrm{F} 22 \mathrm{~mm}$.

\section{Agesias Sub-group}

23b (25). Unf with a discal band.

23 (24). Unf spots in spaces 2, 3 elongate.

kinabala Druce I895: ơ Kina Balu. Fig. Bethune-Baker 1903 as "argesias "; Corbet 19

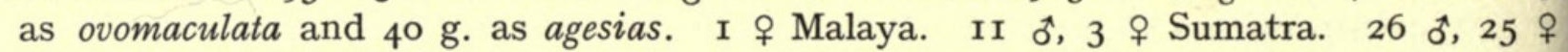
Borneo. 4 ơ Pulo Laut.

Synonym nabala Corbet I94I : ơ Kina Balu ; type B.M.

24 (23). Unf spots in spaces 2, 3, rounded.

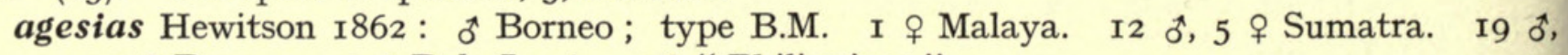
I I ㅇ Borneo. 2 ơ Pulo Laut. I o " Philippines ".

Synonym ovomaculata Hewitson I878: ot Sumatra; type B.M. 
25 (23b). Unf no discal band. Fig. Corbet $\mathrm{I} 8$ and $39 \mathrm{~g}$.

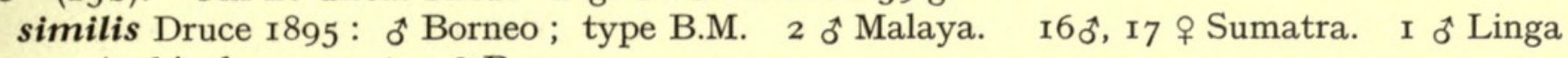
Archipelago. 3 ơ, 3 우 Borneo.

Synonym anila De Nicéville r896: đa Perak.

\section{Abseus Group of Narathura}

1 (2a). Unf no spot in space I2; spot in space 4 completely detached from rest of band. o F $26 \mathrm{~mm}$., purple-blue with broad dark borders. ot unknown. Fig. Corbet $4^{2}$.

anella De Nicéville 1895: ㅇ Perak. 2 아 Malaya. 2 온 Sumatra. 1 ㅇ Borneo.

2a (I). Unf costal spot in space 12 as well as 2 spots each in spaces 7 , I0, II. Unh white streak on costa over spot mid space 7 .

2 (3). Unf discal spot in space 3 far from end-cell spot. ơ F I $8 \mathrm{~mm}$. Fig. Corbet 83 and I05 g.

abseus. Five sub-species.

(a) ot shining violet-blue, border $5 \mathrm{~mm}$. at apex to $2 \mathrm{~mm}$. at dorsum; 9 pale shining blue. Sub-sp. mackwoodi Riley I923: ơ Ceylon; type B.M. 8 ơ, 7 ㅇ Ceylon.

(b) $\sigma^{t}$ dull purple, border $7 \mathrm{~mm}$. at apex to $4 \mathrm{~mm}$. at dorsum and $5 \mathrm{~mm}$. on $\mathrm{H}$. $q$ blue, borders narrower.

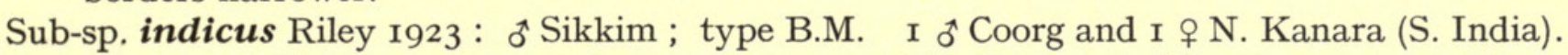

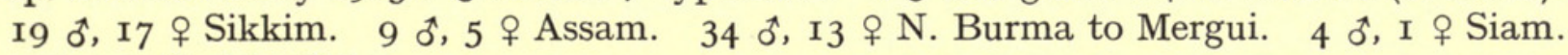
I $\delta$, I + Cochin China.

(c) $\delta$ brilliant deep purple-blue, border $4 \mathrm{~mm}$. at apex to $2 \mathrm{~mm}$. at dorsum and on $\mathrm{H}$. o pale metallic violet-blue. Flies with indicus: underside and genitalia identical.

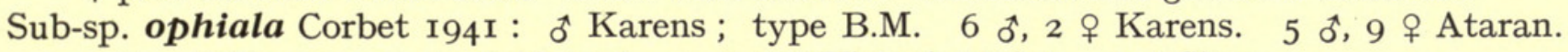

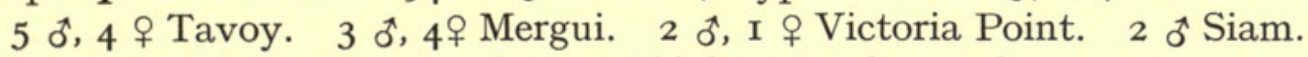

(d) ô dark shining blue, border as ophiala; + pale purple.

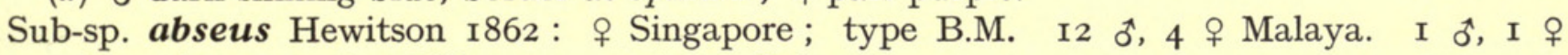
Sumatra. I5 $\delta^{*}, 4$ 우 Borneo. 4 tै, 2 아 Palawan.

Synonym nava Fruhstorfer I9I4: ơ Borneo; type B.M.

(e) Only differs from abseus in o being bluer.

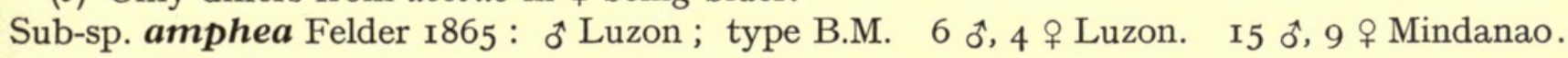
Io ot Mindoro.

(f) ơ upf border I mm., much narrower than in any form.

Sub-sp. oghatina Fruhstorfer I9I4: ơ Bazilan; type B.M. 2 ot Bazilan.

3 (2). Unf discal spot in space 3 produced towards the end-cell spot. of $\mathrm{F} 2 \mathrm{I} \mathrm{mm}$. Below, markings larger, more irregular and more sharply defined.

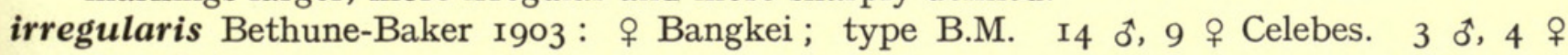
Bangkei.

\section{Theba Group of Narathura}

1 (2a). Unf no markings above cell. Below markings more or less rounded, resembling acetes. ô F $24 \mathrm{~mm}$.; pale shining blue, apex broadly (i I mm.) dark purple, border I $\mathrm{mm}$. क pale blue, dark border $6 \mathrm{~mm}$. Fig. Seitz Pl. I5ob.

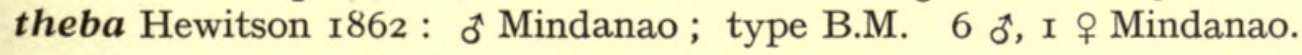

2a (I). Unf long white basal streaks at base costa and base vain $\mathbf{I} 2$, followed by 2 white spots in spaces 7 , I0, II. Below, dark brown with conspicuous white stripes, no rounded markings except at base $\mathrm{F}$ and $\mathrm{H}$.

$2(3,4)$. of F I9 mm., rather pale violet blue with $\frac{1}{2} \mathrm{~mm}$. dark border. 아 bluish-white with dark border F $2 \mathrm{~mm}$. along costa and $4 \mathrm{~mm}$. along termen; suffused bar end cell and a dark spot beyond. Fig. Seitz Pl. $150 b$.

aronya. Hewitson 1869 : ㅇ Mindanao. I t Mindanao.

ENTOM. 5,3 . 
$3(2,4)$. of $\mathrm{F} 23 \mathrm{~mm}$., shining pearly white, with a broad dark, angled apex $5 \mathrm{~mm}$., tapering to I mm. at dorsum; between end cell and apex a narrow purple blue area. Fig. Seitz I 50 Bc.

argentea Staudinger I888: ô Celebes. I to Celebes.

Synonym clarissa Grose-Smith I897 : ô Celebes.

$4(2,3)$. of F 2 I mm., very pale pearly blue, with a broad dark triangular apex, inwardly purple, outwardly brown.

sangira Bethune-Baker I897: ô Sangir; type B.M. I ot Sangir. Fig. Seitz I48b.

\section{E Hercules Group of Narathura}

1 (2). H cell much $<\frac{1}{2}$ wing. $\delta$ above shining blue, border a thread : $H$ all space 6 blue. Fig. Seitz I49 g.

hercules. Ten sub-species, some of which fly together.

(a) ơ $35 \mathrm{~mm}$. \& dull blue, borders ro $\mathrm{mm}$. ; below green.

Sub-sp. hercules Hewitson I862: ơ Macassar. I2 0 , I2 + Celebes.

(b) ô 30 to $33 \mathrm{~mm}$. क brighter purple-blue, border 3 to $5 \mathrm{~mm}$. ; below green.

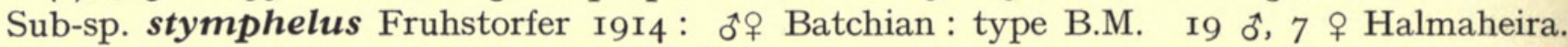
22 ơ Batchian. 2 ơ Obi. I $\sigma^{t}$ Misol.

(c) of 29 to $3 \mathrm{I} \mathrm{mm}$. क purple-blue, borders I to $3 \mathrm{~mm}$. Below, varies from green to white, or pinkish-grey. $\delta$ to brighter blue.

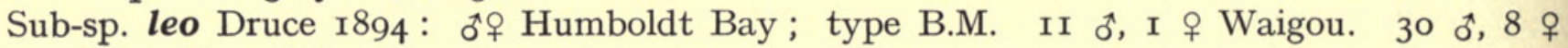
West New Guinea.

Synonyms telephus Toxopeus 1930: ơ SW. New Guinea. leonidas Toxopeus I930: $\widehat{o}$ Salawatti.

(d) As leo. Below, typically pale greenish-white with narrow markings: sometimes brownish, sometimes white with the markings reduced or obsolete.

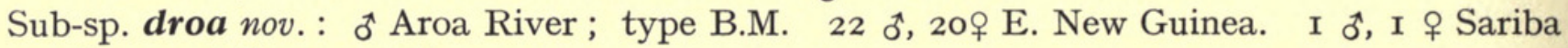
Is. I $\hat{o}$ Fergusson Is.

(e) Small ot F $26 \mathrm{~mm}$. : as $d r o a$, but below more usually pale green with narrow markings.

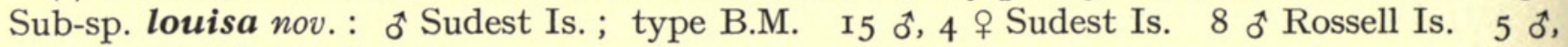
3 ㅇ St. Aignan Is.

(f) o brown above, outer half yellowish. ot brighter blue than leo. Below, pale greenish to pinkish-grey or white : markings liable to much distortion.

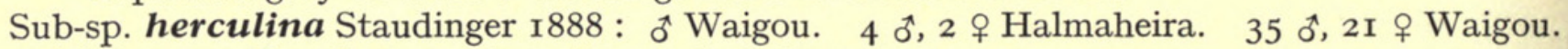

(g) Intermediate between herculina and phalaerus.

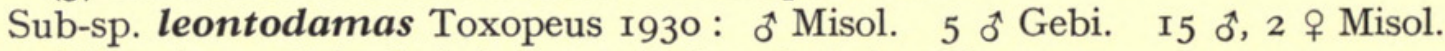

(h) o above plain dark brown. Below dark to pale green.

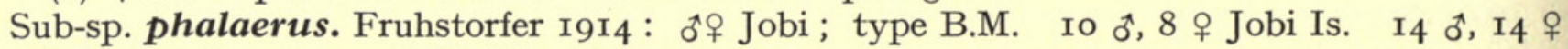

Mioswar Is. 5 o, 3 ㅇ W. New Guinea.

(i) i above and below dark brown.

Sub-sp. tyrannus Felder I865: ot Halmaheira; type B.M. 25 đo, 4 ㅇ Halmaheira. 2 o Batchian. I ơ "Buru ". I to " Aroa R."

Synonyms gilolensis Felder I865: ơ Gilolo ; type B.M. afranius Fruhstorfer I9I4: ot Aroa River; type B.M.

(j) i above, brown : below pale brown.

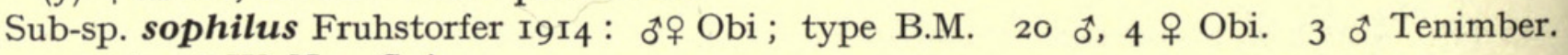
4 ơ, 4 ㅇ W. New Guinea.

Synonym obscurata Ribbe r926: ơ W. New Guinea.

2 (I). $\mathrm{H}$ cell $=\frac{1}{2}$ wing. ơ $\mathrm{F} 23 \mathrm{~mm}$., dark violet-blue, I $\mathrm{mm}$. border. Uph space 6 half brown. + bright shining blue, border $5 \mathrm{~mm}$. Below brown. Fig. Seitz $\mathrm{I}_{5} \mathrm{~b}$.

ate Hewitson I863: ot Amboina ; type B.M. 2 ot Amboina. I 0 , I ㅇ Ceram. 


\section{F. Democritus Group of Narathura}

1a (7a). H tornal lobe conspicuously projecting.

\section{Cleander Sub-group}

I (2a). Unf with spot in space II. ot $23 \mathrm{~mm}$. Fig. Seitz I48c. quercoides Röber I886: ơ Celebes. 32 ơ, 31 \& Celebes.

2a (I). Unf no spot in space I I : generally a spot in space ro.

2 (3a). Unf discal band unbroken, continuous.

cleander. Nine sub-species. Fig. Corbet 45 and $49 \mathrm{~g}$ as aphadantas.

(a) Below pale brown with faint purple wash, markings much darker than ground. o $\mathrm{F}$ $23 \mathrm{~mm}$., dark shining blue, border $2 \mathrm{~mm}$.

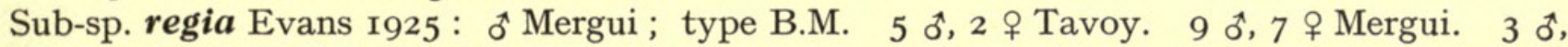
4 ㅇ Victoria Point, S. Burma.

(b) Below plain brown, markings inconspicuous.

Sub-sp. aphadantas Corbet I94I : ơ Malaya; type B.M. $2 \hat{\sigma}$, I + Malaya.

(c) $\sigma^{t}$ above, purple-blue, border $\frac{1}{2} \mathrm{~mm}$. Below, as $(b)$.

Sub-sp. incerta Moulton I9I I : ô Borneo; type B.M. I ô, I + Sumatra. II ô, 9 ㅇ Borneo.

(d) As incerta, but below, conspicuously purple washed.

Sub-sp. apharida Corbet I94I : ơ Lombok; type B.M. 2 ô Java. I of Lombok. Fig. in Rhop. Java as apha.

(e) of $25 \mathrm{~mm}$., dark blue, border $\mathrm{I} \frac{1}{2} \mathrm{~mm}$. क with very reduced purple areas, above, only on half $\mathrm{F}$ and at base $\mathrm{H}$.

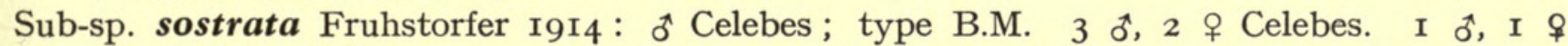
Bangkei. I o Saleyer.

(f) Small, ơ F $20 \mathrm{~mm}$., very dark blue, border $\frac{1}{2} \mathrm{~mm}$. क dark, as sostrata.

Sub-sp. minor nov. : ot Batchian ; type B.M. 2 đ, 2 아 Batchian.

(g) ô F $24 \mathrm{~mm}$., dark blue, border I mm. o brighter blue with broad borders. Below, ochreous brown, like sostrata.

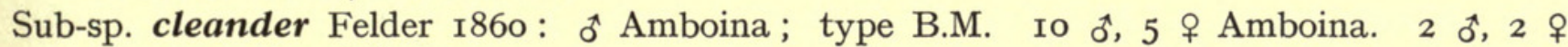
Buru. I $\delta, 2$ ㅇ Ceram.

Synonym adatha Hewitson 1862 : ơ Amboina.

(h) ot F $22 \mathrm{~mm}$., dark blue, border $\frac{1}{2} \mathrm{~mm}$. क क brighter blue, border $4 \mathrm{~mm}$. Below, purple. Unh markings faint, discal spot in space 6 nearer to spot in space 5 than to end-cell spot ; dense whitish scaling between tornal markings and the discal band.

Sub-sp. aruana nov. : ot Aru ; type B.M. 2 o, I 우 Aru.

(i) Above, as aruana but uph space 7 entirely blue, not half brown as in all other cleander forms. Below with purple gloss and conspicuous markings like aruana.

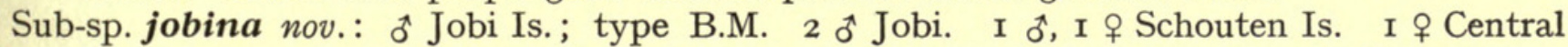
New Guinea. I 우 British New Guinea. I 우 Mefor Is. I 우 “ New Georgia ”.

3a (2). Unf discal band broken or sinuous at vein 4 .

3 (4a). Unf spot in space 6 very much larger than the spot in space 5 . Below, rather pale brown with faint purple gloss and conspicuous markings, irregular and white-edged. ô $\mathrm{F} 23 \mathrm{~mm}$., dark shining blue, border $\frac{3}{4} \mathrm{~mm}$.

nicevillei Bethune-Baker r903: ơ NE. Bengal; type B.M. I + Bhutan, 2 o Jalpaiguri. 2 ot E. Manipur. I o Bhamo, N. Burma.

4a (3). Unf spots in spaces of 6 and 5 of same size.

4 (5a). Unh discal spot in space 6 with its outer edge in line with the inner edge of the spot in space 5 .

athada. Three sub-species.

(a) Below, with a conspicuous purple wash. of $\mathrm{F} 23 \mathrm{~mm}$., dark blue, border $\mathrm{I}_{\frac{1}{2}} \mathrm{~mm}$. o brighter blue, border $3 \mathrm{~mm}$. 
Sub-sp. apha De Nicéville I895: đo Martaban, Burma. I ㅇ Assam. 4 ơ N. Shan States.

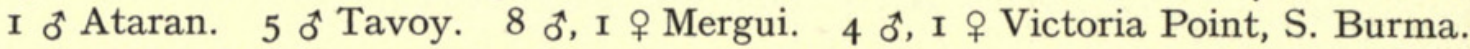

(b) ot upf border $\frac{3}{4} \mathrm{~mm}$. Below, no purple wash.

Sub-sp. athada Staudinger 1889: + Malaya: fig. by Distant as adatha; type B.M. 7 o, 3 우

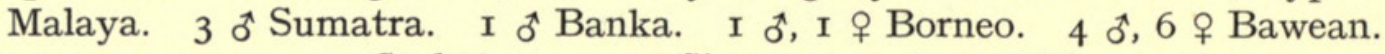

Synonym agamemnon Corbet 194I : ot Singapore ; type B.M.

(c) of F $22 \mathrm{~mm}$. Below very much darker brown than athada, with a faint purple gloss. ô upf dark border $\frac{3}{4} \mathrm{~mm}$.

Sub-sp. wilemani nov. : ô Mindanao ; type B.M. 5 ot Mindanao.

5a (4). Unh discal spot in space 6 not reaching the inner edge of the spot in space 5 .

5 (6). Unh discal spot in space 6 outwardly concave or straight. Fig. Corbet 43 (as adorea) and $47 \mathrm{~g}$.

silhetensis. Four sub-species.

(a) ơ F $25 \mathrm{~mm}$., bright shining blue, border I mm. ㅇ lighter blue, border $4 \mathrm{~mm}$. Below somewhat ochreous brown, no purple wash.

Sub-sp. silhetensis Hewitson I862: o Sylhet; type B.M. I ơ Sikkim. I 아 Cachar.

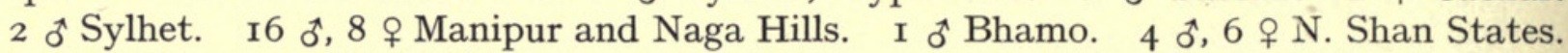

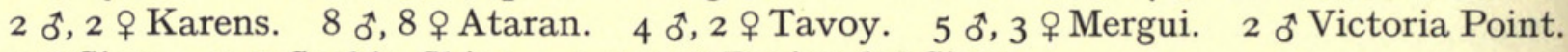
I + Siam. I + Cochin China. I 0 , I i Peninsular Siam.

Synonym arama De Nicéville I895: đo Sikkim.

(b) Below, browner. ot upf border $\frac{1}{2} \mathrm{~mm}$.

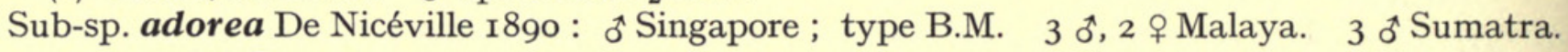
Io ${ }^{*}, 6$ ㅇ B Borneo.

Synonym drucei Bethune-Baker I896 : ơ Borneo.

(c) of $\mathrm{F} 22 \mathrm{~mm}$., border $\frac{3}{4} \mathrm{~mm}$. Below, markings wide apart as in silhetensis, not close together as in adorea.

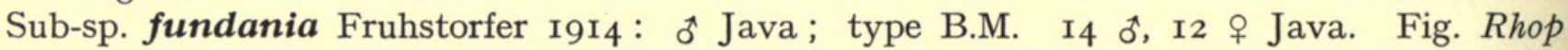
Java as vihara.

(d) Like fundania, with narrow markings. Larger of $\mathrm{F} 25 \mathrm{~mm}$., border very narrow, $\frac{1}{2} \mathrm{~mm}$.

Sub-sp. malayica Bethune-Baker I903: ơ Philippines; type B.M. 4 ơ Mindanao. 7 đ๋ Mindoro.

6 (5). Unh discal spot in space 6 outwardly convex, set obliquely against end-cell spot and directed to apex $\mathrm{H}$.

zambra. Two sub-species. Fig. Corbet 44 and $48 \mathrm{~g}$.

(a) ot F $22 \mathrm{~mm}$., border $\frac{1}{2} \mathrm{~mm}$. Below somewhat ochreous brown, markings well defined.

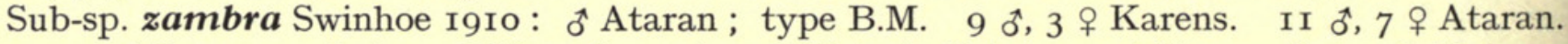

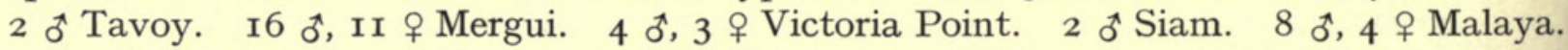

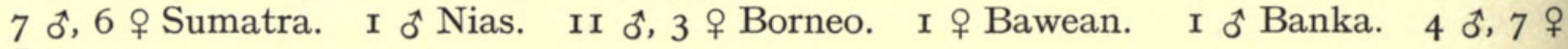
Java.

Synonyms antura Swinhoe I910: ot Ataran ; type B.M.

georgias Piepers \& Snellen I918: ô Java: figured as adorea.

vandenberghi Corbet I94I : ô Java, citing Toxopeus as author.

(b) Larger, ơ F $24 \mathrm{~mm}$. Below, much darker.

Sub-sp. plateni nov. : of Mindanao; type B.M. 2 oै, 2 우 Mindanao.

7a (га). H tornal lobe not conspicuously projecting.

$7 \mathrm{~b}(2 \mathrm{oa})$. Unf discal spot in space 4 not or not much out of line with those in spaces 5 and

6 ; unf. no spot mid space II.

\section{Atrax Sub-group}

7c (I6a). Unh discal spot in space 6 about equal to the gap between the end-cell spot and the spot in space 5 . 
$7 \mathrm{~d}(9 \mathrm{a})$. Unh central cell spot elongate, across cell.

7 (8). Unf discal band broken at vein 4 .

ace. Two sub-species. Fig. Corbet 46 and $50 \mathrm{~g}$.

(a) Small ơ $\mathrm{F} 20 \mathrm{~mm}$., border broader $\frac{3}{4} \mathrm{~mm}$.

Sub-sp. arata Tytler I915: $\approx$ Manipur; type B.M. 4 o Manipur. I $\approx$ Ruby Mines, N. Burma. 2 ơ Ataran.

(b) ơ F $22 \mathrm{~mm}$., dark blue, border a thread. o purple with broad borders.

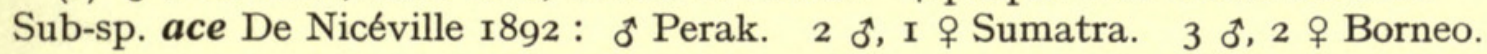

8 (7). Unf discal band unbroken.

azinis. Two sub-species. Fig. Corbet 50.

(a) ot F I $8 \mathrm{~mm}$., dark blue, border $\mathrm{I}_{4}^{\frac{1}{4}} \mathrm{~mm}$. F and $3 \mathrm{~mm} . \mathrm{H}$.

Sub-sp. azinis De Nicéville I896: ơ Sumatra; type B.M. 3 đ, I 오 Sumatra. 2 우 Java.

(b) ơ $\mathrm{F} 20 \mathrm{~mm}$., bluer, border $\frac{1}{2} \mathrm{~mm}$. (see Appendix 3).

Sub-sp. kounga Bethune-Baker I896: ㅇ Kina Balu. 2 ơ, 2 우 Borneo.

9a (7d). Unh central cell spot circular.

9 (roa). Unf discal spot in space 9 absent or very faint.

agrata. Three sub-species. Fig. Corbet 47 and $5 \mathrm{I}$ g.

(a) Apex more pointed, termen straighter. ot above, paler and bluer : $q$ much bluer and more shining.

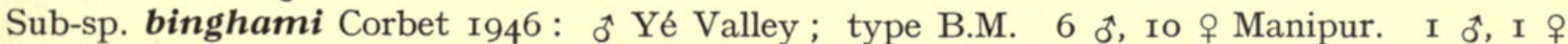

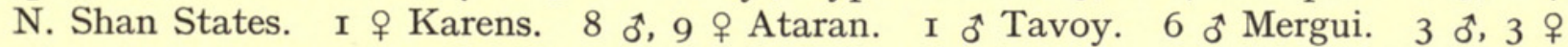
Victoria Point. 2 o, 5 \& Peninsular Siam.

(b) đิ F I9 mm., very dark blue, border $\frac{1}{2} \mathrm{~mm}$. Below, markings not darker than ground, inconspicuous.

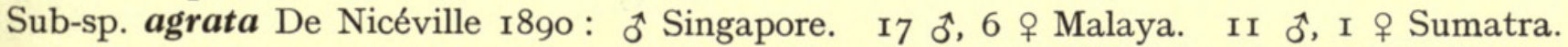
I $\delta$, I + Nias. 2 ô Java.

(c) $\delta$ as agrata; + purple instead of blue.

Sub-sp. brookei Bethune-Baker I903: ô Pulo Laut; type B.M. 9 ô, 4 ㅇ Borneo. I $\sigma^{\star}$ "Hong Kong ". I శึ " New Guinea ".

10a (9). Unf discal spot in space 9 conspicuous.

Io (i Ia). Below, glazed pale purple. oै $\mathrm{F} 20 \mathrm{~mm}$., blue, border I $\mathrm{mm}$. Wings more pointed.

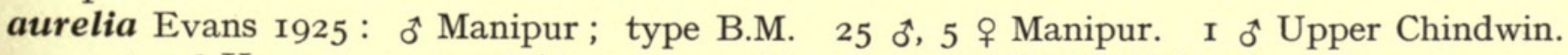

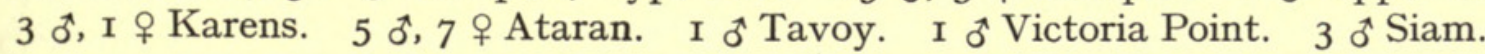

11 (го). Below brown.

I I (I 2a). ot upf border broad, > I mm. Below, often washed pinkish-purple. Wings rounded.

selta. Two sub-species. Fig. Corbet as alea 53 and $59 \mathrm{~g}$.

(a) of F I7 mm., border $1 \frac{1}{4} \mathrm{~mm}$.

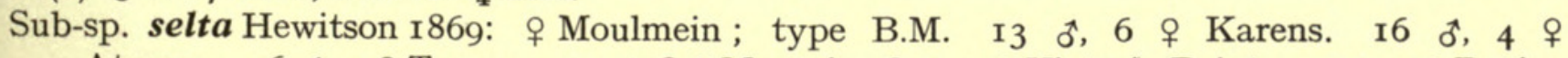

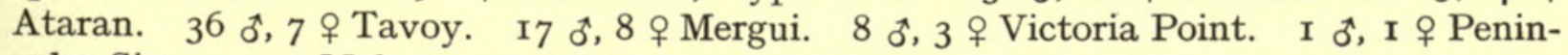
sular Siam. I đ Malaya. I ơ "Sumatra".

(b) ơ F $20 \mathrm{~mm}$., border $2 \mathrm{~mm}$. Below, dark brown, markings darker than ground : no tornal metallic scaling.

Sub-sp. constanceae De Nicéville r 894 : † S. Andaman Is. 6 б, I 오 S. Andaman Is.

12a (II). đo upf border narrow, < I mm.

I2 (13a). ot above, clear blue, no admixture of purple, border $\frac{1}{2} \mathrm{~mm}$. : uph space 6 mostly blue. Unf discal band generally sinuous, due to spot in space 3 being shifted inwards. ralanda. Four sub-species. Fig. Corbet 48 and $53 \mathrm{~g}$ as ridleyi. 
(a) Typical form (see Appendix 3, re kounga).

Sub-sp. ralanda Corbet I94I : đ Tavoy; type B.M. I đ* “Assam ”. 29 đే, II $q$ Karens.

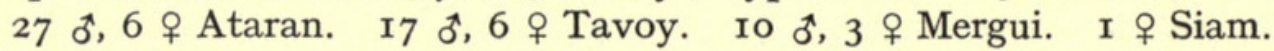

(b) ot upf border broader. क duller, more purple, borders broader.

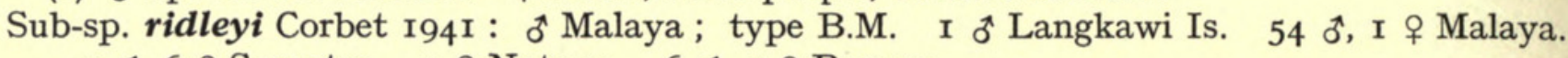
5 o, 6 o Sumatra. I $\quad$ \& Natuna. 6 o, 5 우 Borneo.

Synonym milleri Corbet I94I : o Langkawi Is. ; type B.M.

(c) ot above, faint, but perceptible, indigo hue.

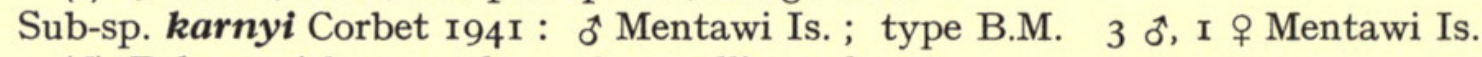

(d) Below, with a purple wash, recalling selta.

Sub-sp. molta nov. : đo Java; type B.M. 4 ơ Java.

13a (12). ơ above, purple blue.

I3 (I4a). Unh discal spot in space 6 is an elongate oval over the end-cell spot and is remote from the discal spot in space 5 . 0 uph space 6 mostly or all blue.

aroa. Two sub-species. Fig. Corbet 49 and $55 \mathrm{~g}$.

(a) Shining purple with narrow dark borders uniform : o dark borders narrower.

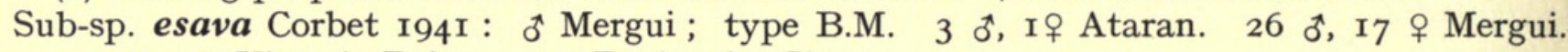
4 đo, 4 ㅇ Victoria Point. I ot Peninsular Siam.

(b) Darker, ot F 2 I mm., border $\frac{1}{2} \mathrm{~mm}$.

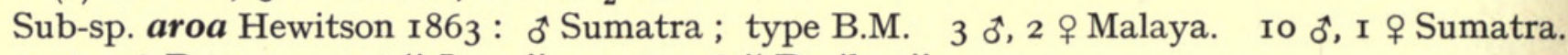

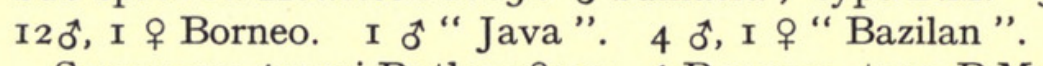

Synonyms pryeri Butler I892: đ Borneo; type B.M.

arops Corbet 194I : ot Malaya; type B.M.

14a (13). Unh spot in space 6 more or less quadrate, between end-cell spot and spot in space 5 . I4 (I5). ơ uph space 6 mostly blue.

sublustris. Two sub-species.

(a) ơ F I9 mm., dark purple blue, border $\frac{1}{2} \mathrm{~mm}$.

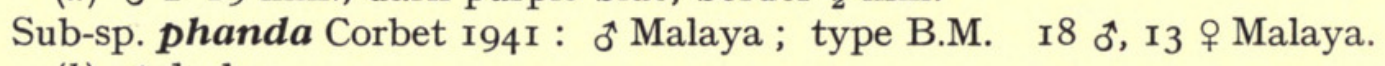

(b) ơ darker.

Sub-sp. sublustris Bethune-Baker I904: क Kina Balu; type B.M. 4 đ, I ㅇ Sumatra. 4 ơ, 2 우 Borneo.

15 (I4). đơ uph space 6 mostly brown.

phaenops. Six sub-species. Fig. Corbet $5^{1}$ and $56 \mathrm{~g}$.

(a) Described as form of azinis, from a discolored specimen, marked as in phaenops. Fig. Corbet $57 \mathrm{~g}$.

Sub-sp. evansi Corbet I94I: đot Malaya ; type B.M. and I $\sigma^{\star}$ Renong.

(b) ơ F I9 mm., dark purple-blue, border $\mathrm{I}_{4}^{\frac{1}{4}} \mathrm{~mm}$. at apex to $\frac{1}{2} \mathrm{~mm}$. at dorsum F. Below, ochreous-brown with darker markings.

Sub-sp. sandakani Bethune-Baker I896: đ Borneo; type B.M. I ot Sumatra. I3 ô, 2 우 Borneo.

(c) Smaller and with a broader dark border.

Sub-sp. detrita Staudinger I889: ot Palawan. None in B.M.

(d) ơ F I $8 \mathrm{~mm}$., border $2 \mathrm{~mm}$. at apex to I mm. at dorsum $\mathrm{F}$.

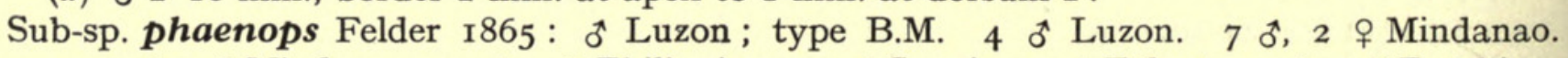

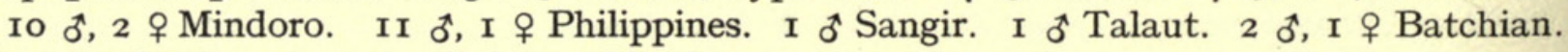

(e) $\delta$ border $\mathrm{F}$ narrower. Below redder brown.

Sub-sp. termerion Fruhstorfer I914: o Bazilan; type B.M. Only the type in B.M.

$(f)$ of F I 7 mm., dark purple-blue, border narrower. Unh outer third free from maculation, except for the tornal metallic spots.

Sub-sp. buruensis Holland 1900 : ơ Buru. I to Obi. 3 ot Buru. 
16a $(7 \mathrm{c})$. Unh discal spot in space 6 not nearly equal to the gap between the end-cell spot and the discal spot in space 5 .

I6b (18a). Unh discal spot in space 6 not overlapping the spot in space 5 .

I6 (I7). Unh purple washed. ơ $20 \mathrm{~mm}$., purple-blue, border I mm. F, $2 \mathrm{~mm}$. H. Name formerly wrongly used for selta.

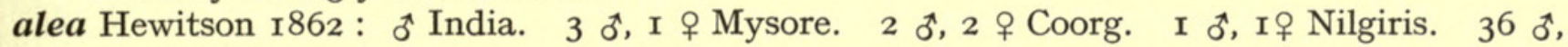
22 ㅇ N. Kanara.

Synonym canaraica Moore $\mathrm{r} 884$ : $\sigma^{\star} \mathrm{N}$. Kanara ; type B.M.

17 (I6). Unh plain brown. There seem to be 2 forms flying together with identical and very peculiar genitalia (see Corbet $52 \mathrm{~g}$ ). Not seasonal forms ; possibly ecological sub-species. oenea. Two sub-species.

(a) of F I9 mm., bright dark blue, border I mm. to a thread: uph space 6 half brown. Below, light brown, markings faint: no tornal metallic scaling.

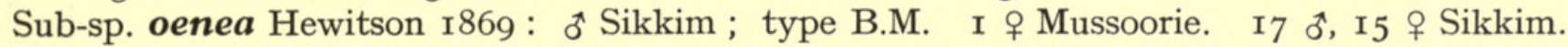

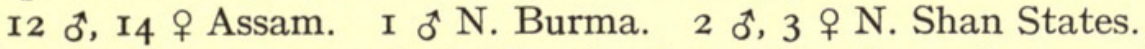

(b) of F $22 \mathrm{~mm}$., very dark blue, border a thread: uph space 6 mostly blue. Below, as oenea but unh with a black tornal lobe and a more or less black spot alongside it crowned with metallic scales.

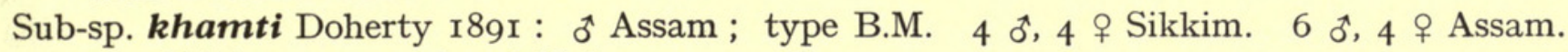
I ot Chittagong. 2 o, 3 o Hainan.

18a (r6b). Unh discal spot in space 6 overlaps spot in space 5 .

I 8 (I9). Upf $\delta^{*}$ ㅇ no conspicuous dark spot at end of cell. $\sigma^{\star} \mathrm{F}$ I $8 \mathrm{~mm}$. dull purple-blue,

border $3 \mathrm{~mm}$. $\mathrm{F}$ : on $\mathrm{H}$, blue not extending beyond end cell. + lighter blue. Below, grey brown, with a slight purple wash (see Appendix 4 for name).

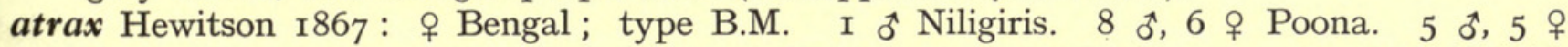

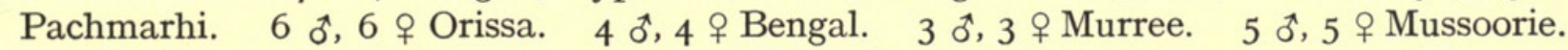

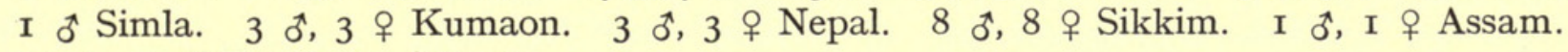
24 đิ, 34 o Burma to Ataran.

Synonyms alemon De Nicéville I891 : đ Burma.

hewitsoni Bethune-Baker r9o3: of India; type B.M.

19 (I8). $\delta^{t}$ ㅇ upf with a conspicuous dark spot at end of cell. $\sigma^{*} \mathrm{~F} 20 \mathrm{~mm}$., purple-blue, border $3 \mathrm{~mm}$. : uph blue area to just beyond end cell. o bluer. Unh no green scaling. Fig. Corbet $62 \mathrm{~g}$.

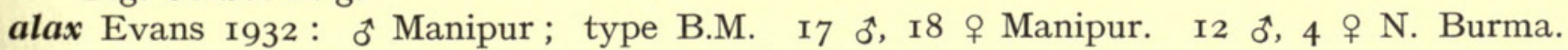

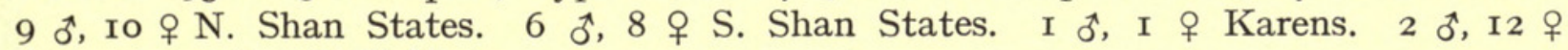
Ataran. 3 đ, I 우 W. Siam.

20a (7b). Unf discal spot in space 4 shifted outwards out of line with the spots in spaces 5 and 6 ; unf. a spot present mid space Ir.

\section{Democritus Sub-group}

20 (2ra). Unh outer edge of discal spot in space 6 concave.

democritus. Four sub-species. Fig. Corbet 37 and $42 \mathrm{~g}$.

(a) o F I $8 \mathrm{~mm}$., pale metallic silvery blue, shading to violet at apex F, border $\frac{1}{2} \mathrm{~mm}$. Below dark chocolate with white dots and dashes.

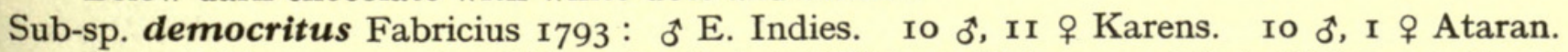

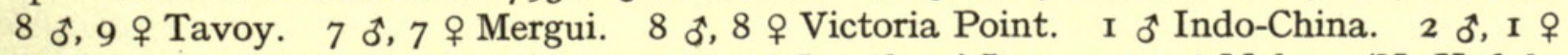

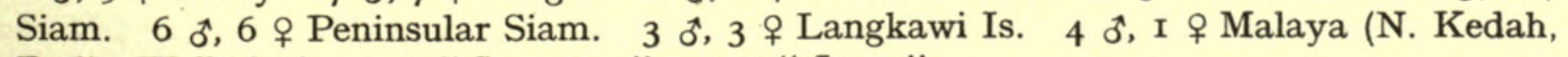
Perlis, Wellesley). I $\delta$ " Sumatra ". I $\delta$ “ Java ".

Synonym albopunctata Hewitson I869: o Moulmein ; type B.M. 
(b) Below, duller with inconspicuous markings of the usual type. Above, o nearly as bright as democritus: $q$ more purple-blue, with narrow borders, $\frac{1}{2} \mathrm{~mm}$. on uph. $\sigma^{\star} \mathrm{F}$ I9 $\mathrm{mm}$.

Sub-sp. lycaenaria Felder I860: đ Malacca; type B.M. I đ “Naga Hills". 7 đ, 8 q

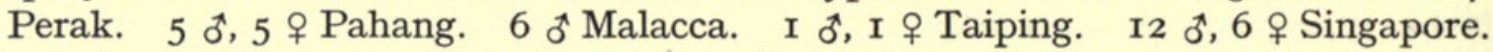

(c) Larger, of $\mathrm{F} 20 \mathrm{~mm}$. Intermediate to olinda.

Sub-sp. buxtoni Hewitson 1878: 우 Sumatra : type B.M. I2 ot, Io 우 Sumatra.

(d) ot more uniform: + purple with much broader borders, $3 \mathrm{~mm}$. on $\mathrm{H}$, and upf with a dark spot at end of cell.

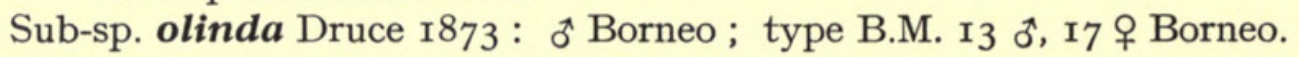

21a (20). Unh outer edge of discal spot in space 6 convex or straight.

$2 \mathrm{Ib}(25 \mathrm{a})$. Unf with a spot at base of space Io : rarely absent on one side.

2 Ic (23a). Below, markings conspicuously darker than the ground.

2 I (22). Unh grey-brown.

alitaeus. Six sub-species. Fig. Corbet 38 and $43 \mathrm{~g}$.

(a) ơ F I9 mm., bright blue, border I mm. : uph space 6 half blue. Below brown with more or less of a purple wash, markings irregular, as in in alitaeus.

Sub-sp. mirabella Doherty I889: क Mergui ; type B.M. I đ Karens. 9 đ. 7 o Ataran.

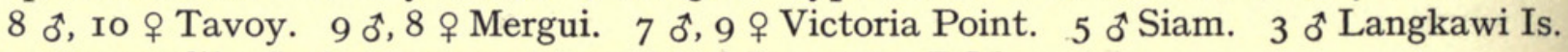

Synonym valika Corbet I94I : ơ Langkawi Is. ; type B.M.

(b) ot upf border narrower, $\frac{3}{4} \mathrm{~mm}$.

Sub-sp. pardenas Corbet I94I : ot Singapore; type B.M. 3 ơ, 3 ㅇ Malaya.

(c) ot duller, purple blue, border $\frac{3}{4}$ to $\frac{1}{2} \mathrm{~mm}$. Below, markings rather less conspicuous.

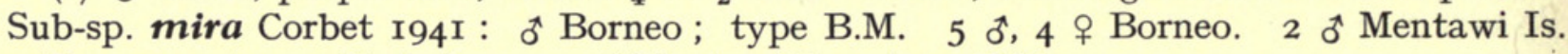

Synonym psama Corbet I94I : o Mentawi Is. ; type B.M.

(d) of F $20 \mathrm{~mm}$., border a thread. Below, with a slatey glaze and a more uniform appearance.

Sub-sp. myrtale Staudinger I889: o Palawan. 5 o Palawan.

(e) Unh more or less whitened, presenting an appearance quite different from myrtale.

Sub-sp. panta nov. : $\sigma^{\star}$ Mindanao; type B.M. 5 ot Mindanao. I $\delta$ Luzon.

(f) ơ F $20 \mathrm{~mm}$., dark blue, border I $\mathrm{mm}$. क very different, all brown except for some dull purple on basal half upf.

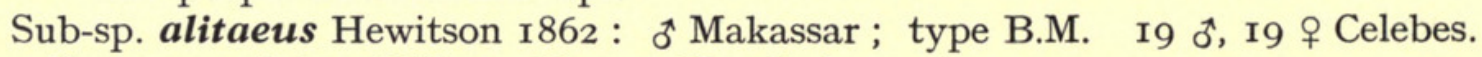

Synonym viviana Röber I887 : ơ Bangkei.

22 (2I). Unh dark brown with a purple wash. $\approx \mathrm{F} 20 \mathrm{~mm}$., dark blue, border $\frac{1}{2} \mathrm{~mm}$. o purple-blue, border $3 \mathrm{~mm}$. : uph all brown. Genitalia differ considerably.

sintanga Corbet I948: ot Borneo ; type B.M. 2 ot, 2 우 Borneo.

23a (2Ic). Below, markings not darker than ground.

23 (24). ot above, dark blue with a dark border.

mindanensis. Four sub-species.

(a) ơ $\mathrm{F} 20 \mathrm{~mm}$., blue, border I mm. o brighter blue, border $4 \mathrm{~mm}$. Below, markings outlined brownish-white.

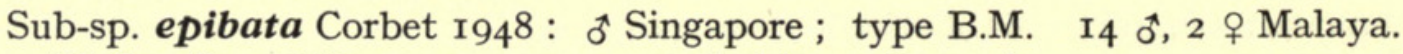

(b) Smaller, ot F I9 mm., more purple-blue : क purple.

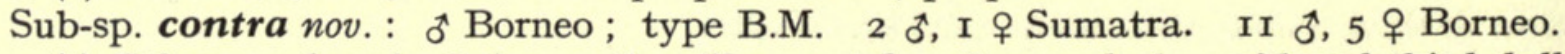

(c) F less produced : below rather like myrtale: $q$ very dark, upf basal third dull purple, uph all brown.

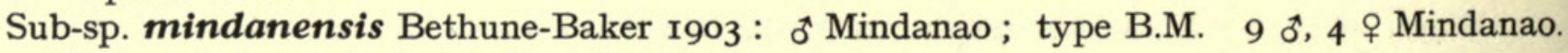

(d) As mindanensis, but unh whitened.

Sub-sp. zilensis Fruhstorfer 1914: $\sigma^{*}$ Bazilan; type B.M. I $\sigma^{*}$ Bazilan. 
24 (23). ot above, bright shining blue, border a thread: uph space 6 all blue : F I9 mm. $q$ purple blue, border 2 to $3 \mathrm{~mm}$., dark spot about end of cell upf. Below rather pale brown, markings as in alitaeus. Uncus hooks not expanded at their ends.

denta nov. : $\sigma^{\star}$ Mt. Marapok, Dent Province, Borneo; type B.M. I 4 ot, 5 ㅇ Borneo. Fig. Corbet $46 \mathrm{~g}$ as elopura.

25a (2rb). Unf no spot at base of space ro.

25 (26a). Unf spots in spaces 4 to 7 almost in line.

aida. Two sub-species. Fig. Corbet $44 \mathrm{~g}$ (see Appendix 4).

(a) ot F I $8 \mathrm{~mm}$., dark shining blue, border $\mathrm{I}_{2} \frac{1}{\mathrm{~mm}}$. Uph one-third of space 6 blue. Below grey-brown.

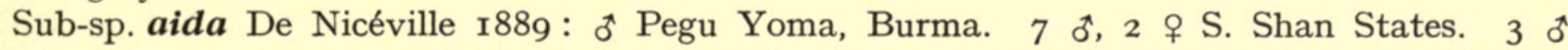

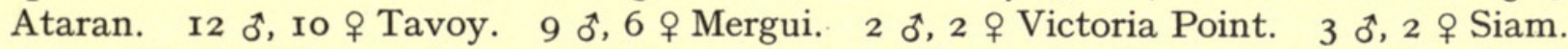

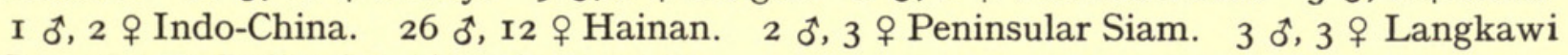
Is. I $\sigma^{\star} \mathrm{E}$. Indies (Hewitson's atrax $\sigma^{\star}$ ).

(b) ot F $16 \mathrm{~mm}$., bright shining blue, border I mm. : uph half of space 6 blue. Below, with distinct purple gloss. Fig. Corbet 39 as atrax.

Sub-sp. ophir nov. : ${ }^{\star}$ Mt. Ophir, Malaya; type B.M. Only the type.

26a (25). Unf spots in spaces 4 to 7 irregular, those in spaces 4 and 7 out of line. 26 (27a). क upf border broad, $3 \mathrm{~mm}$. : F $18 \mathrm{~mm}$. Uph $\frac{3}{4}$ of space 6 brown. Below grey-brown.

myrtha Staudinger 1889: đo Palawan. 3 o Palawan.

27a (26). $\delta$ upf border not $>$ I $\mathrm{mm}$.

27 (28). Below brown, markings not darker than the ground.

pseudomuta. Four sub-species. Fig. Corbet 40 and $45 \mathrm{~g}$ as arianaga.

(a) of $\mathrm{F} 20 \mathrm{~mm}$., bright shining blue, border $\frac{3}{4} \mathrm{~mm}$.

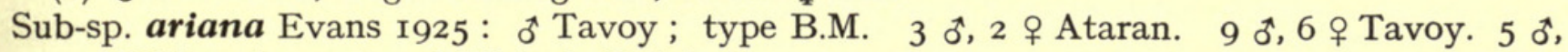
2 우 Mergui. 2 ơ, 2 o Victoria Point.

(b) Darker shining blue, border I mm. Flies with ariana.

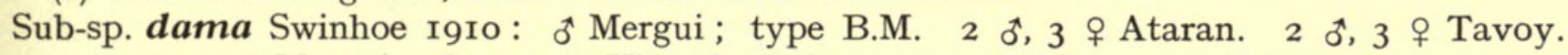

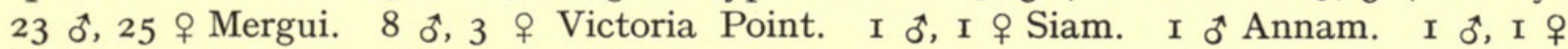
Peninsular Siam. I ot Langkawi Is.

Synonym ariavana Corbet I94I : o Langkawi Is. : type B.M.

(c) of F $20 \mathrm{~mm}$., dark blue, border $\frac{1}{2} \mathrm{~mm}$. : uph more than half of space 6 is blue (see Appendix 5 for name).

Sub-sp. pseudomuta Staudinger I889: đ Malaya. 29 §, 13 ㅇ Malaya.

Synonyms rafflesii De Nicéville I890: ơ Singapore; type B.M. Fig. Corbet 4 I. arianaga Corbet I94I : ơ Malaya ; type B.M.

(d) o $\mathrm{I} 8 \mathrm{~mm}$., wings more rounded, border a thread.

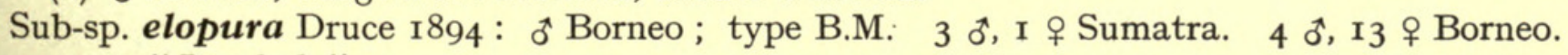
I ㅇ" Lombok".

28 (27). Below, purple washed: markings darker than the ground.

havilandi. Two sub-species.

(a) Smaller, ot F I8 mm., brighter blue, border a thread. क blue.

Sub-sp. kota nov. : ơ Kota Tinggi, Johore, Ist May I938: J. N. Eliot; type B.M. 2 đ, 2 ㅇ Malaya.

(b) of F $22 \mathrm{~mm}$., border $\frac{1}{2} \mathrm{~mm}$. Uph nearly all space 6 blue.

Sub-sp. havilandi Bethune-Baker I896: ơ Borneo. 3 đo, 4 우 Borneo. 


\section{G. Eumolphus Group of Narathura}

1 (2a). $\mathrm{H}$ tornal lobe conspicuously projecting.

\section{Nobilis Sub-group}

nobilis. Four sub-species. Fig. Seitz I49f.

(a) of $\mathrm{F} 27 \mathrm{~mm}$., dark shining blue border $\frac{1}{2} \mathrm{~mm}$. क o dull purple with very broad borders. Below, uniform brown. Unf costal spots in spaces 7, ro, II : discal spots in spaces 4, 5 out of line, elongate, nearly reaching termen.

Sub-sp. alce Hewitson I862 : đ "Aru " (probably Halmaheira) ; type B.M. I " "Celebes ". 7 ơ, I + Halmaheira. 2 ơ Aru.

Synonym ajusa Fruhstorfer I9r3: ot Halmaheira ; type B.M.

(b) Similar, but + blue with narrow dark border. Below, less strongly marked. ${ }^{\star}$ brighter blue.

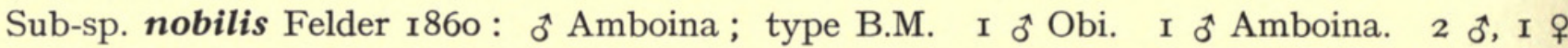
Ceram. I + Key Is.

Synonym nobilior Fruhstorfer I9I3: ot Obi ; type B.M.

(c) o F $25 \mathrm{~mm}$. Unh variegated, much paler and markings fainter below a dark costal area obscuring the spots.

Sub-sp. alcestis Grose Smith I902: ơ Milne Bay; type B.M. I o "Batchian”. I đa Gebi. I of Aru. 8 ot, 3 o W. New Guinea. 2 o British New Guinea.

Synonyms athara Grose-Smith I902: o Stephansort; type B.M. A variety with a darker underside.

caelestis Röber I93I : đ̊ SW. New Guinea.

(d) $\mathrm{F}+20 \mathrm{~mm}$. Above, as alcestis. Below plain brown with faint markings.

Sub-sp. bosnikiana Joicey \& Talbot I9I6: o Schouten Is. ; type B.M., and I $q$ Mefor Is., Geelvink Bay.

2a (I) $\mathrm{H}$ tornal lobe not conspicuously projecting.

2b (8a). Below, markings macular, not banded.

\section{Wildei Sub-group}

2 (3a). Unf with a costal spot in space ro. o $\mathrm{F} 26 \mathrm{~mm}$.

antharita. Two sub-species.

(a) $\delta$ very dark blue, border 7 to $8 \mathrm{~mm}$. : uph only blue in cell. o bright purple blue, border $3 \mathrm{~mm}$. Below, ot light brown, o nearly white: unh costal markings enlarged and conjoined.

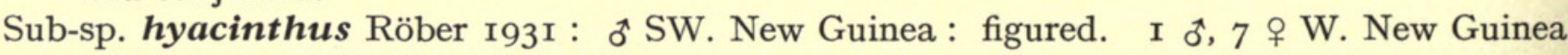
(Eilanden and Oetakwa Rivers).

(b) ot above, entirely dark brown, with some obscure blue scaling about end cell $\mathrm{F}$.

Sub-sp. antharita Grose-Smith I894: ơ Humboldt Bay; type B.M. : figured Rhop. Exot. I878. Only the type.

3a (2). Unf no costal spot in space ro.

$3 \mathrm{~b}(5 \mathrm{a})$. Unf discal spots in spaces $6,5,4$ directed to mid-termen.

3 (4). Below white with small brown markings.

wildei. Three sub-species. Fig. Seitz $\mathrm{I}_{47} \mathrm{~g}$.

(a) of F 2 I mm., light blue, border 2 to $3 \mathrm{~mm}$., dark spot end cell F. $q$ white with dark borders $5 \mathrm{~mm}$. and blue bases.

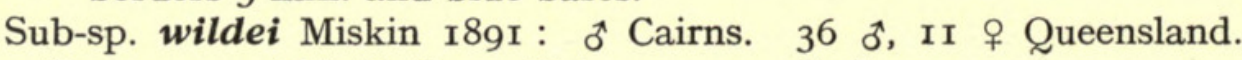

Synonym cupido Bethune-Baker 1903: cited as a synonym.

(b) o uph white area reduced, entire costa and apex dark brown. Smaller. 


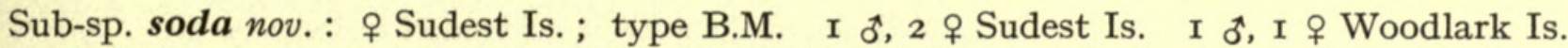

(c) \& F $23 \mathrm{~mm}$., no blue colouring at bases $\mathrm{F}$ and $\mathrm{H}$, or dark spot at end of cell upf in $\sigma^{*}$ or 우.

Sub-sp. neva nov. : 오 Stephansort ; type B.M. Type and I $\delta^{\star}$ W. New Guinea (Ninay Valley).

4 (3). Below brown with conspicuously white ringed large markings: unh discal spots in spaces 6, 7 united to a single large round spot. of $\mathrm{F} 23 \mathrm{~mm}$., light purple-blue, border 2 to $3 \mathrm{~mm}$., as in wildei.

halma nov. : ơ Halmaheira ; type B.M. 2 ot type locality.

5a (3b). Unf discal spots in spaces 6, 5, 4 directed to tornus.

5 (6a). Unf discal spots in spaces 2,3 much smaller than those in spaces 4 to 6 . $\approx \mathrm{F}$ I $7 \mathrm{~mm}$., dull pale blue, border $2 \frac{1}{2} \mathrm{~mm}$., dark spot end cell $\mathrm{F}$. 우 inner half of disc dull light blue, outer half white : dark border 6 to $4 \mathrm{~mm}$., dark spot end cell : uph similar, pale area more restricted. Below, light grey, markings white-edged.

asma nov. : ot Woodlark Is. ; type B.M. I 0 , I 9 Woodlark Is.

6a (5). Unf discal spots in spaces 2, 3 not smaller than those in spaces 4 to 6 .

6 (7). Unf discal spot in space Ib absent or faint.

irma. Two sub-species.

(a) ot F 22 mm., shining light blue, border 2 to I mm., veins narrowly black. Below light brown, markings faint.

Sub-sp. irma Fruhstorfer I9I4: ơ Obi ; type B.M., unique.

(b) Light purple-blue, veins not black. o shining light blue, border 6 to $2 \mathrm{~mm}$. Below, violet brown, markings clear.

Sub-sp. purpura nov. : đ̊ Oetakwa River, W. New Guinea; type B.M. I ơ (type): I $ᄋ$ Ron Is. (W. Doherty, I897).

7 (6). Unf discal spot in space rb conspicuous. o $\mathrm{F} 26 \mathrm{~mm}$., shining light blue, border $2 \frac{1}{2}$ to $\mathrm{I} \mathrm{mm}$. on $\mathrm{F}$ and $\frac{1}{2} \mathrm{~mm}$. on $\mathrm{H}$. $\&$ light blue, border $7 \mathrm{~mm}$. Below, dark brown, white-edged darker markings.

halmaheira Bethune-Baker I904: o Halmaheira: type B.M. 40, 2 \& Halmaheira.

8a (2b). Below, markings banded.

$8 \mathrm{~b}$ (г ra). Below, markings not darker than ground.

\section{Acetes Sub-group}

8 (9a). Unh in space 7 central spot not nearer to the basal than to the discal spot. of $\mathrm{F}$ 22 to $30 \mathrm{~mm}$., dark blue, border a thread. क purple-blue on basal third $\mathrm{F}$ and in cell $\mathrm{H}$. Fig. Seitz I $49 d$ and I5O $a$ and $b$.

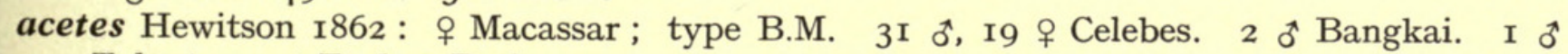
Talaut. I $\mathbf{0}$ Toeken Besi.

Synonym kitjila Ribbe I926: W. Celebes.

9a (8). Unh in space 7 central spot much nearer to the basal than to the discal spot.

9 (10). Unf and unh lower part of end-cell spot expanded outwards.

tephlis. Two sub-species. Fig. Seitz I $49 e$ (poorly).

(a) Unh more or less whitened beyond the discal band and above the cell : in one $\sigma^{t}$ unf is also whitened. of $\mathrm{F} 23 \mathrm{~mm}$., purple-blue, border $2 \frac{1}{2}$ to $\mathrm{I} \frac{1}{2} \mathrm{~mm}$. : $q$ blue, border 8 $\mathrm{mm}$.

Sub-sp. bicolora Röber I886 : 오 S. Celebes. 23 đૈ, I 5 ㅇ Celebes.

(b) Unh a white streak from base to termen over cell and vein 6 . ơ upf dark border narrow, $\mathrm{I} \frac{1}{2}$ to $\frac{1}{2} \mathrm{~mm}$.

Sub-sp. tephlis Hewitson r869: đ Gilolo; type B.M. Unique. 
10 (7). Unf and with unh lower part of end-cell spot not expanded outwards.

bazaloides. Two sub-species. Fig. Corbet $80 \mathrm{~g}$. Seitz I48a.

(a) ot upf dark border I mm. : uph half of space 6 blue.

Sub-sp. lanka nov. : ot Ceylon; type B.M. Unique.

(b) ơ F $2 \mathrm{I} \mathrm{mm}$., dark purple-blue, border $2 \mathrm{~mm}$. : uph space 6 mostly brown. q lighter purple-blue, border $4 \mathrm{~mm}$. Unh very variable, purple-brown, more or less white scaled : tornal metallic scaling vestigial.

Sub-sp. bazaloides Hewitson I878: ? ? loc. ; type B.M. I $\mathbf{0}$ Travancore. I 우 Mysore.

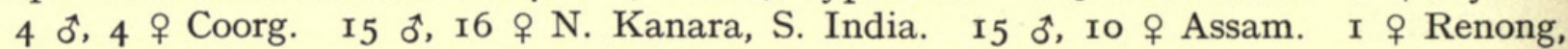
Siam. 2 i Hainan. (Langkawi Is., Corbet).

11a (8b). Below, markings darker than the ground.

\section{Eumolphus Sub-group}

I Ib (20a). Unh discal spot in space 6 outwardly concave.

I I (I 2a). Unf dark area under cell extends to the discal band. $\mathrm{H}$ cell $<\frac{1}{2}$ wing.

amantes. Three sub-species. Fig. Seitz I $47 f$. Corbet 83 g. Fig. of amantes in Rhop. Java is araxes onetor Fruh.

(a) ô $\mathrm{F} 27 \mathrm{~mm}$., shining blue, border $\frac{1}{2} \mathrm{~mm}$. 우 lighter, borders very broad. Below, grey-brown, paler apically on $\mathrm{F}$ and $\mathrm{H}$.

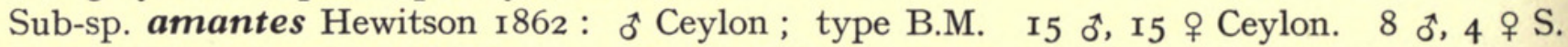
India. 13 o, I3 o N. Kanara. 6 ๙ 6 우 Poona.

(b) of upf border broader, $4 \mathrm{~mm}$. at apex to $2 \mathrm{~mm}$. at dorsum. Generally paler below and has slightly different seasonal forms.

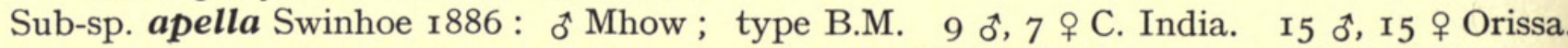

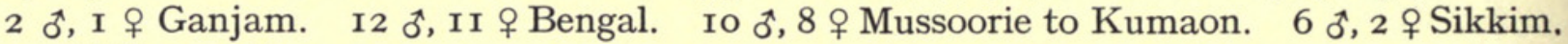
I ơ "Borneo".

(c) $\sigma^{*}$ upf dark border $4 \mathrm{~mm}$. on $\mathrm{F}$ and $7 \mathrm{~mm}$. on $\mathrm{H}$.

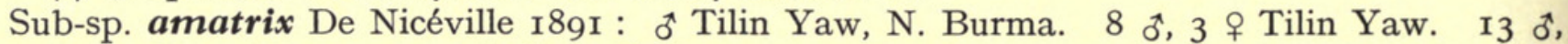

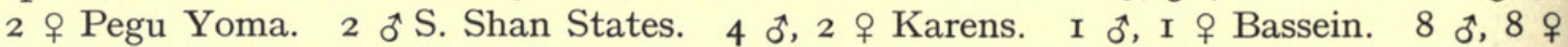
Ataran. I + Tavoy. 5 ơ Siam.

12a (II). Unf dark area under cell not extending beyond mid wing. $\mathrm{H}$ cell $=\frac{1}{2}$ wing.

I 2 (гза). Unh spots mid space 7 and mid cell conjoined. ơ $\mathrm{F} 23 \mathrm{~mm}$., purple, border $2 \mathrm{~mm}$. and a black spot at end of cell. ㅇ purple-blue with broad borders. Below, variegated with yellow, purple, grey and brown areas. Fig. Lep. Ind. Corbet 82 g.

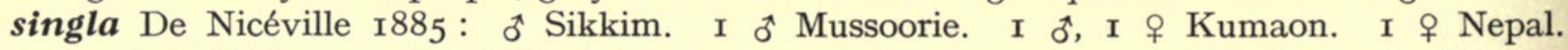

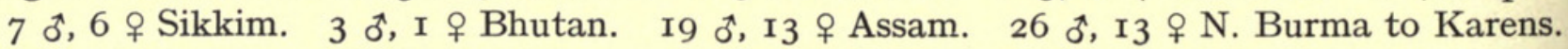
I ơ Yunnan. I 우 “Perak".

13a (I2). Unh spots mid space 7 and mid cell wide apart as usual.

I3b (I9). Unf discal spot in space 4 not nearer to termen than to the end-cell spot.

I3 (I4a. Unh and apex unf powdered pale violet scales. $t$ blue. Considerable seasonal and individual variation.

bazalus. Four sub-species. Fig. Corbet 59 and 8I g.

(a) Unh costal half of wings conspicuously paler, markings faint, tornal lobe brown, white scaling under the tornal metallic scaling usually absent. + purple-blue.

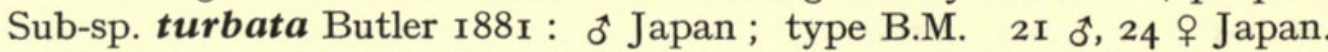

(b) Unh markings yellowish on the white-scaled purple-brown ground. Unh of wet season form more uniform, tornal lobe black with some metallic green scaling.

Sub-sp. teesta De Nicéville I886: đ Sikkim; type B.M. 6 o, 4 q China (W. and SE.).

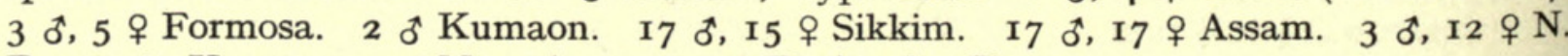
Burma to Karens. I $\delta^{\star}$ Mergui. I $\delta$, I 9 Peninsular Siam. 
(c) \& quite different from other forms. Large, F $24 \mathrm{~mm}$., clear blue, dark border on costa $\mathrm{F}$ to vein 6, leaving dark spot end cell and another mid-space 5 ; border $2 \frac{1}{2} \mathrm{~mm}$. mid termen : uph mostly blue with dark veins, border $5 \mathrm{~mm}$. to $2 \frac{1}{2} \mathrm{~mm}$. mid-termen.

Sub-sp. zalinda Corbet I94I : 우 Kedah; type B.M. I o , 2 아 Kedah, Malaya.

(d) ô F $23 \mathrm{~mm}$., very dark blue, border F I mm., $\mathrm{H}_{4} \mathrm{~mm}$. Below, like teesta wet season form. o more purple-blue than blue.

Sub-sp. bazalus Hewitson I862: ㅇ Java; type B.M. I + Malaya. 2 dै, ro ㅇ Sumatra. 24 ơ, I 8 ㅇ Java.

Synonyms nebenius Fruhstorfer 19I4: o Sumatra ; type B.M. pratinas Fruhstorfer I9I4: ot W. Java: type B.M.

14a (г3). Unh and apex unf no pale violet scaling. ôt green.

I4 (I5a). ô upf apical half black.

horsfieldi. Four sub-species. Fig. Corbet 63 and $77 \mathrm{~g}$.

(a) Above green colour brighter, more extensive. क blue, border $3 \frac{1}{2} \mathrm{~mm}$.

Sub-sp. eurysthenes Fruhstorfer I9I4: ot Tenasserim. I of, I + Karens. 2 of, 3 우 Ataran.

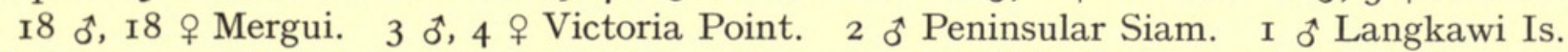

(b) Larger, of F $24 \mathrm{~mm}$., extent of green colour very variable, ㅇ purple. Below ochreousbrown with broad markings.

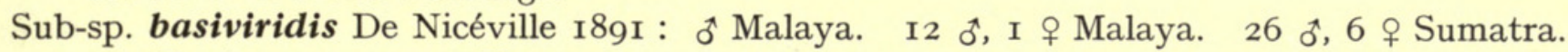
4 ơ Banka. I7 ơ, 4 우 Borneo.

Synonyms herodianus Fruhstorfer I9I4: ${ }^{*} \mathrm{~W}$. Sumatra ; type B.M.

leokvates Fruhstorfer I9I4: ơ Borneo ; type B.M.

(c) Unh tornal metallic scaling larger. \& above dark border broader.

Sub-sp. serpa Fruhstorfer 1899: ơ Nias. 6 ơ, 3 우 Nias.

Synonym biru Fruhstorfer I9I4: ơ Nias ; type B.M.

(d) Small, ot $\mathrm{F} 20 \mathrm{~mm}$. : base to mid-wing shining green and in cell $\mathrm{H}$. क purple, border as in $\sigma^{t}$. Below, grey-brown, with small markings, conspicuous on $\mathrm{F}$, faint on $\mathrm{H}$.

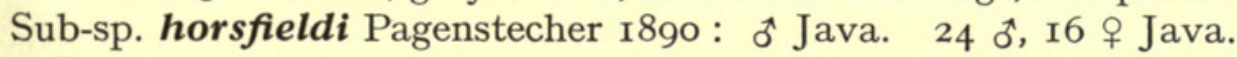

Synonym vellanus Fruhstorfer I9I4: ${ }^{\star} \mathrm{W}$. Java; type B.M.

15a (I4). ô upf green extending nearly to apex.

I5 $\mathrm{b}(\mathrm{I} 8)$. ot uph with a broad dark border.

I5C (I 7$)$. Unh discal spots normal.

I5 (I6). ô wings not produced, termen F convex : upf border at apex I to $3 \mathrm{~mm}$.

eumolphus. Four sub-species. Fig. Corbet 62 and $76 \mathrm{~g}$.

(a) ô F $23 \mathrm{~mm}$., border $3 \mathrm{~mm}$. at apex to $4 \mathrm{~mm}$. at dorsum; uph green to just beyond end cell. o purple-blue, border 6 to $7 \mathrm{~mm}$.

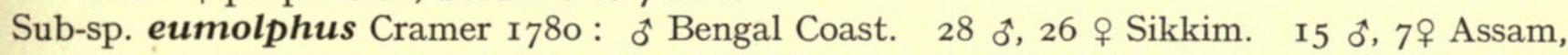

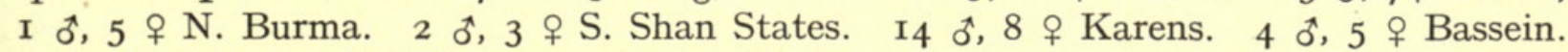
3 ơ, 1 + Ataran. 8 ơ Siam. 20 ơ, 14 + Hainan.

Synonyms bupola Hewitson I878: o Sikkim : type B.M.

elis Fruhstorfer I9I4: ot Sikkim ; type B.M.

tagove Fruhstorfer I9I4: ơ Assam; type B.M.

(b) o purple area much more extensive, border $3 \mathrm{~mm}$. on $\mathrm{F}$ and $\mathrm{H}$. ot border $\mathrm{F}$ narrower.

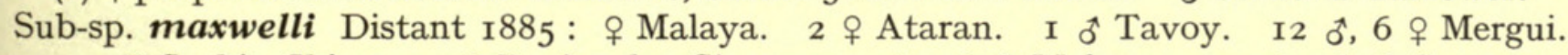

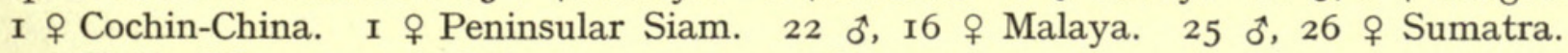

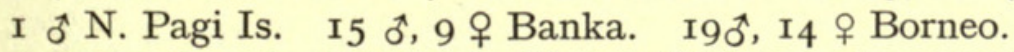

Synonyms farquhari Distant I885: ơ Malaya; type B.M. caesarion Fruhstorfer I9I4: ô Sumatra ; type B.M. caesetius Fruhstorfer I9I4: ot Borneo.

(c) + bright pale blue instead of purple. 


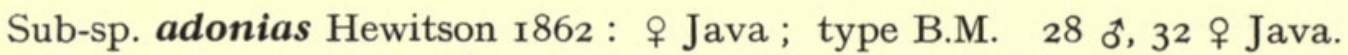

Synonyms grynea Hewitson I878: 아 Java ; type B.M.

aytonia Fruhstorfer I9I4: o W. Java ; type B.M.

(d) o paler than adonias.

Sub-sp. aristomachus Fruhstorfer 1914: ㅇ Palawan. None in B.M.

16 (I5). ot wings produced, termen F straight. ot upf border at apex not $>\frac{1}{2} \mathrm{~mm}$.

hellenore. Two sub-species. Fig Lep. Ind.

(a) of $\mathrm{F} 24 \mathrm{~mm}$. Below more or less variegated: costal half $\mathrm{H}$ and apical half $\mathrm{F}$ more or less whitened. o purple-blue, border $\mathrm{F}_{4} \mathrm{~mm}$. Unh tornal metallic scaling faint or absent.

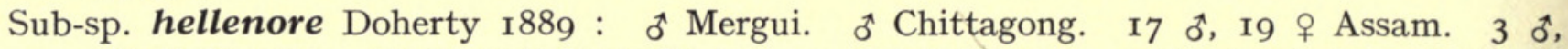

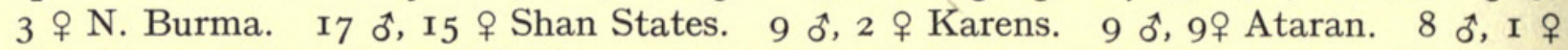

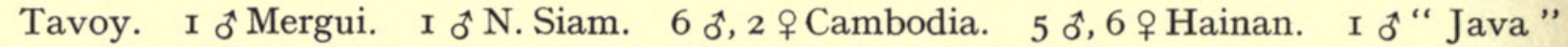
Synonyms viridissima Swinhoe I89o: ô Mandalay; type B.M.

sanherib Fruhstorfer I9I4: ot Java; type B.M. Fig. in Rhop. Java, but locality seems very doubtful.

(b) $\widehat{o}$ upf border very narrow, not reaching apex. Unh metallic scaling conspicuous. + differs from maxwelli in the greater extent of the purple beyond the cell upf and between the veins above the costa.

Sub-sp. siroes Fruhstorfer I9I4: ot Sumatra; type B.M. I2 0 , 7 우 Sumatra. (From Malaya in coll. Eliot.)

17 ( I $_{5} \mathrm{C}$. Unh discal spots abnormal, those in spaces 6, 7 enlarged and conjoined to the spots mid-space 7 and mid-cell. $\delta$ above, as eumolphus. + purple-blue scaling to beyond end cell upf, leaving a dark spot end cell, dark border $6 \frac{1}{2} \mathrm{~mm}$. Fig. Seitz $\mathrm{I}_{5} \mathrm{o}$.

staudingeri Semper I89o: ơ Mindanao. I 우 Mindanao.

18 ( $15 \mathrm{~b}) . \quad \sigma^{x} \mathrm{uph}$ all green. Fig. Seitz $\mathrm{I62a}$ as heliagabulus.

chamaeleona. Two sub-species.

(a) ô F $25 \mathrm{~mm}$. Below, uniform brown, no white areas : unh with well-developed tornal metallic scaling.

Sub-sp. rileyi Joicey \& Talbot I922: ơ Ceram ; type B.M. 4 ô, 2 우 Ceram.

(b) of F $23 \mathrm{~mm}$., entirely green with a violet flush on outer half of wing in a side light. o bright blue, border $4 \mathrm{~mm}$. Below, variegated with whitened areas, as in hellenore: unh no metallic scaling.

Sub-sp. chamaeleona Bethune-Baker 1903: ot Aroa Bay ; type B.M. 5 of, 3 o Schouten

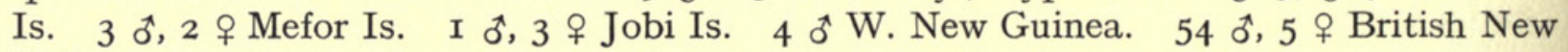
Guinea.

Synonyms elegabulus Fruhstorfer I9I4: ô Aroa R. ; type B.M. restricta Rothschild I9I5: 우 W. New Guinea; type B.M. heliagabulus Seitz I926: mis-spelling.

19 ( $13 \mathrm{~b})$. Unf discal spot in space 4 nearer to termen than to end-cell spot. of $\mathrm{F} 23 \mathrm{~mm}$., very dark purple-blue, border $\frac{1}{2} \mathrm{~mm}$. at apex to I $\mathrm{mm}$. at tornus and on $\mathrm{H}$. o purpleblue, border $2 \frac{1}{2} \mathrm{~mm}$. Below, dark purple brown. Fig. Seitz $\mathrm{I}_{5} \mathrm{OB} b$.

bella Bethune-Baker I896: đ Borneo. I 우 “Sikkim ”. I 호, 3 우 Borneo.

20a (I Ib). Unh discal spot in space 6 not outwardly concave.

2ob (22). Unf without a conspicuous dark area in basal half of space $\mathrm{rb}$.

20 (2I). Below ochreous-brown. Fig. Seitz I5oe, $f$.

tameanga. Two sub-species.

(a) ơ F $22 \mathrm{~mm}$., much lighter violet-blue. Unf discal band continued to vein $\mathrm{I}$. $\subsetneq$ border narrower, decreasing to $\mathrm{I} \frac{1}{2} \mathrm{~mm}$. at tornus $\mathrm{F}$ and $\mathrm{I} \mathrm{mm}$. uph. 


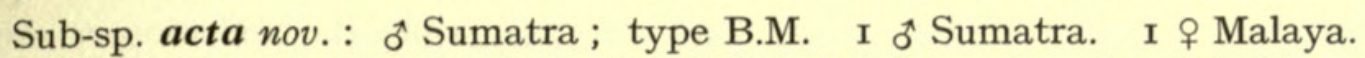

(b) ô F $27 \mathrm{~mm}$., very dark violet-blue, border a thread. क lighter purple-blue, border $4 \mathrm{~mm}$., and dark spot at end cell.

Sub-sp. tameanga Bethune-Baker I896: ô Borneo; type B.M. 2 ot, I 9 Borneo. I 웅 Labuan.

21 (20). Below plain brown. Fig. Corbet $78 \mathrm{~g}$ and, as bella, Ioo.

overdijkinki Two sub-species.

(a) đิ F $22 \mathrm{~mm}$., shining rather dark violet blue, broad border, $7 \mathrm{~mm}$. at apex to $2 \frac{1}{2} \mathrm{~mm}$. at tornus, I mm. on $\mathrm{H}$. क o brighter blue, border as $\delta$ a and dark spot end cell $\mathrm{F}$.

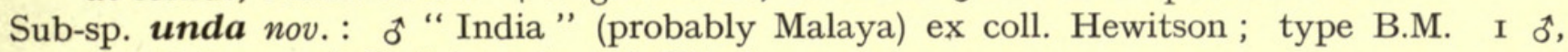
I o Malaya. (오 S. Johore in coll. Eliot).

(b) o F 2 I mm., lustrous purple, with outer half $\mathrm{F}$ from mid-costa to tornus broadly black : $\mathrm{H}$ with costal and apical half of outer margin broadly darkened. $q$ shining blue, with a dark spot at end of cell.

Sub-sp. overdijkinki Corbet I94I : đิ Java; type B.M. 27 đิ, 2 I 우 Java.

22 (2ob). Unf basal half of space rb conspicuously dark brown.

corinda. Three sub-species. Fig. Corbet 57 and $72 \mathrm{~g}$.

(a) Above paler, ㅇ bluer.

Sub-sp. corestes Corbet I94I : ơ Langkawi Is. ; type B.M. I + Ataran. 8 đ, 2 우 Mergui. I ㅇ Victoria Point. 4 oै, 2 우 Langkawi Is.

(b) o uph purple-blue colour as extensive as in $\delta^{t}$.

Sub-sp. acestes De Nicéville I893: ô Perak. I $q$ Malaya. I q Sumatra. 5 đૈ, 9 ㅇ Borneo. I $\sigma^{*}$, I + Java.

(c) ơ F $25 \mathrm{~mm}$., very dark blue, border a thread. ㅇ purple-blue, border $3 \mathrm{~mm}$., continued along dorsum.

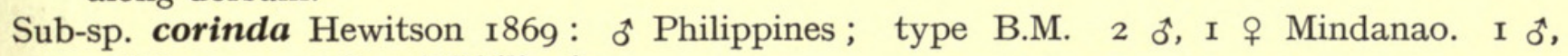
I ㅇ Luzon. 2 oै, I ㅇ Philippines.

\section{H. Centaurus Group of Narathura}

1a (12a). Unh discal band more or less broken at vein 6.

Ib (8a). Unf discal band of even width or tapering towards dorsum.

Ic (3a). Unh discal spot in space 6 outwardly concave.

I (2). Unf discal band curved (see Appendix 6 for name).

centaurus. Seven sub-species. Fig. Seitz I50a. Corbet 93 and $70 \mathrm{~g}$.

(a) ô F $29 \mathrm{~mm}$., shining dark purple-blue : 아 blue, basally conspicuously brighter : border $\mathrm{I} \frac{1}{2}$ to $\frac{1}{2} \mathrm{~mm}$. of, 8 to $3 \mathrm{~mm}$. ㅇ.

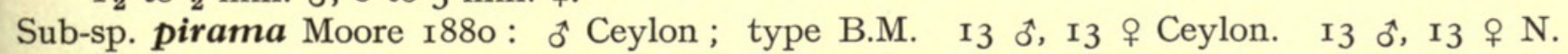
Kanara.

(b) Above, more uniform, borders the same.

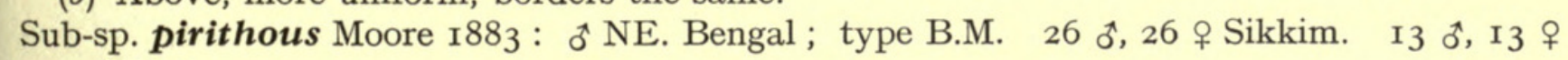
Assam.

(c) $\widehat{\jmath}$ upf border $\frac{1}{2} \mathrm{~mm}$. Above, bases much brighter.

Sub-sp. coruscans Wood-Mason \& De Nicéville I880: ơ Andaman Is. I 3 ô, I3 우 Andaman Is.

(d) Darker, uniform purple-blue, border $\frac{1}{2} \mathrm{~mm}$.

Sub-sp. centaurus Fabricius I775: “ “New Holland” (recte Malaya); type B.M. (Banks

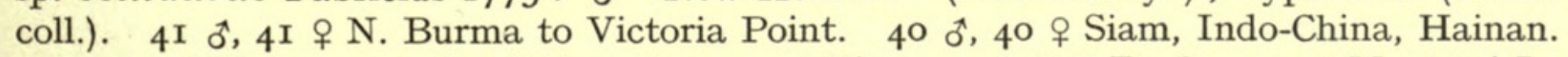

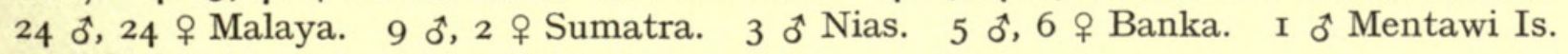
I $\delta$ Natuna Is. I6 $\delta^{\star}$, Io ㅇ Borneo.

Synonyms nakula Felder I86o: ơ Sumatra ; type B.M. cervidius Fruhstorfer I9I4 : ơ Borneo ; type B.M. 
(e) Large, ot $\mathrm{F}$ 30 $\mathrm{mm}$. Above, as centaurus. Below markings broader and more showy, particularly the tornal metallic scaling.

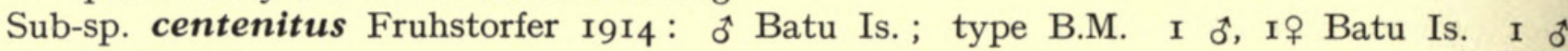
N. Pagi Is.

(f) Below much more variegated than centaurus. Variable.

Sub-sp. pseudo-centaurus Doubleday I847: 우 Java ; type B.M. 3I ô, 31 우 Java. 9 o,

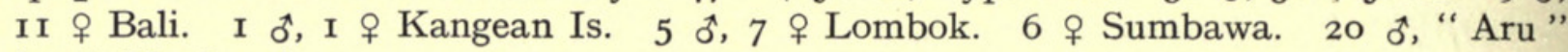
(probably Java).

Synonym amazona Pagenstecher 189o: ot Java.

$(g)$ Unf white outer edge of the spot end cell nearly fused to the inner edge of the discal band. Unh vareigated.

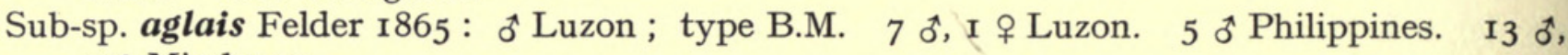
I ㅇ Mindanao.

2 (I). Unf discal band straight.

araxes. Nine sub-species. Fig. Seitz I $49 e$ and $149 b$ as eupolis.

(a) of F $27 \mathrm{~mm}$., shining blue, darker apically, border $\mathrm{I} \mathrm{mm}$. to a thread at dorsum $\mathrm{F}$ and H. Fig. Rhop. Java as amantes.

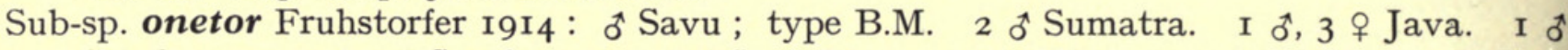

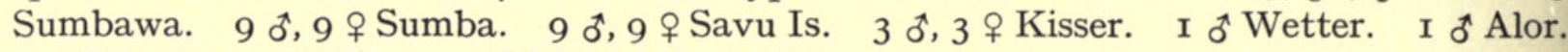
I ô Moa Is. I o Timor. 2 ㅇ Larau Luka Is.

Synonym aphobus Fruhstorfer I9I4: o Java; type B.M.

(b) ot like araxes, smaller. क pale blue, dark border intermediate to onetor.

Sub-sp. verelius Fruhstorfer I9I4: $\sigma^{\star}$ Kalao; type B.M. 3 o, 3 i Kalao.

(c) Small, of F $26 \mathrm{~mm}$., darker, like onetor, 우 as araxes.

Sub-sp. talauta nov. : ot Talaut; type B.M. 4 ô, 4 क Talaut.

(d) ơ $\mathrm{F} 29 \mathrm{~mm}$., brilliant shining blue, darkening apically, border $\mathrm{I} \frac{1}{2} \mathrm{~mm}$. at apex to $\frac{1}{2} \mathrm{~mm}$. at dorsum and on $\mathrm{H}$. $\quad$ light blue, dark border broader than the blue area.

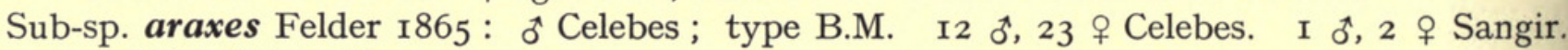
2 ot Sula-Mangoli.

Synonym grandiosa Fruhstorfer I9I4: ot Celebes.

(e) ot above dull purple, border a thread: 아 bluer, border $3 \mathrm{~mm}$. Below, light brown, no violet gloss. ot $\mathrm{F} 26 \mathrm{~mm}$.

Sub-sp. philtron Fruhstorfer I9I4: ot Yule Is. ; type B.M. 4 ot, 4 우 Key Is. I $\delta^{\star}$, I 우 Aru.

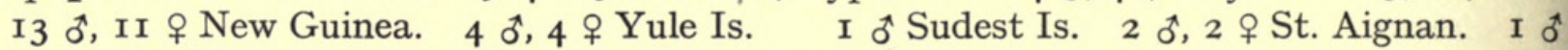
New Hebrides.

$(f)$ Similar, but below, with a violet gloss.

Sub-sp. eupolis Miskin I890: ơ Cape York. 29 ơ, 29 \& Queensland.

(g) Much duller than eupolis. + more often purple.

Sub-sp. asopus Waterhouse \& Lyell I9I4: ơ Darwin. is of, i I + Darwin.

(h) ơ F $26 \mathrm{~mm}$., dark shining blue, border $\frac{1}{2} \mathrm{~mm}$. के bright shining blue, border $8 \mathrm{~mm}$. on $\mathrm{F}$, I mm. on $\mathrm{H}$. Below much darker brown.

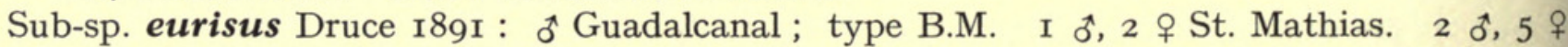

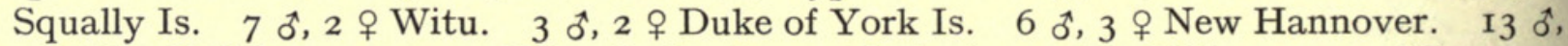

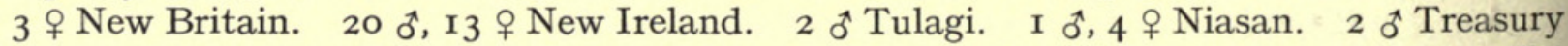

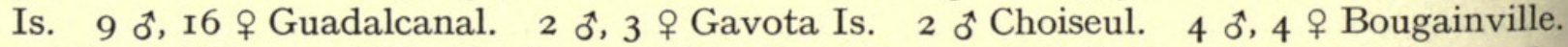

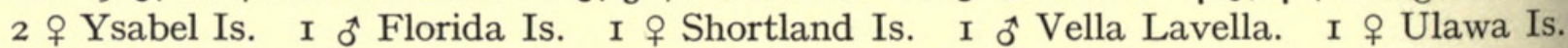
I 9 Fauro Is. I ot Rendova.

(i) + purple instead of blue. Perhaps a dimorph.

Sub-sp. tindali Ribbe r899: Shortland Is. I $q$ Malaita. I + Bougainville. Note.Absence of araxes in the Moluccas is remarkable.

3a (Ic). Unh discal spot in space 6 not outwardly concave.

$3 \mathrm{~b}(5 \mathrm{a})$. Unh discal spot in space 6 very broad and overlapping the end-cell spot. 
3 (4). Unh a spot at the base of space 6 (a unique feature), which may be conjoined to the discal spot in space 6 . Unf discal band broad and straight. of $\mathrm{F} 26 \mathrm{~mm}$., above as meander: below dark purple-brown, markings very broad.

lata nov. : ơ Halmaheira; type B.M. 5 ot Halmaheira.

4 (3). Unh no spot at base of space 6. Unf discal band curved. Above as meander. Below, like lata. Unh usually a whitish area between the discal spots in spaces 6, 7 and the central spots. ơ F $25 \mathrm{~mm}$.

adherbal Grose-Smith : ơ Milne Bay ; type B.M. I ot Halmaheira. I ơ Aru. 3 ot Waigou.

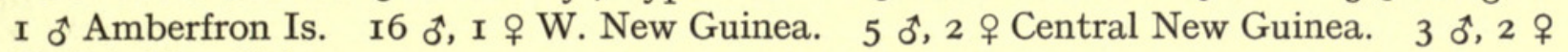
British New Guinea.

Synonym appianus Grose-Smith I902 : ơ Humboldt Bay ; type B.M.

5a (3b). Unh discal spot in space 6 not overlapping the end-cell spot.

$5(6,7)$. Below, ochreous-brown with distinct narrow markings. Unf discal band narrow, straight, tapering towards tornus. क $\mathrm{F} 20 \mathrm{~mm}$., purple with broad dark borders, $7 \mathrm{~mm}$. at apex to $5 \mathrm{~mm}$. at dorsum $\mathrm{F}$ and $3 \mathrm{~mm}$. on $\mathrm{H}$.

wanda nov. : Wandesi, Geelvink Bay, New Guinea type B.M. Unique.

$6(5,7)$. Below plain brown, markings faint: unf discal band irregular and broken at vein 4. of $\mathrm{F} 22 \mathrm{~mm}$., bright shining blue, border a thread: + purple-blue; broad borders.

hylander Grose-Smith 1894 ： đ Schouten Is. ; type B.M. : fig. Rhop. Exot. 2 đ, I o Schouten Is., New Guinea.

$7(5,6)$. Below, very dark purple, markings well defined. Unf discal band sinuous, narrow. ơ F $25 \mathrm{~mm}$., dark blue, border a thread. Genitalia aberrant, distal end of clasp on ventral side very conspicuously produced.

styx nov. : $₫$ New Britain, Kinigunang, C. Ribbe; type B.M. 2 ๙ New Britain. I $\sigma^{\star}$ Guadalcanal. I ot Ysabel, Solomon Is.

8a (rb). Unf discal band tapering to costa.

8 (9a). Unh discal band completely dislocated at vein $\mathrm{rb}$. Below, violet with more or less conspicuous whitish areas at apex $\mathrm{F}$ and $\mathrm{H}$ : unh mid-termen broadly darkened. F more produced. of $\mathrm{F} 26 \mathrm{~mm}$. (2I mm. in Louisade Is.). Above, like meander but dark border rather wider in Australia than elsewhere.

madytus Fruhstorfer I9I4: $\widehat{0}$ Queensland; type B.M. 2 oै Amboina. I $\hat{\sigma}$ Aru. I $\hat{\sigma}$ Waigou. I6 0 , 5 क W. New Guinea. Io ơ Central New Guinea. 5 ot British New Guinea. 3 ot Woodlark Is. 4 to St. Aignan. 6 oै, I ㅇ Sudest Is. 2 우 Russell Is.

9a (8). Unh discal band more or less constricted at vein $\mathrm{Ib}$ rather than dislocated.

9b (II). Unh discal spot in space 6 not overlapping the end-cell spot.

9 (Iо). Below, uniform violet (often fading to brown) with narrow and regular discal bands: unh discal band from space 2 to space 5 more or less in line. of $\mathrm{F} 23 \mathrm{~mm}$., dark blue, border a thread. क purple, border broad on $\mathrm{F}$ narrow on $\mathrm{H}$.

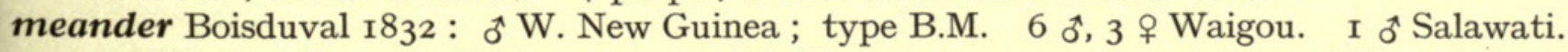

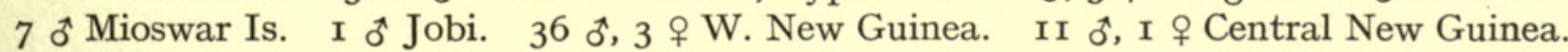
5 o British New Guinea. $2 \delta^{\star}$ Fergusson Is. I $\delta^{\star}$ Dampier. I 9 Vulcan Is. $2 \sigma^{\star}$ "New Britain ". 2 ot "Solomons".

Synonyms periander Grose-Smith I894: $\widehat{0}$ Jobi ; type B.M. anicius Fruhstorfer I9I4: $\delta$ " Solomons" ; type B.M.

10 (9). Below brown or purple-brown, markings more or less irregular. Unh discal band with the spot in space 3 pushed out of line. Above, as meander.

ENTOM. $5,3$. 
philander. Eight sub-species. Fig. Seitz I5oB $a$ (badly).

(a) Below brown without any trace of purple wash. Unf discal band broad. Unh darker about mid-termen. of $\mathrm{F} 26 \mathrm{~mm}$.

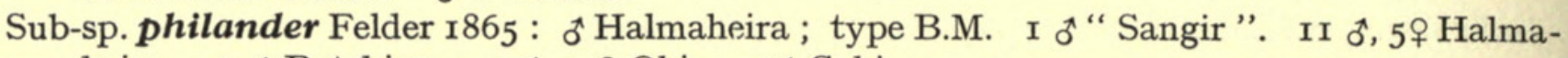
heira. $50^{\star}$ Batchian. $2 \delta^{\star}, 2$ o Obi. $30^{\star}$ Gebi.

(b) o $\mathrm{F} 25 \mathrm{~mm}$. Below purple-brown, with somewhat irregular dark reddish-brown markings. Very variable: unf apical area may be whitish : unh centre of termen may be broadly darkened and central area may be whitish : some, all brown unh.

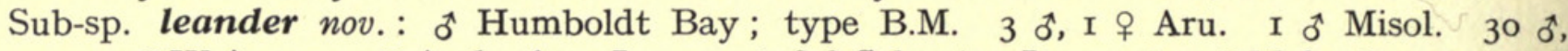

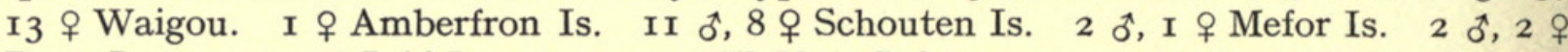

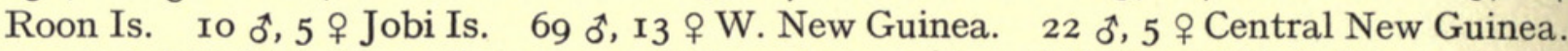

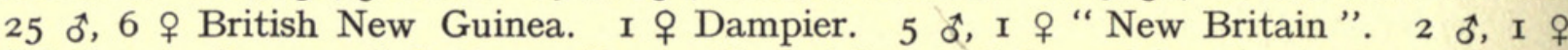
"Solomons". I $\sigma^{*}$ "S. Burma " ex coll. Swinhoe and figured by him in Lep. Ind. as ot of constanceae! I o " Burma Ataran" ex coll. Swinhoe.

(c) Below, paler, violet-grey. Unh centrally conspicuously darkened from base to midtermen.

Sub-sp. ander nov. : đo Kapaur ; type B.M. 3 đ, 2 우 W. New Guinea.

(d) of F $25 \mathrm{~mm}$., as philander below, may have a faint purple wash. Darker blue above, like gazella.

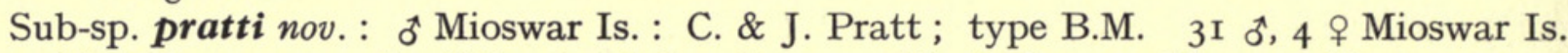

(e) ot F $24 \mathrm{~mm}$. As philander, below brown with darker markings. Above, not so dark as pratti. $q$ above, purple with broad dark borders as in leander, much broader than in philander.

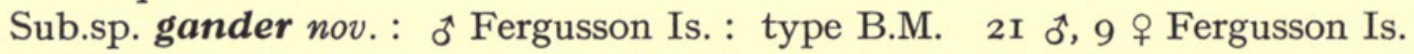

(f) ô F $24 \mathrm{~mm}$., very much paler blue than any other form. Below, rather dark brown with a purple wash : markings rather narrow, but more conspicuously outlined than usual. Unf discal band centrally angled.

Sub-sp. meeki nov. : New Hannover: A. S. Meek; type B.M. 2 б, I + New Hannover.

(g) ơ F $26 \mathrm{~mm}$. Lighter blue than usual, but not so light as meeki. Below, darker than any other form, with a well-marked purple wash : markings narrow and even, faintly outlined.

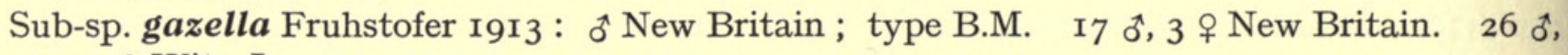
4 ㅇ Witu Is.

(h) Large, of F $27 \mathrm{~mm}$. Above, rather dark blue, as philander. Below, dark brown, faint purple wash on outer half $\mathrm{H}$ and beyond discal band $\mathrm{F}$ : markings narrow, clearly defined.

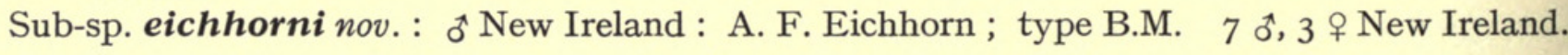

11 (9b). Unh discal spot in space 6 overlapping end-cell spot. Below, purple-brown, all markings very broad. ot F $22 \mathrm{~mm}$. Above as philander. Fig. Seitz I49b and (as “menander") I $47 f$.

kiriwinii Bethune-Baker I903: कै Trobriand Is. ; type B.M. 21 tै, 9 o Trobriand Is. 4 o I 아 Fergusson Is. I $\delta^{\star}$ Woodlark Is. 6 đ, 4 우 British New Guinea.

12a (ra). Unh discal band continuous from costa to vein 2. Unf discal band tapered towards dorsum.

I2b (I4a). Unh with the usual dark spots and discal band.

I2 (I3). Unh discal band more or less irregular and may be variegated. End of genitalia clasp equally divided.

micale. Sixteen sub-species. Fig. Seitz I49f.

(a) Unh markings broad: intervals between the spots in space 7 wider than the spots. ot F $25 \mathrm{~mm}$., bright blue turning to violet-blue on outer half $\mathrm{F}$, border a thread. of blue, border F $6 \mathrm{~mm}$. Unh usually a whitish area above cell. 


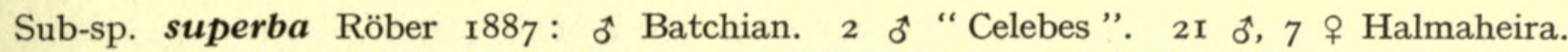

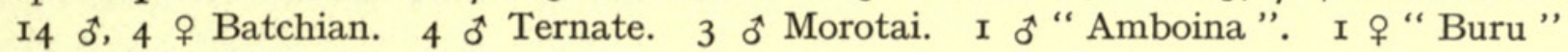
I 0 " Cape York".

(b) Smaller, of F $23 \mathrm{~mm}$. क क border narrower, I to $2 \mathrm{~mm}$. at dorsum F.

Sub-sp. obina nov. : ơ Obi ; type B.M. 5 đึ, 5 우 Obi.

(c) Unh markings narrow: intervals between the spots in space 7 wider than the spots. $\delta$ upf border at apex not $>\frac{1}{2} \mathrm{~mm}$. $\sigma^{*}$ above, shining pale blue darkening to violet-blue on apical half $\mathrm{F}$. Below, very dark brown, markings faint.

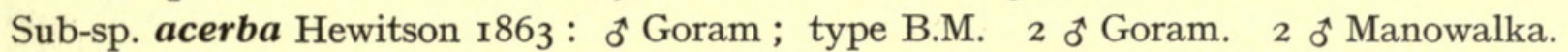

(d) As acerba, smaller, ô $\mathrm{F} 22 \mathrm{~mm}$. : below, markings more distinct. $\hat{\sigma}$ more uniform above: 아 like superba.

Sub-sp. leptines Fruhstorfer I9I4 : ơ Kei Is. : type B.M. $9 \sigma^{\star}, 6$ o Kei Is.

(e) ơ F $26 \mathrm{~mm}$., plain purple-blue as micale, border $\frac{1}{2} \mathrm{~mm}$., o purple-blue with broad border. Below, typically variegated, conspicuous whitish area above cell $\mathrm{H}$ and about apex $\mathrm{F}$ and $\mathrm{H}$ : grades to the acerba form.

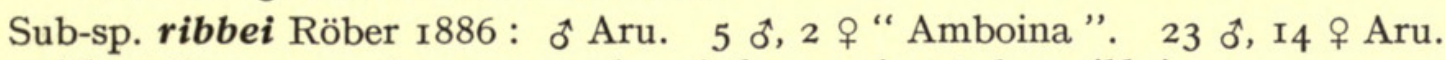

(f) ơ F $24 \mathrm{~mm}$., above as acerba: below variegated as ribbei.

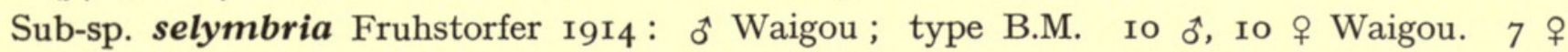
Misol.

(g) of $\mathrm{F} 27 \mathrm{~mm}$., above as acerba: क shining rather dark clear blue, border broad. Below, like micale, but unf the whitish areas on either side of the discal band are conspicuously streaked.

Sub-sp. bosnika nov. : $\sigma^{t}$ Schouten Is. ; type B.M. 5 $\hat{\delta}, 5$ ㅇ Schouten Is.

(h) ot F $27 \mathrm{~mm}$., above as acerba. क pale shining blue as amytis, border broad. Below, uniform as micale, markings broad and clearly defined.

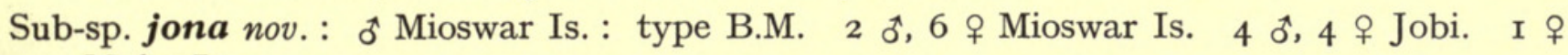
Mefor Is.

(i) of F $26 \mathrm{~mm}$., above as acerba. . very variable, from rather dark purple-blue to pale blue, border broad. Below, varying from the pale micale type to the variegated ribbei form.

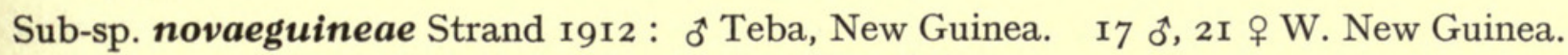

Synonym tebaensis Strand I92I : ơ Teba, New Guinea.

(j) 우 F $26 \mathrm{~mm}$., bright shining light blue, as amytis, borders broad. Below, variegated or plain. $\delta$ above, as acerba.

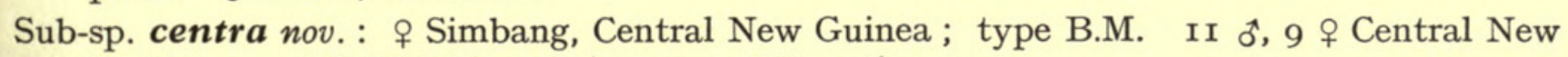
Guinea. I $\approx$ British New Guinea. 2 o Dampier.

(k) ô F $26 \mathrm{~mm}$., uniform dark shining blue, border a thread : + dark purple-blue, borders broad. Below, generally plain brown, markings rather faint, but the variegated ribbei form occurs rarely.

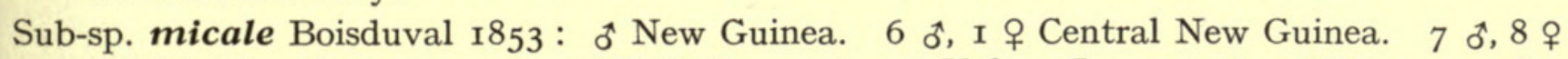
British New Guinea. $2 \hat{\delta}, 2$ ㅇ Yule Is. $3 \hat{0}$, I + Vulcan Is. $\quad$ Io $\hat{0}, 5$ ㅇ Fergusson Is.

Synonym androtion Fruhstorfer I9I4: 0 Yule Is. ; type B.M.

(l) ơ F $28 \mathrm{~mm}$., like micale, but o light blue with broad ( $8 \mathrm{~mm}$.) dark border.

Sub-sp. cidona Fruhstorfer I9I4: 우 Kiriwini; type B.M. I7 초 7 우 Trobriand Is. 4 oै, 4 우 Woodlark Is.

(m) Small, ơ F $24 \mathrm{~mm}$. Above as acerba. Below as micale. + as amytis.

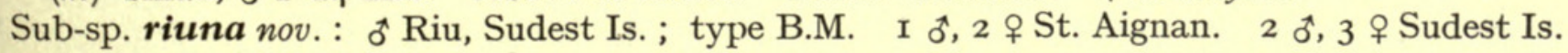
I $\delta$, 9 우 Rossell Is.

(n) ô F $26 \mathrm{~mm}$., like acerba, uph shining light blue, turning conspicuously dark blue on outer half upf: border broader, $\mathrm{I} \frac{1}{2} \mathrm{~mm}$. at apex to $\mathrm{I} \mathrm{mm}$. at dorsum $\mathrm{F}$ and $\frac{1}{2} \mathrm{~mm}$. on H. \& paler blue with dark veins, broad dark border. Below, typically variegated like ribbei, but grading to the uniform dark form of typical micale. 


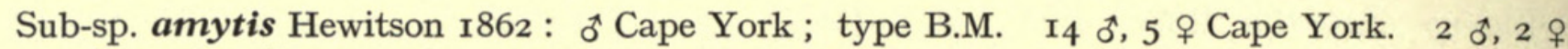
Thursday Is.

Synonym cyronthe Miskin I89o: ơ Cape York.

(o) As amytis, but border $4 \mathrm{~mm}$. at apex in 0 .

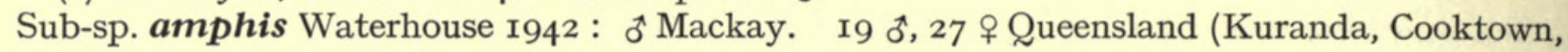
Mackay, Cedar Bay).

( $p$ ) Small, ot F $25 \mathrm{~mm}$. Above like micale: below mostly purple-brown, but the ribbei-like form occurs.

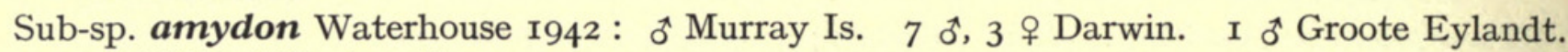
I ơ "Port Denison".

13 (I2). Unh discal band quite regular: plain dark brown, markings faint, not variegated. End of clasp of genitalia expanded on the ventral side. Above and below very like micale.

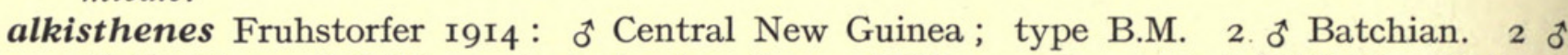

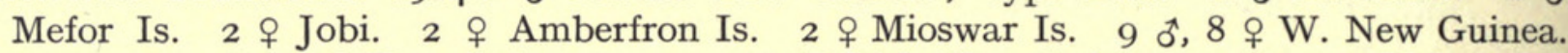

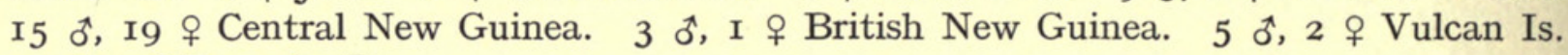
II 0 , 4 o Dampier Is.

14a (I2b). Below not normal.

I4 (I5). Unh no markings internal to the pale postdiscal band. of F $25 \mathrm{~mm}$., shining light blue, turning to dark blue at apex and costa $\mathrm{F}$, border $\frac{1}{2} \mathrm{~mm}$. क o shining light blue, border broad. Unf cell spots may be absent, dark discal band in the middle of a broad pale apical area.

aexone. Two sub-species. Fig. Seitz. $147 g$.

(a) Unf discal band wider, $2 \frac{1}{2} \mathrm{~mm}$.: unh pale postdiscal band $\mathrm{I} \frac{1}{2} \mathrm{~mm}$.

Sub-sp. chrysoana Fruhstorfer I9I4: ot Halmaheira. 2 ơ Halmaheira.

(b) Unf discal band $\mathrm{I} \frac{1}{2} \mathrm{~mm}$. Unh pale postdiscal band $2 \frac{1}{2} \mathrm{~mm}$.

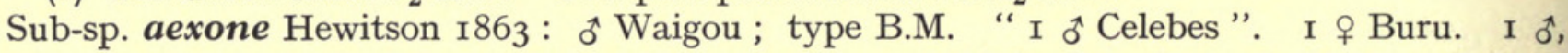

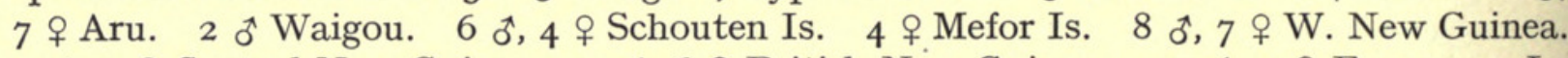

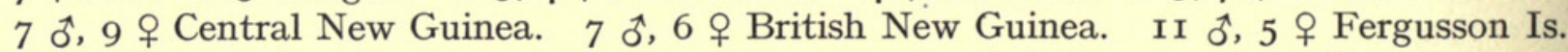

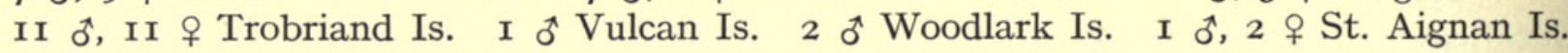
I $\sigma^{t}$ New Ireland.

Synonyms hevana Fruhstorfer I9I4: ô Fergusson Is. ; type B.M. natanda Fruhstorfer I9I4: ơ Fergusson Is. ; type B.M.

15 (I4). Unh with central and basal broken white dots and dashes: no discal band. Otherwise as aexone. Fig. Seitz I $50 \mathrm{~B} b$.

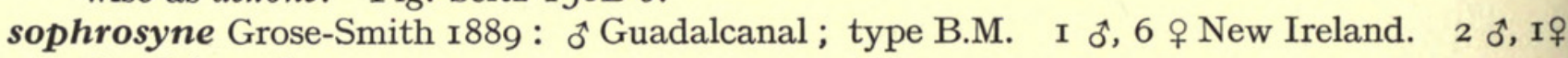
Guadalcanal.

\section{Vihara Group of Narathura}

1a (3a). $\mathrm{H}$ cell $<$ half wing: long tail.

\section{Vihara Sub-group}

I (2). Unf discal band more or less broken at vein 4 .

vihara. Three sub-species. Fig. Corbet 55 and $75 \mathrm{~g}$.

(a) 우 blue instead of purple.

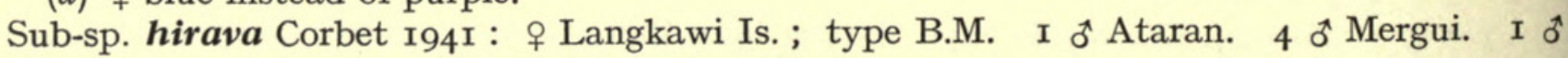
Victoria Point. I $\hat{\delta}, 2$ i Langkawi Is.

(b) ơ F $24 \mathrm{~mm}$., dark violet-blue, border I mm. : q purple-blue, border $4 \mathrm{~mm}$. Below, ochreous-brown, markings more macular than usual : with tornal metallic scaling. 


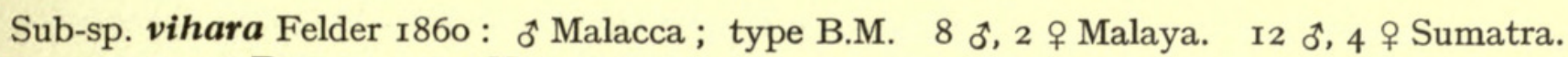
I3 ot $^{*} 4$ ㅇ Borneo. I ơ Natuna Is.

(c) of $\mathrm{F} 20 \mathrm{~mm}$., border F $\mathrm{I}_{2}^{\frac{1}{2}} \mathrm{~mm}$. Below, deeper purple-brown.

Sub-sp. pagia Corbet I94I : đ N. Pagi Is. ; type B.M. Unique.

2 (I). Unf discal band unbroken.

barami. Three sub-species. Fig. Corbet 56 and $69 \mathrm{~g}$.

(a) of F $22 \mathrm{~mm}$., bright shining blue, border very broad $7 \frac{1}{2} \mathrm{~mm}$. at apex and above cell mostly black. Below markings narrower and unf discal band centrally angled. Sexes alike.

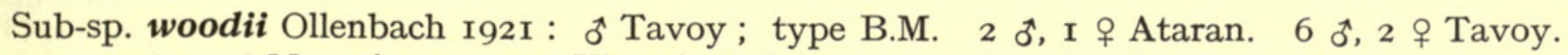

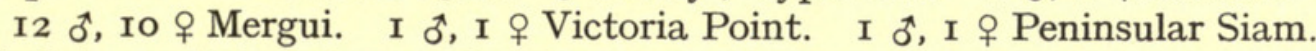

(b) Intermediate between the Burmese and Bornean forms. $q$ purple.

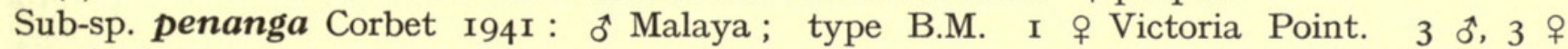
Malaya.

(c) of F $24 \mathrm{~mm}$., purple-blue, border $5 \mathrm{~mm}$. at apex to $3 \mathrm{~mm}$. at tornus and on $\mathrm{H}$ : 우 lighter, border rather broader. Below, ochreous-brown, markings rather darker than the ground.

Sub-sp. barami Bethune-Baker I903: ô Borneo; type B.M. I3 s, 3 o Borneo. I $q$ "Java".

3a (га). $\mathrm{H}$ cell $=$ half wing.

3b (8a). Unf discal band irregular, slightly broken at vein 4 . $\sigma^{t}$ upf dark border narrow.

3c (7). Tailed.

Agaba Sub-group

3d (6). Tail long, $2 \frac{1}{2} \mathrm{~mm}$.

3 (4a). Below, conspicuously whitened on all $\mathrm{H}$. $\sigma^{*} \mathrm{~F} 2 \mathrm{I} \mathrm{mm}$. ot dark purple-blue, border $\frac{1}{2} \mathrm{~mm}$. : + all brown. Fig. Ormiston 1921 (Butterflies of Ceylon).

ormistoni Riley I920: ô Ceylon ; type B.M. 2 ô, I $q$ Ceylon.

4a (3). Below, purple-brown.

4 (5). Below, variegated with whitish patches unf and unh. $\sigma^{\top} \mathrm{F} 20 \mathrm{~mm}$., shining violetblue, border I mm. : o lighter blue, border $4 \mathrm{~mm}$. Fig. Seitz I5Oc and Corbet 52 and $5^{8} \mathrm{~g}$.

agaba Hewitson I862: đo "India " (recte Cochin China); type B.M. I q “N. India ".

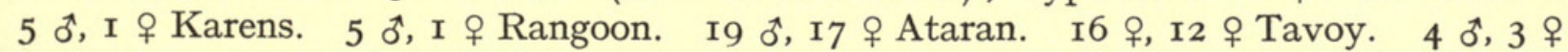
Mergui. I + Victoria Point. $7 \hat{\delta}, 2$ ㅇ Siam. $3 \hat{\delta}, 2$ \& Cochin China. I + Peninsular Siam. I ơ Langkawi Is. 2 o Sumatra.

5 (4). Below, uniform. ơ F I9 mm., shining violet-blue, border $\mathrm{I}_{2}^{\frac{1}{2} \mathrm{~mm} \text {. } ~}$ lighter, border 5 to $3 \mathrm{~mm}$. and a dark spot at end of cell. Clasp of genitalia bifid as in buddha. Fig. Corbet $68 \mathrm{~g}$.

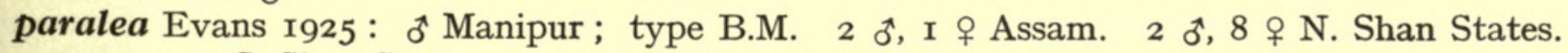
3 d, I 오 S. Shan States. I 0 Karens. I ㅇ Ataran.

6 (3d). Tail short, I mm.

buddha. Two sub-species. Fig. Corbet (as cooperi) 58 and $7 \mathrm{r}$ g.

(a) ơ $17 \mathrm{~mm}$., shining violet-blue, border I mm. ; o lighter, border $6 \mathrm{~mm}$. at apex to $2 \mathrm{~mm}$. at dorsum, and dark spot at end of cell. Below brown, markings narrow : tornal metallic scaling conspicuous.

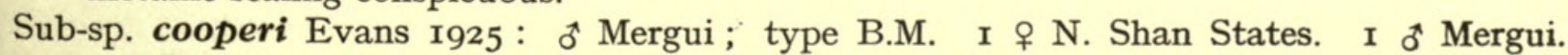

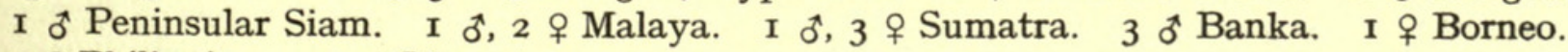

I $q$ Philippines. I $\delta$ Siberut. 
Synonyms gana Corbet I948: ơ Malaya ; type B.M.

siberuta Corbet I94I : ơ Siberut ; type B.M.

whiteheadi Corbet 1948: o Borneo ; type B.M.

(b) Smaller, ơ F I $8 \mathrm{~mm}$., below purple, tornal metallic scaling reduced.

Sub-sp. buddha Bethune-Baker r903: 아 Java; type B.M. I + Java.

Synonym aleta Piepens r9r8: 우 Java.

7 (3c). Not tailed.

arvina. Four sub-species. Fig. Corbet 64 and $93 \mathrm{~g}$.

(a) Like aboe, but 9 purple-blue with very broad borders, $5 \mathrm{~mm}$. on $\mathrm{F}$ and on $\mathrm{H}$, blue only in cell. Unf discal band more evenly curved.

Sub-sp. ardea Evans 1932: 우 Assam; type B.M. I ơ, 9 우 Assam. I ot Hainan.

(b) of F I7 to $23 \mathrm{~mm}$., of as arvina, + rather pale blue, width of border very variable, from 3 to $6 \mathrm{~mm}$. at apex. Below purple glazed.

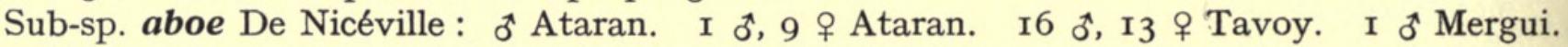
I ㅇ Victoria Point. 3 우 Peninsular Siam.

Synonyms adala De Nicéville r895: ơ Ataran. adulans De Nicéville 1895: † Ataran. Both varieties.

(c) Below, plain brown, no purple gloss, with tornal metallic scaling $\mathrm{H}$. ot as arvina; 우 purple, border $6 \mathrm{~mm}$. at apex to $\mathrm{I} \frac{1}{2} \mathrm{~mm}$. at tornus.

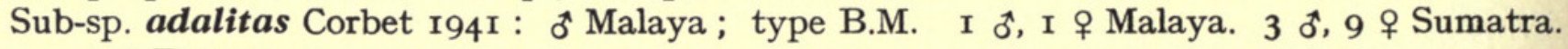
I 오 Borneo.

(d) ot shining dark blue, border a thread : o shining pale blue, border $4 \mathrm{~mm}$. on $\mathrm{F}, 5 \mathrm{~mm}$. on $\mathrm{H}$. Below, glazed purple-brown : no tornal metallic scaling on $\mathrm{H}$.

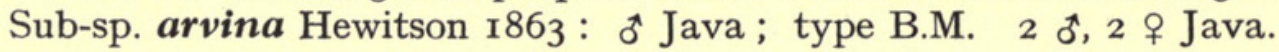

8a (3b). Unh discal band regular, no break at vein 4 . $\widehat{\sigma}$ Upf border broad, except in labuana.

\section{Agelastus Sub-group}

$8 \mathrm{~b}$ (roa). With long $\left(2 \frac{1}{2} \mathrm{~mm}\right.$.) tail, white tipped.

8 (9). Below uniform, not variegated. ot F $22 \mathrm{~mm}$. Sexes alike. Light blue, border $6 \mathrm{~mm}$. to $3 \mathrm{~mm}$. at dorsum, $6 \mathrm{~mm}$. on $\mathrm{H}$. Below rather pale brown, with tornal metallic scaling.

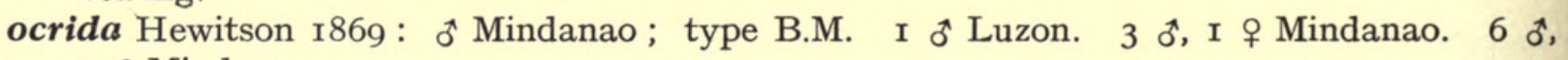
I 우 Mindoro.

9 (8). Below, variegated with whitish patches at apex $\mathrm{F}$ and on $\mathrm{H}$, as in alaconia. Above, generally as ocrida.

alesia. Three sub-species. Fig. Corbet 54 and $67 \mathrm{~g}$.

(a) Above, paler, softer blue than alesia, veins not darkened, border narrower : below, much paler and less variegated. Unf markings at apex obsolete.

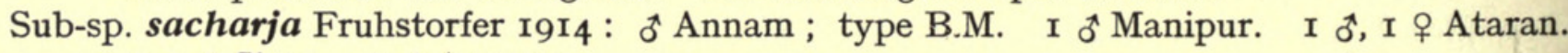
I 0 , I + Siam. I ơ Annam.

(b) o F $22 \mathrm{~mm}$. rather larger than alesia: below, darker, particularly above tornus $\mathrm{H}$ : unf markings at apex obsolete.

Sub-sp. wimberleyi De Nicéville 1887: q Andamans. I đa, 2 우 Andamans.

(c) of $\mathrm{F} 20 \mathrm{~mm}$., pale shining blue, border $8 \mathrm{~mm}$. at apex to $6 \mathrm{~mm}$. at tornus. Unf markings at apex conspicuous.

Sub-sp. alesia Felder 1865: \& Luzon. 7 §, 6 \% Mindanao.

10a (6b). Tail a tooth, not white-tipped.

Io (Ira). Unh variegated, exactly as in alesia. Sexes alike. 
alaconia. Four sub-species. Fig. Corbet 66 and $84 \mathrm{~g}$.

(a) of $\mathrm{F}$ I $8 \mathrm{~mm}$., pale shining blue, border $6 \mathrm{~mm}$. to $3 \mathrm{~mm}$. at dorsum.

Sub-sp. aloana Corbet I94I : + Tavoy; type B.M. 3 oै, 2 \& Karens. 5 of, 2 \& Ataran. I of, 5 o Tavoy.

(b) Bright blue, not shining, border as in aloana.

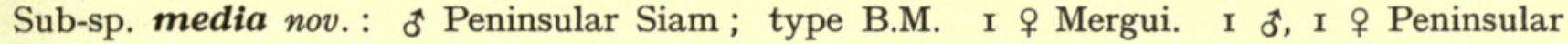
Siam. I ㅇ Malaya.

(c) Above, dark purple with broad dark borders. Below, duller.

Sub-sp. alaconia Hewitson I869: ơ Borneo; type B.M. 9 đ*, 3 \& Borneo.

(d) Above, pale shining blue, border $7 \mathrm{~mm}$. at apex, reaching to end of cell, $4 \mathrm{~mm}$. at tornus and on $\mathrm{H}$.

Sub-sp. oberthüri Staudinger I889: Palawan. 3 ơ, 5 ㅇ Palawan.

11a (го). Unh not variegated.

II (I 2a). $\mathrm{H}$ tornus rounded, dorsum $=$ costa, as in $\mathrm{K}$ (Perimuta) Group, but termen $\mathrm{H}$ is toothed. $\delta \mathrm{F} I 6 \mathrm{~mm}$. bright shining blue, border $4 \mathrm{~mm}$. at apex to $\mathrm{I} \frac{1}{2}$ at dorsum $\mathrm{F}$ and mid $\mathrm{H}$. $\%$ rather paler and borders rather wider. Below as agelastus, tornal metallic scaling conspicuous. Fig. Corbet 68 and $86 \mathrm{~g}$.

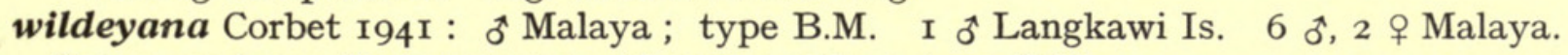
Synonym havea Corbet I94I : ơ Langkawi Is. ; type B.M.

12a (II). $\mathrm{H}$ tornus angled, dorsum $>$ costa. $\delta^{\star} \mathrm{F}>\mathrm{I} 7 \mathrm{~mm}$.

I2 (13a). Below, markings conspicuously pale edged, of upf border narrow, ot $\mathrm{F}$ 2I mm. $\mathrm{mm}$. very dark purple-blue, border $2 \mathrm{~mm}$. at apex to $\mathrm{I} \mathrm{mm}$. at dorsum and on $\mathrm{H}$. o lighter, borders broad and a dark spot at end of cell F. Unh with conspicuous tornal metallic scaling. Fig. Corbet 72 and $90 \mathrm{~g}$.

labuana Bethune-Baker I896: ơ Labuan. 3 ot, I $q$ S. Burma, Ataran to Victoria Point. I ot Sumatra. I o N. Pagi Is. 7 ơ Borneo.

Synonym etuna Corbet I94I : 오 N. Pagi Is. ; type B.M.

13a (12). Below, markings inconspicuously pale edged. ot upf with broad dark border.

I3b (I7a). F termen evenly convex throughout.

I3c (I6). Unh discal band broken at vein 4 as usual.

I3d (I5). $\mathrm{H}$ tooth at end of vein 2 inconspicuous. Unh no metallic scaling.

I3 (I4). Below, pinkish-grey. ơ F $18 \mathrm{~mm}$., violet-blue, border F $5 \mathrm{~mm}$. at apex to $2 \mathrm{~mm}$. at tornus and on H. Fig. Lep. Ind. : Corbet 9I g. Genitalia distinct from its allies.

aeeta De Nicéville I893: ot Ataran. I ot Manipur. I ot N. Chin Hills. 6 oै, 4 ㅇ Ataran. I ơ S. Annam.

14 (13). Below, grey-brown, otherwise as aeeta. Fig. Lep. Ind. and Corbet 87 g. $\quad$ o much lighter blue.

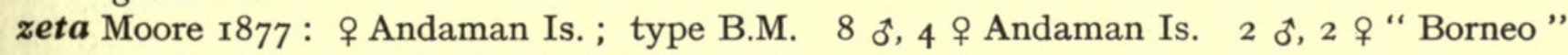
ex coll. Adams, probably from Andaman Is.

Synonym roona Moore $\mathrm{I} 88_{4}$; ơ Andaman Is.

15 (I3d). $\mathrm{H}$ tooth at end of vein 2 conspicuous $\frac{1}{2}$ to $\mathrm{I}_{\frac{1}{2}} \mathrm{~mm}$., but not white-tipped. Unh with metallic scaling.

arsenius. Two sub-species.

(a) ot F $20 \mathrm{~mm}$., dark purple-blue, o lighter and with dark spot at end of cell, border $5 \mathrm{~mm}$. at apex to $2 \mathrm{~mm}$. elsewhere. Tail short $\frac{1}{2} \mathrm{~mm}$.

Sub-sp. arsenius Felder 1867 : o Luzon : figured. 2 के, 1 \& Luzon.

(b) Tail $\mathrm{I} \frac{1}{2} \mathrm{~mm}$. Unh metallic scaling more profuse.

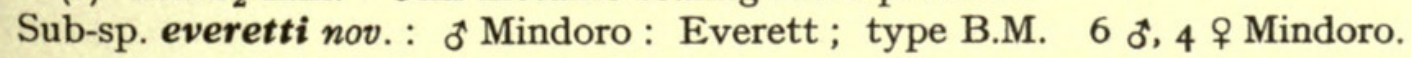


16 (г3c). Unh discal band not broken at vein 4: with or without metallic scaling. agelastus. Two sub-species. Fig. Corbet 70 and $89 \mathrm{~g}$.

(a) of F $2 \mathrm{I} \mathrm{mm}$., purple-blue, border $6 \mathrm{~mm}$. at apex to $\mathrm{I} \frac{1}{2} \mathrm{~mm}$. at dorsum and $\mathrm{I} \mathrm{mm}$. on $\mathrm{H}$ : o bluer. Very variable in respect of width of border and presence or absence of metallic scaling unh. Below ochreous-brown.

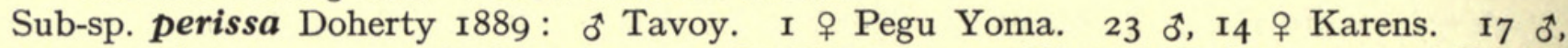

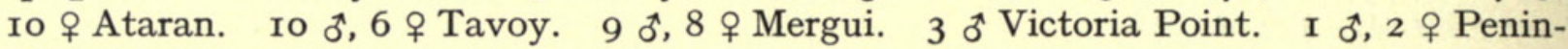
sular Siam.

(b) Below, dull plain brown, markings fainter, metallic scaling conspicuous.

Sub-sp. agelastus Hewitson I862: ơ "India "; type B.M. 3 б, 2 + Malaya.

17a $(13 \mathrm{~b})$. F termen concave before a pointed apex. Unh no metallic scaling. A link to J. (Rama) Group.

I7 (I8). F termen straight. of $\mathrm{F} 22 \mathrm{~mm}$., purple, border $6 \mathrm{~mm}$. at apex to $4 \mathrm{~mm}$. at dorsum and on $\mathrm{H}$ : i blue with broader borders. Below brown with a faint purple wash.

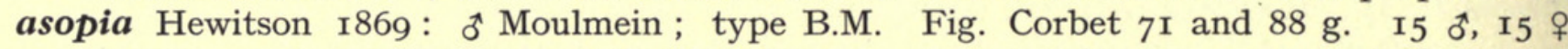

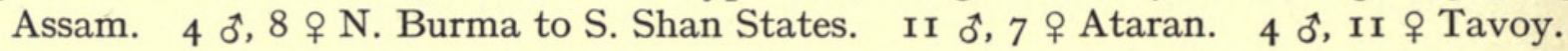

18 (I 7$)$. F termen convex.

asinarus. Two sub-species. Fig. Seitz $1_{50} g$ as tounguva.

(a) $\sigma^{*}$ F 2 I mm., rather dark shining blue, border $7 \mathrm{~mm}$. at apex to $3 \mathrm{~mm}$. at dorsum and $2 \mathrm{~mm}$. on $\mathrm{H}$. Below, darker and may have a faint purple gloss. + blue, border as $\delta^{\star}$. Sub-sp. tounguva Grose-Smith 1887 : $q$ Toungoo ; type B.M. 2 ㅇ Karens. 3 우 Bassein.

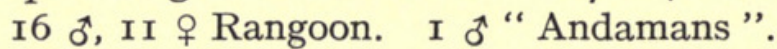

(b) ot F I9 mm., borders narrower: below, paler.

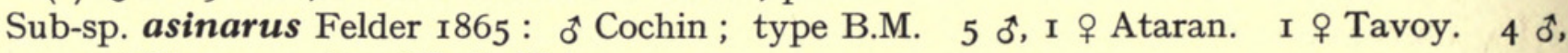

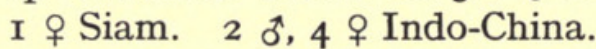

Synonym enoma Corbet I946 : 오. Annam ; type B.M.

1a (3a). H not tailed.

\section{J. Rama Group of Narathura}

I (2). Unh discal spots in spaces 4, 5 mid termen and end-cell spot.

paramuta. Two sub-species. Fig. Corbet 76 and $97 \mathrm{~g}$.

(a) ỡ F I7 mm., purple-blue, border $2 \frac{1}{2} \mathrm{~mm}$. : 우 paler, border broader. Below, pale brown, markings faint.

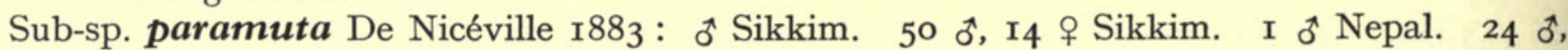
I6 우 Assam. I 아 N. Burma. $200^{\star}, 6$ 우 N. Shan States. I d, I 오 S. Shan States. 3 d, 6 ㅇ Karens. I ơ Siam. I o Szechwan. I ơ Canton.

Synonym newara Moore 1884 : $\delta$ Nepal ; type B.M.

(b) Larger, ot F I $8 \mathrm{~mm}$., upf borders $4 \mathrm{~mm}$. Below, rather darker.

Sub-sp. horishana Matsumura I9ıо: Formosa. 8 ot, 6 우 Formosa.

2 (I). Unh discal spots in spaces 4, 5 much nearer to end-cell spot than to termen. $\delta^{t} \mathrm{~F}$ I6 to $19 \mathrm{~mm}$., dark border $3 \mathrm{~mm}$. Below markings vary from sharply defined as in dodonaea to dull as in rama. Fig. Seitz, vol. I.

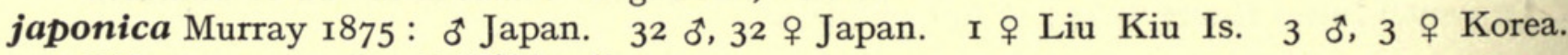
2 우 Formosa. I ơ, I 우 "China ".

Synonym kotoshona Sonan 1947 : Formosa.

3a (ra). $\mathrm{H}$ tailed.

$3 \mathrm{~b}(5 \mathrm{a})$. H not conspicuously lobed at tornus.

3 (4). Below, purple-brown.

rama. Two sub-species. Fig. Corbet $94 \mathrm{~g}$ : Seitz $\mathrm{I}_{5} \mathrm{OB} d$. o $\mathrm{F} 2 \mathrm{I} \mathrm{mm}$., shining dark purple-blue, border $\mathrm{I}_{2}^{\frac{1}{2}}$ to $3 \mathrm{~mm}$. : $q$ bluer and borders broader. Below, rather pale brown with a glossy sheen, markings faint. 


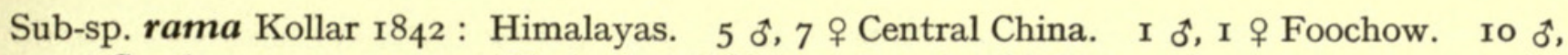
I o Szechwan. 24 ot, 20 아 Kashmir to Nepal. 8 oే, 8 우 Sikkim.

Synonyms querceti Moore 1857 : N. India ; type B.M. violacea Röber 1886 : E. Indies.

(b) $\delta$ a above, bluer and more shining, border narrower $\frac{1}{2}$ to $2 \mathrm{~mm}$. Below, darker, more conspicuously purple washed.

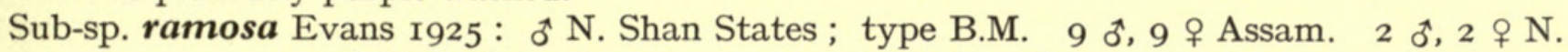

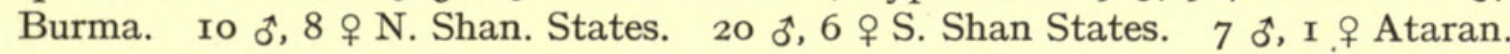

4 (3). Below, grey. of F $20 \mathrm{~mm}$. Sexes alike. Above, blue with broad border, $6 \mathrm{~mm}$. at apex, 5 at dorsum F, $4 \mathrm{~mm}$. on H. Termen F very crenulate. Fig. Seitz $150 f$ and Corbet $95 \mathrm{~g}$.

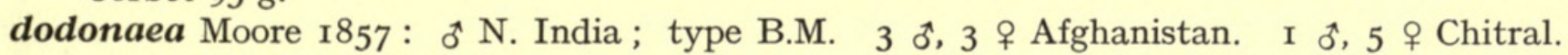
43 ઠే, 55 ㅇ Kashmir to Kumaon. 2 ㅇ Sikkim.

5a (3b). H conspicuously lobed at tornus : dorsum concave.

5 (6). Unf discal band unbroken. F termen conspicuously concave. क F I6 mm. Above purple-blue, border $4 \mathrm{~mm}$. mid-termen $\mathrm{F}, 3 \mathrm{~mm}$. on $\mathrm{H}$. Unf brown, paler and purple washed at apex, markings faint: discal band continued into space $\mathrm{I}$ b : costal spot in space Io. Unh reddish-brown, with a purple wash : markings broad and black : discal spot in space 6 separated from the spot in space 5 and overlaps the end-cell spot.

curiosa nov. : + Dokyong La, Bhutan ro,ooo ft. : 25th March, 1927 : F. M. Bailey. Unique.

6 (5). Unf discal band very broken and irregular. F termen straight. Sexes alike. o F I $8 \mathrm{~mm}$. : blue with very broad borders : below, reddish-brown, with faint purple gloss and dark markings. Fig. Lep. Ind. : Corbet $96 \mathrm{~g}$.

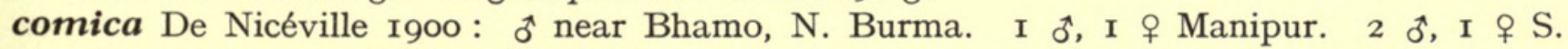
Shan States. I i Siam (Tukdah).

Synonym learmondii Tytler 1940: $₫$ S. Shan States : type B.M.

\section{$K$. Perimuta Group of Narathura}

1a (3a). Unf discal band broad, $2 \mathrm{~mm}$.

I (2). Unh with central yellow area.

perimuta. Two sub-species. Fig. Corbet 75 and $66 \mathrm{~g}$.

(a) F I7 mm., dark shining blue, border $\mathrm{I}_{2} \frac{1}{2} \mathrm{~mm}$. : i bright blue, border $5 \mathrm{~mm}$.

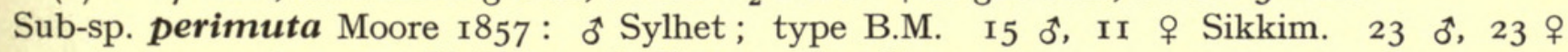
Assam. 36 ơ, 24 ㅇ N. Burma to Tavoy. 2 ơ Siam.

(b) ô bright shining metallic blue : क border $3 \mathrm{~mm}$.

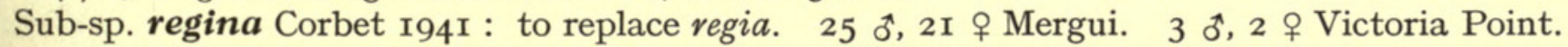
5 ơ, 4 우 Peninsular Siam. I ㅇ Malaya.

Synonyms regia Evans I925: ơ Mergui ; type B.M. Homonym.

linta Corbet I94I : o Malaya ; type B.M.

2 (I). Unh no central yellow area. Sexes alike.

epimete. Three sub-species. Fig. Corbet 65 and $92 \mathrm{~g}$.

(a) o F I7 mm., bright shining blue, border $6 \mathrm{~mm}$. at apex to $2 \mathrm{~mm}$. at dorsum : on $\mathrm{H}$, only blue in cell. Below, pale purple-brown, variegated with white at apex $\mathrm{F}$ and $\mathrm{H}$.

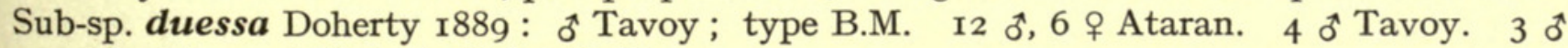
Mergui. I o Victoria Point, S. Burma.

(b) Below, darker uniform brown, with a purple wash.

Sub-sp. suedas Corbet I94I : ơ Malaya ; type B.M. I ơ Malaya.

(c) ơ F $18 \mathrm{~mm}$., purple, border $5 \mathrm{~mm}$. at apex to $3 \mathrm{~mm}$. at dorsum. Below, light brown with faint purple wash.

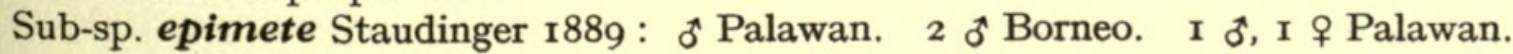


3a (ra). Unf discal band narrow, I $\mathrm{mm}$.

3b (6a). Unh no tornal metallic scaling.

3 (4a). Below, markings conspicuous. of $\mathrm{F} \mathrm{I} 7 \mathrm{~mm}$. shining blue, border $5 \mathrm{~mm}$. at apex to $2 \mathrm{~mm}$. at dorsum and on $\mathrm{H}$. Below, markings small. Fig. Corbet 67 and $85 \mathrm{~g}$.

cardoni Corbet I94I : ot Malaya ; type B.M. Unique.

4a (3). Below, markings faint.

4 (5). Unh discal band completely broken at vein 2 . o $\mathrm{F} 23 \mathrm{~mm}$., dark violet-blue, no border.

inornata. Two sub-species. Fig. Corbet 73 and $63 \mathrm{~g}, 64 \mathrm{~g}$.

(a) \& paler purple-blue, border $3 \mathrm{~mm}$. at apex to $\frac{1}{2} \mathrm{~mm}$. at dorsum and on $\mathrm{H}$. Unf discal band narrow, sinuous.

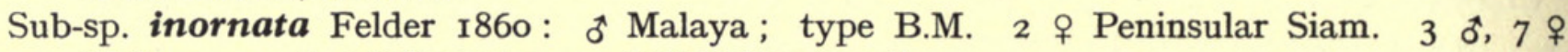
Malaya. $4 \delta^{\star}, 5$ 오 Sumatra. I 9 "Philippines ".

Synonym brahma Bethune-Baker I897: đo Perak; type B.M. A small specimen, ơ F I9 $\mathrm{mm}$.

(b) $q$ purple, border $8 \mathrm{~mm}$. at apex to 5 at dorsum : on $\mathrm{H}_{5} \mathrm{~mm}$. and the veins darkened. Sub-sp. empesta Corbet I94I : ơ Borneo ; type B.M. 3 đ, 2 우 Borneo.

5 (4). Unh discal band overlapping at vein 2 . क F I6 mm. very dark violet-blue, border $3 \mathrm{~mm}$. at apex to $2 \mathrm{~mm}$. mid-termen and $4 \mathrm{~mm}$. at dorsum. $q$ dark purple-blue to just beyond end cell $\mathrm{F}$ and only in cell $\mathrm{H}$. Fig. Seitz $\mathrm{I} 48 f$.

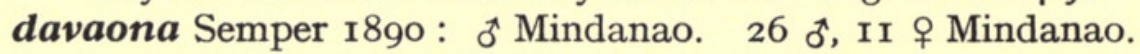

6a (3b). Unh with tornal metallic scaling. Below, spots faint.

6 (7). Unh discal band completely broken at vein 2 .

antimuta. Three sub-species. Fig. Corbet 74 and $65 \mathrm{~g}$.

(a) o bluer.

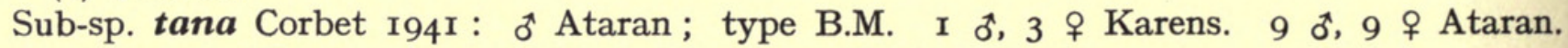

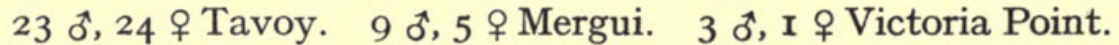

(b) ơ F I6 mm., dark violet-blue, border $\frac{1}{2} \mathrm{~mm}$. : क purple-blue, border $5 \mathrm{~mm}$. at apex to $3 \mathrm{~mm}$. at dorsum, $2 \mathrm{~mm}$. on $\mathrm{H}$ where the veins are black.

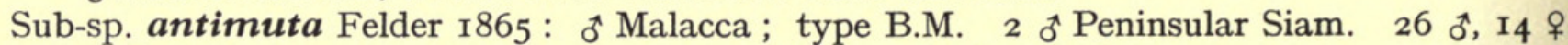

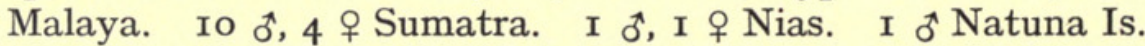

Synonym davisonii De Nicéville r89o: ơ Singapore.

(c) o more purple than blue.

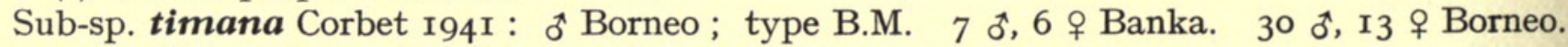
4 o "Java" (not in Rhop. Java).

7 (6). Unh discal band overlapping at vein 2.

avatha. Two sub-species. Fig. Corbet 26 and $28 \mathrm{~g}$.

(a) of F $16 \mathrm{~mm}$., dark violet blue, border $\mathrm{I} \frac{1}{2} \mathrm{~mm}$. : o shining purple, border as in antimuta, but broader on $\mathrm{H}$.

Sub-sp. avatha De Nicéville I896: đo Sumatra. 6 o Malaya. 4 đo I 9 Sumatra.

(b) ơ F I4 mm. Below, markings not faint, small and macular : unf discal band slightly broken at vein 4: unh cilia white-tipped at end of vein 2.

Sub-sp. lana nov. : ot Mindanao: A. E. Wileman; type B.M. Unique.

\section{Fulla Group of Narathura}

1a (3a). Unh markings complete.

I (2). Unh discal band completely broken at vein 6 .

acron. Two sub-species. Fig. Seitz $\mathbf{1}_{50} \mathrm{~g}$. 
(a) o $\mathrm{F}_{2} 3 \mathrm{~mm}$., brilliant shining blue, turning darker at apex $\mathrm{F}$, border $\frac{1}{2} \mathrm{~mm}$. $q$ similar, but apex broadly black, $9 \mathrm{~mm}$. to 6 at dorsum : $\mathrm{H}$ only blue in cell. Below, brown with conspicuously white-edged markings.

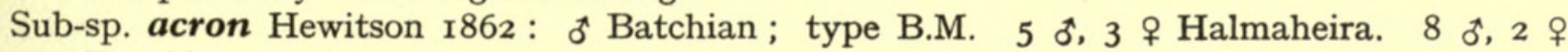
Batchian.

(b) ot similar. क shining light blue, border $7 \mathrm{~mm}$. at apex to $\mathrm{I} \mathrm{mm}$. at dorsum and on $\mathrm{H}$. Below, white with pale brown markings. Fig. Seitz $149 \mathrm{~g}$.

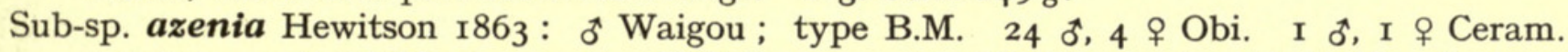
I $\delta^{\star}$ Aru. $2 \delta^{\star}, \mathrm{I}$ ㅇ Misol. $10 \delta^{\star}, \mathrm{I}$ ㅇ Waigou. I $\delta^{\star}, \mathrm{I}$ ㅇ Jobi. $20 \delta^{\star}, \mathrm{I} 2$ 우 W. New Guinea. $8 \delta, 2$ ㅇ Central New Guinea. $\quad$ I6 $\delta, 16$ ㅇ British New Guinea.

2 (I). Unh discal band not completely broken at vein 6.

admete. Three sub-species. Fig. Seitz I49c.

(a) ot $\mathrm{F} 20$ to $24 \mathrm{~mm}$., dark blue, border $2 \mathrm{~mm}$. at apex to I mm. elsewhere. o purple-blue with broad borders. Unh dark brown, discal band outwardly more or less white-edged.

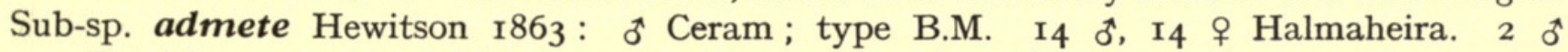
Batchian. I I $\delta^{\star}, 6$ o Obi. $70^{\star}, 4$ \& Ceram. 4 ot Amboina.

(b) o blue or purple. Unh purple-brown, typically with a broad white band exterior to the discal band, but, particularly in $\$$, this band may be reduced or absent : no trace of metallic scaling.

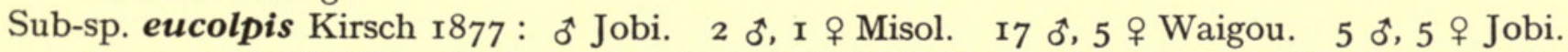

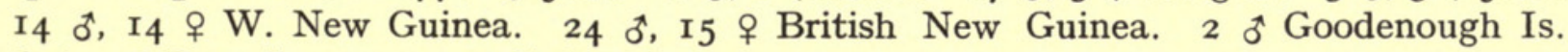

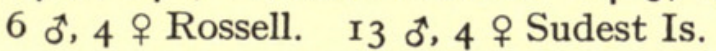

Synonym waigeoensis Bethune-Baker I903: o Waigou; type B.M.

(c) Louisade specimens generally are referable to eucolpis, but there is also a sub-specifically different form. ot $18 \mathrm{~mm}$., much brighter, shining blue. $q$ very pale shining blue, border as in eucolpis. Below, much paler grey, no purple wash.

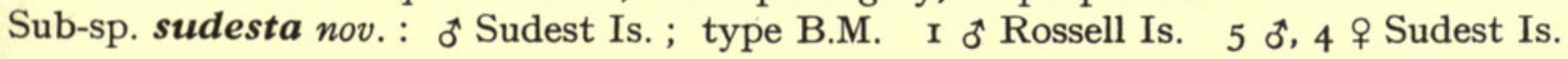

3a (ra). Unh markings incomplete.

3 (4). Below, white. of $\mathrm{F} 20 \mathrm{~mm}$., rather pale blue, border I mm. o white, blue suffusion at darkened bases, border $\mathrm{F} 5 \mathrm{~mm}$. Below, well marked post-discal band, interior to which small dark markings of the usual type may be more or less present or entirely absent.

disparilis Felder I860: $\sigma^{\star}$ Amboina ; type B.M. ; figured in Reise Novara. 3 ऽ, r 9 Amboina. Synonym courvoisieri Ribbe I901 : ơ Ceram.

4 (3). Below, not white : generally no markings interior to the discal band on either wing. fulla. Seven sub-species. Fig. Corbet 90 and II $3 \mathrm{~g}$.

(a) of F I9 mm., bright shining blue, border at apex $2 \mathrm{~mm}$., elsewhere $\frac{1}{2} \mathrm{~mm}$. 우 pale shining blue, border $7 \mathrm{~mm}$. at apex, $\mathrm{I} \frac{1}{2} \mathrm{~mm}$. at dorsum, I $\mathrm{mm}$. on $\mathrm{H}$. Below dull pale brown, markings narrow and faint.

Sub-sp. andamanica Wood-Mason \& De Nicéville I88I : đ Andaman Is. I9 đ, I9 우 Andaman Is.

Synonym subfasciata Moore r88I : đ Andaman Is. : type B.M.

(b) Below, more ochreous brown., o border F narrower.

Sub-sp. ignara Riley \& Godfrey I92I : o N. Siam; type B.M. 6 đ, I $\circ$ N. Shan States.

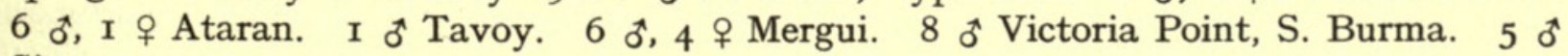
Siam.

(c) $\delta$ more purple-blue, border a thread : termen more rounded. $q$ purple with broader borders. Below, dull pale brown, discal band $\mathrm{H}$ much broader.

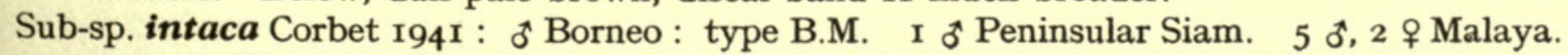
2 ơ, I 우 Borneo. 
(d) ot F I6 mm., dark shining blue, border I mm. : क purple, border $5 \mathrm{~mm}$. at apex to I mm. at dorsum. Below, like intaca, but unh with a subtornal black spot in space 2 crowned with metallic scales and a similar vestigial spot at the tornus.

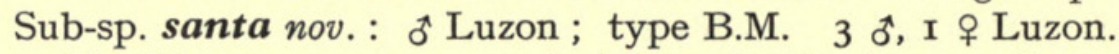

(e) ô F I9 to $23 \mathrm{~mm}$., very dark blue, border $\frac{1}{2} \mathrm{~mm}$. क purple with broad border $\mathrm{F}$. Below, grey-brown: unh with whitish postdiscal band and tornal black spots crowned white and with some metallic scaling.

Sub-sp. canulia Hewitson I869: đ* "Philippines ”, recte Halmaheira ; type B.M. I3 đే, 5 우 Halmaheira. I $\delta^{\star}$, I우 Ternate. 3 đ̃ Obi.

Synonym sosias Fruhstorfer I9I4: ơ Obi ; type B.M.

$(f)$ ot $\mathrm{I} 9 \mathrm{~mm}$., bright shining blue, border $\mathrm{I} \mathrm{mm}$. at apex, $\frac{1}{2} \mathrm{~mm}$. elsewhere. $q$ bluer, border $7 \mathrm{~mm}$. at apex, $2 \mathrm{~mm}$. at dorsum and $\mathrm{I} \mathrm{mm}$. on $\mathrm{H}$. Below, ochreous-brown, very like ignara, but with faint whitish postdiscal and submarginal bands on $\mathrm{H}$.

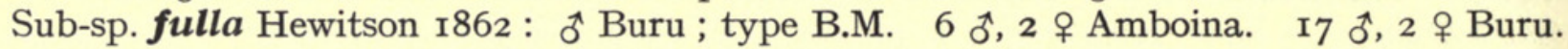

Synonym prasia Fruhstorfer I9I4: Amboina; type B.M.

(g) Above, as fulla, o bluer. Below, discal bands better marked and very broad on unh, $4 \mathrm{~mm}$. All unh and apical part of unf more or less reddened and purple glazed.

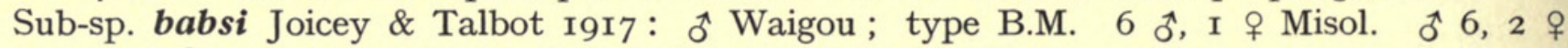

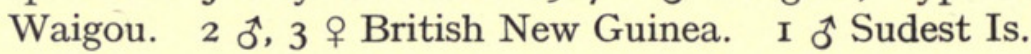

\section{Genus AUREA gen. nov.}

1a (4). Below, markings of the Narathura type : unf with 3 cell spots and a discal band.

I (2a). Below, plain brown, markings inconspicuous. of $\mathrm{F} 20 \mathrm{~mm}$., brilliant shining green, border a thread at apex increasing to $\frac{1}{2}$ to $\mathrm{I}_{2} \frac{1}{\mathrm{~mm}}$. at dorsum, $5 \mathrm{~mm}$. on $\mathrm{H}$. क o blue or purple with broad borders. Termen F convex in $\delta$. Fig. Corbet 60 and $73 \mathrm{~g}$.

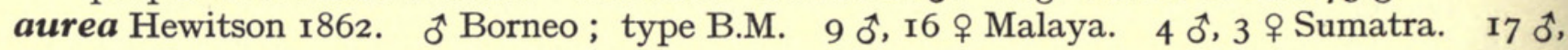
8 우 Borneo.

Synonyms borneensis Bethune-Baker 1896: ôt Borneo.

tembaga Moulton I9I I : ô Borneo ; type B.M.

2a (I). Below, purple glazed, markings conspicuous.

2 (3). ô above, as aurea, but border $\mathrm{F}$ a thread and on $\mathrm{H} 3 \mathrm{~mm}$., but the green colour reaches termen in space 6 : termen $\mathrm{F}$ straight. $\quad$ o above, purple-blue, like aurea.

trogon Distant I884: $\hat{\sigma}$ Malaya. Fig. Corbet $6 \mathrm{I}$ and 74 g. 7 ô, I2 9 Malaya. 3 ô, 4 우 Sumatra. I $\hat{0}$, I 우 Boneo.

Synonym rajah Moulton I9I I : o Sarawak ; type B.M.

3 (2). ot above, as aurea, but border $\mathrm{H}$ broader, $6 \mathrm{~mm}$. : no basal bluish reflection as is conspicuous in trogon and faint in aurea. Below, as trogon.

stinga nov. : ơ Johore; type B.M. 2 ơ Malaya.

4 (га). Below, markings abnormal : greyish-brown : unf dark brown bar at end of cell and a narrow, sinuous discal band: unh tornal half of wing darkened, the usual basal and central spots very small, end-cell spot continued to costa, discal band begins at vein 6 and is not broken at vein 2. $\widehat{\alpha} \mathrm{F}$ I9 mm., brilliant shining green, no dark border, but mid-termen to tornus on $\mathrm{H}$ the green colour changes to violet-blue for a width of $2 \frac{1}{2} \mathrm{~mm}$. o purple with broad dark borders. Fig. Corbet 9I and II $4 \mathrm{~g}$.

caeca Hewitson I863: ot Borneo; type B.M. 2 , I 9 Borneo. Hewitson's type is an aberrant and stained specimen. There is a $\delta$ from Malaya in coll. Stubbs and a $\delta$ from Sumatra in coll. Nieuwenhuis of Rotterdam. 


\section{N. Genus ARHOPALA Boisduval 1832}

1a (3a). Unf discal band macular and angled at vein 6.

I (2). Unh no white area mid dorsum.

thamyras. Five sub-species. Fig. Aurivillius 1882: Kong. Svenska Vet.-Ak. Handlingar 19/5 : I09, Pl. I, fig. 2.

(a) Below striped, markings concolorous with ground.

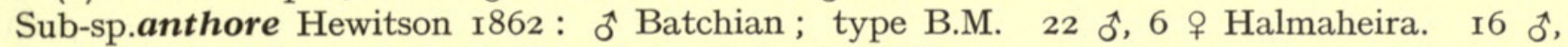
I6 우 Batchian. 2 ô, 2 우 Ternate. 16 ô, 16 \& Obi.

Synonym potidaea Fruhstorfer I9I3: ô Obi ; type B.M.

(b) Intermediate between anthore and phryxus : markings unh rather darker than ground, rather elongate tending to be striped. of $\mathrm{F} 23 \mathrm{~mm}$., brilliant shining light blue, turning violet about apex $\mathrm{F}$, border $\frac{3}{4} \mathrm{~mm}$. क paler blue, border $6 \mathrm{~mm}$. at apex, decreasing to $2 \mathrm{~mm}$. at dorsum and $\mathrm{I} \mathrm{mm}$. on $\mathrm{H}$ : much narrower than in anthore.

Sub-sp. thamyras Linnaeus 1758: ô Indies (recte Amboina). I9 0 , 12 o Amboina. 2 우

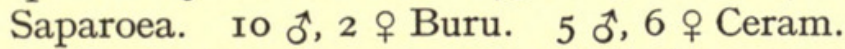

Synonyms helius Cramer I779: ô Surinam (recte Amboina).

esra Herbst I8oo. helus Godart I823: to replace helius.

carolina Holland I900: $\widehat{o}$ Buru ; paratype in B.M.

tamyrus Bethune-Baker I903: mis-spelling.

(c) Unh outwardly whitened: otherwise as phryxus.

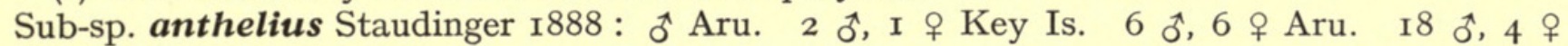
Misol.

Synonym calaureia Fruhstorfer I9I I : ô Misol ; type B.M.

(d) Unh markings fully macular and conspicuously darker than the ground: uniform. Very variable.

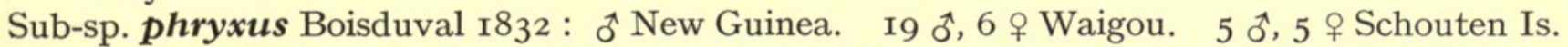

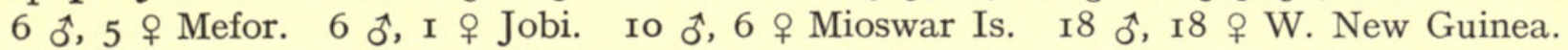

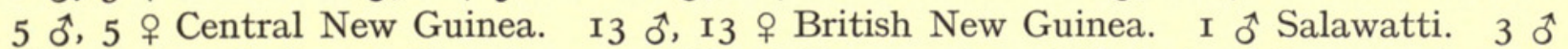

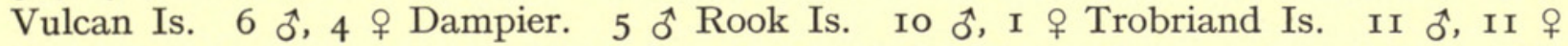

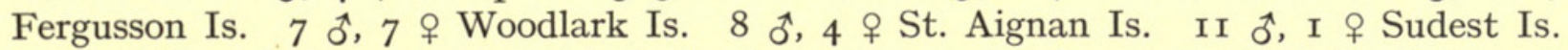

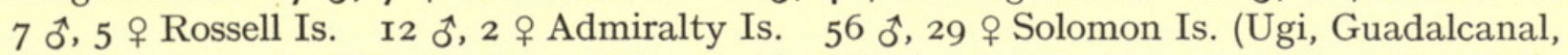
Tugela, Bougainville Rendova, Ulava, Alu, Choiseul, Florida, New Georgia, Vella Lavella, Ysabel, Kulanbangre, Guizo, Tulayi, Niasam).

Synonyms sophax Matthew I887: ô Ugi ; type B.M.

latimarginata Strand r912 : ơ Teba, New Guinea.

interniplaga Strand I9I2: ô Waigou.

teuthrone Fruhstorfer I9I3: $\widehat{\alpha}$ Eilanden R., New Guinea ; type B.M.

zelea Fruhstorfer I9I3: ô Fergusson Is. ; type B.M.

(e) Below, grey and markings much smaller.

Sub-sp. minnetta Butler I882: đิ Duke of York Is. ; type B.M. 9 ô, 5 ㅇ New Hannover.

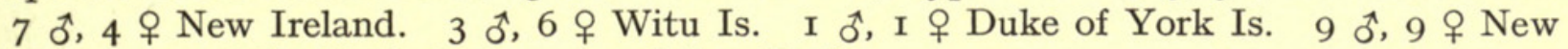
Britain. 5 오 St. Mathais. II $\hat{\delta}, 5$ 우 Squally Is.

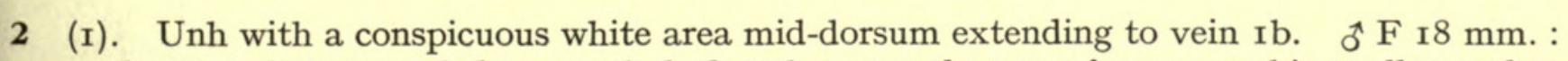
above as thamyras ; below, much darker than any thamyras form : markings all macular, scarcely darker than the ground, but conspicuously white-edged.

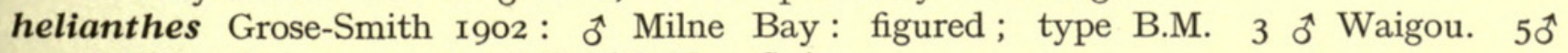
W. New Guinea. 5 $\widehat{0}$, I 우 British New Guinea.

3a (га). Unf discal band not macular, nor angled. Unh tornal area broadly darkened. + above, as thamyras.

$3 \mathrm{~b}(5)$. Unh discal and central markings macular. 
3 (4). Unh no white area mid-dorsum. of $\mathrm{F} 22 \mathrm{~mm}$., as thamyras, but apical half $\mathrm{F}$ much darker blue and borders broader, $3 \frac{1}{2} \mathrm{~mm}$. at apex to $\mathrm{I} \mathrm{mm}$. at dorsum and on $\mathrm{H}$. Unh like thamyras phryxus.

arta nov. : ơ Owgarra, Upper Aroa R., British New Guinea : A. S. Meek ; type B.M. I 우 Jobi Is. $2 \hat{\jmath}, 2$ 아. Wew Guinea. $3 \hat{\jmath}, 5$ 우 British New Guinea.

4 (3). Unh with white area mid-dorsum, as in helianthes. Appears to be a species intermediate between arta and axiothea. ô $\mathrm{F} 2 \mathrm{I} \mathrm{mm}$., above as arta. Unf central and end-cell spots connected by a dark band as in axiothea. Unh markings as in arta, but tornal area much darker.

axina nov. : $\widehat{t}$ Wangaar River, 15 miles from coast, W. New Guinea, $600 \mathrm{ft}$. : January I92I : C. \& J. Pratt; type B.M. I $\widehat{\delta}, \mathbf{I}$ 우 W. New Guinea. 5 ot British New Guinea.

5 (3b). Unh discal and central markings conjoined to continuous bands on a white ground. ô F $22 \mathrm{~mm}$., above like arta. Unf white, central and end-cell spots continued as bands to costa, where they are conjoined. Unh white area mid-dorsum is extended to the base. Fig. Seitz I46B $b$.

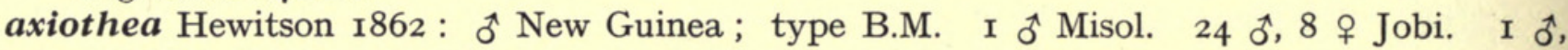
I ㅇ New Guinea.

Synonym strophe Grose-Smith 1877 : ㅇ Kapaur ; type B.M.

\section{O. Genus PANCHALA Moore 1882}

1 a (3a). Not tailed. Sexes alike.

I (2). Unf markings conspicuously darker than ground. $\mathrm{F}$ conspicuously falcate and $\mathrm{H}$ angled at apex.

ganesa. Five sub-species. Fig. Seitz $147 f$ and Corbet $98 \mathrm{~g}$.

(a) of F $15 \mathrm{~mm}$., blue with broad dark border F. Unh whitish, markings faint on a white ground. Upf white-flanked black spot about end of cell.

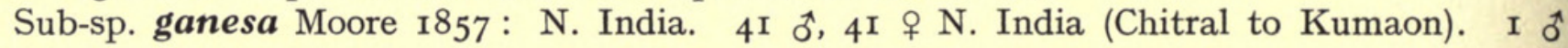
Sikkim.

(b) Below, bases rather pale purple-brown : markings $\mathrm{F}$ more prominent, not being overlaid whitish : $\mathrm{H}$ markings prominent.

Sub-sp. watsoni r9ı 2: ㅇ Chin Hills; type B.M. 4 st, 4 우 Assam. I 우 Chin Hills. I 우 S. Shan States.

(c) Upf black spot at end cell not white flanked, at least in $\delta$.

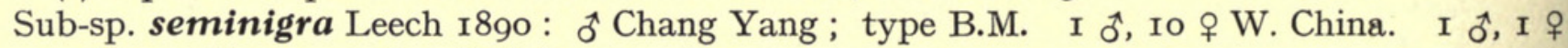
Chang Yang. $2 \hat{0}, 2$ o Hainan.

(d) Upf no black spot at end of cell ; blue colouring as extensive as in seminigra.

Sub-sp. formosana Kato I930: Formosa. None in B.M.

(e) Blue colouring much restricted, duskier : vestigial on $\mathrm{H}$.

Sub-sp. loomisi Pryer I886: ơ Kanozan. 8 ऽૈ, 5 우 Japan.

2 (I). Unf and unh marking faint on the grey ground. Wings rounded. F I5 mm. : powdery blue, border $5 \mathrm{~mm}$. at apex to $2 \mathrm{~mm}$. at dorsum : I $\mathrm{mm}$. on $\mathrm{H}$, where all space 6 is darkened and the veins are dark on both wings. Unf discal band broken at vein 4, not continued below vein 2, reaches vein ro and there are faint costal spots in spaces Io and II. Unh very like ganesa, but with two tiny submarginal black dots as in paraganesa: no metallic scaling.

weelii Piepers I9I 8: “ of" Java ; type Leiden Mus., the Director of which kindly sent me the type for examination. It was found to have the long, slender, tapered form of ovipositor characteristic of the Ganesa Group. None in B.M. 
3a (ra). Tailed.

$3 \mathrm{~b}(6 \mathrm{a})$. Below, markings darker than the ground.

3 (4a). Unf discal spots in spaces 2, 3, 4 in line and inwardly flanked by an equally broad whitish band as in ganesa.

paraganesa. Four sub-species. Fig. Seitz I $47 b$ (badly).

(a) ôt F I5 mm., sexes alike. Dry season form almost exactly like ganesa: wet season form has the blue colour restricted, particularly on $\mathrm{H}$, where it may be confined to the cell.

Sub-sp. paraganesa De Nicéville I882: Sikkim. 2 ô Kumaon. 3 우 Nepal. 31 ô, 8 우 Sikkim.

(b) The type pertains to the wet season form, where on upf the powdered blue colouring only extends to just beyond the end of the cell on $\mathrm{F}$ and is absent on $\mathrm{H}$. Dry season specimens are more like paraganesa. Sexes alike.

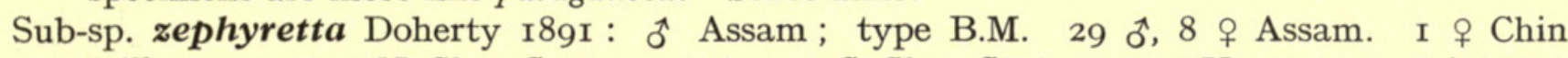

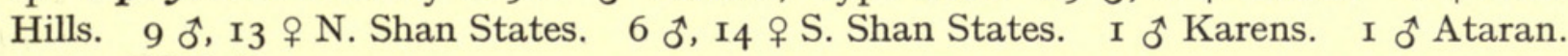
I $\hat{\sigma}$, I 우 W. Siam.

(c) ô above, bright blue colouring extensive, dark border $\mathrm{F} 4 \mathrm{~mm}$. at apex to $2 \mathrm{~mm}$. at dorsum, like ammonides. + as paraganesa.

Sub-sp. mendava Corbet I94I : ô Larut Hill, Perak; type B.M. and I Malaya.

(d) 우 F $15 \mathrm{~mm}$.: above as ammonides, unf as paraganesa, unh as ammonides, with a conspicuous large white spot mid-costa and apex broadly white.

Sub-sp. hammon Fruhstorfer I9I4: ㅇJ Java ; type B.M. Figured in Rhop. Java as ammon. 2 + Java.

4a (3). Unf spot in space 4 out of line. Sexes not alike.

4 (5). Unf spots in spaces 3 and 4 quite separate. ô $\mathrm{F} \mathrm{I} 8 \mathrm{~mm}$., rather pale blue, border a thread in dry season form, $2 \mathrm{~mm}$. at apex $\mathrm{F}$ to $\mathrm{I} \mathrm{mm}$. at dorsum in wet season form (ellisi). ㅇ like ganesa, above and below. Fig. Seitz I5oB $d$ : Corbet $99 \mathrm{~g}$.

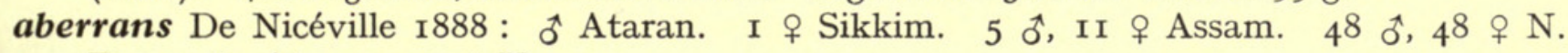
Burma to Ataran. I $\widehat{c}$ Yunnan.

Synonym ellisi: Evans I9I4: đô Maymyo ; type B.M.

5 (4). Unf spots in spaces 3 and 4 overlap.

birmana. Two sub-species. Fig. Corbet 77 and $100 \mathrm{~g}$.

(a) ô F I7 mm., rather dark blue, border $4 \mathrm{~mm}$. at apex to $2 \mathrm{~mm}$. at dorsum and $2 \frac{1}{2} \mathrm{~mm}$. on $\mathrm{H}$, narrower in dry season form. \& above as ganesa, seasonally variable. Below of the ganesa type: unh may be uniform or with a large white subcostal and apical area.

Sub-sp. birmana Moore I883: ㅇ Karens ; type B.M. 20 o, 27 아 Manipur. 42 ô, 27 우 N. Burma to Ataran. I ô, I ㅇ Hong-Kong. I ơ "Sumatra ".

Synonyms arisba De Nicéville r891 : ô Tilin Yaw, N. Burma. corthatha Fruhstorfer I9I4: ô Hong Kong.

dascia Swinhoe 1917 : ơ Karens ; type B.M.

maymoica Tytler I926: ô N. Shan States ; type B.M.

(b) Smaller, of F $15 \mathrm{~mm}$., border broader : 우 border much broader : no white-edged dark spot at end of cell.

Sub-sp. asakurae Matsumura I910: Formosa. 2 o 0,2 ㅇ Formosa.

Synonyms uchidae Matsumura 1926: ô Formosa.

oryuzana Corbet 194I : Formosa: placed as the Formosan form of paraganesa with Wileman as author (not traceable) ; type B.M.

6a (3b). Below, markings not darker than the ground. Unf spot in space 4 out of line.

6 (7a). Unh in space 7, central spot generally not nearer to the discal than to the basal spot: tornal metallic scaling absent, or rarely, vestigial. 
ammonides. Five sub-species. Fig. Corbet 79, 80 and $102 \mathrm{~g}$.

(a) ô F I5 mm., dark blue with broad borders, $4 \mathrm{~mm}$. ㅇ paler blue, border $6 \mathrm{~mm}$. and on $\mathrm{H}$ only vestigial blue scaling in cell. Unh generally with large subcostal white spot.

Sub-sp. elira Corbet I94I : ô Assam ; type B.M. II ô, 9 우 Assam.

(b) Larger, ô F I6 mm. Unh no large white subcostal spot.

Sub-sp bowringi nov. : ôt Hainan ; type B.M. $3 \hat{\delta}$, I + Hainan.

(c) ô $^{\text {F I }} 4 \mathrm{~mm}$., bright shining light blue, sexes alike ; border $5 \mathrm{~mm}$. at apex to $2 \mathrm{~mm}$. at dorsum and on $\mathrm{H}$. Unf with conspicuous white subcostal spot: apex unf and unh whitened.

Sub-sp. ammonides Doherty I891 : ô Tenasserim ; type B.M. 7 ô, 4 우 Ataran. 7 of, 3 우

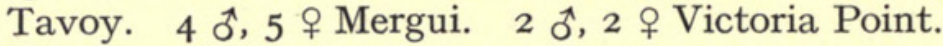

(d) Intermediate to chunsu. Above, duller, borders as in ammonides: below as chunsu. Sub-sp. monava Corbet I94I : ô Langkawi Is. : type B.M. Only the type.

(e) $\hat{\sigma}$ above, duller blue, border $5 \mathrm{~mm}$. at apex to 3 at dorsum and $4 \mathrm{~mm}$. on $\mathrm{H}$ : $q$ paler, with narrower borders, like ammonides. Unh subcostal white spot conspicuous, but apex unf and unh not whitened.

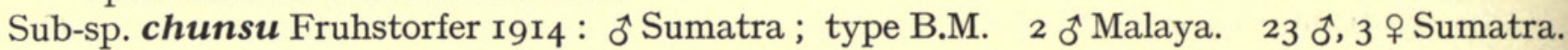

7a (6). Unh, in space 7, central spot nearer and linked to the discal spot: tornal metallic scales present.

7 (8). Unh no white spot separating the central and discal spots in space 7 . Small, ô F $13 \mathrm{~mm}$. Above, dark blue with broad border, as in ammonides. Fig. Corbet 78 , 82 and Ior $\mathrm{g}$.

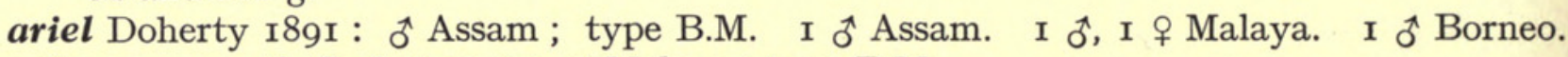

Synonym antis Corbet I94I : ơ Malaya; type B.M.

8 (7). Unh with a white spot between the central and discal spots in space 7. 0 above, dark blue, border $\frac{1}{2}$ to I $\mathrm{mm}$.

ammon. Two sub-species. Fig. Corbet 8I and $103 \mathrm{~g}$.

(a) o $\mathrm{F}$ I6 mm. ㅇ bright blue to purple, borders as in ammonides. Below, purple washed : subcostal white spot $\mathrm{H}$ conspicuous.

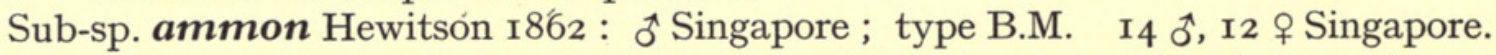

(b) ô F I7 mm. Below, not purple washed. Unh subcostal white spot inconspicuous.

Sub-sp. sarawaca Moulton I9I2: ơ Borneo; type B.M. I ot Borneo. The described $q$ is a ôt of ariel.

\section{P. Genus FLOS Doherty 1889}

1a (6a). $\mathrm{H}$ produced at tornus, vein $\mathrm{rb}=$ vein 2 .

Ib (5). $\mathrm{H}$ tailed.

Ic (3a). Unh discal band in spaces 7, 6 oblique and tapered from apex to end-cell spot.

I (2). Unh with a bifid spot mid-costa, separated from the dark basal area.

diardi. Two sub-species. Fig. Corbet 84 and $106 \mathrm{~g}$.

(a) ô F $23 \mathrm{~mm}$., dark purple-blue, no border : क purple with broad borders.

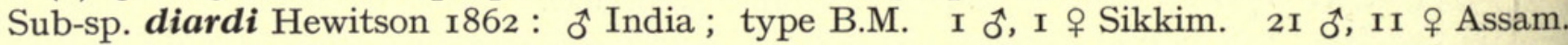
26 ô, 5 오 N. Burma to Mergui.

(b) ô clear dark blue instead of purple-blue.

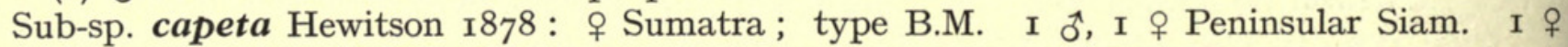

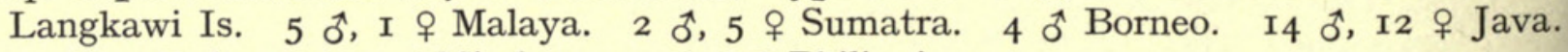

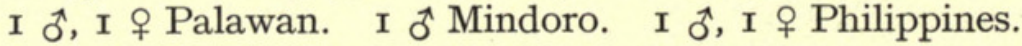

Synonyms viardi Staudinger I889: mis-spelling.

almansor Fruhstorfer I9I4: $ᄋ$ Malaya; type B.M.

amha Fruhstorfer I9I4: ô Borneo ; type B.M.

asatha Fruhstorfer I9I4: ô Java; type B.M. 
2 (I). Unh dark basal area continued as a band to mid-costa.

fulgida. Three sub-species. Fig. Corbet 85 and $107 \mathrm{~g}$.

(a) ô $\mathrm{F} 22 \mathrm{~mm}$. Above, dark purple-blue, as diardi.

Sub-sp. fulgida Hewitson I863: 우 “Philippines" (recte Sikkim) ; type B.M. I7 ô, I7 우

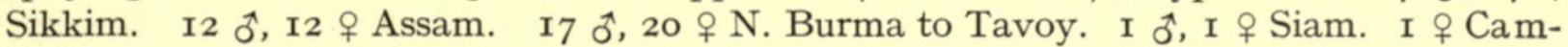
bodia.

(b) Above, clear dark blue, as diardi capeta.

Sub-sp. singhapura Distant I885: 소 Singapore. 3 ô, 3 우 Malaya. 5 ô, 3 우 Sumatra. I ô Nias. 5 ô, 2 우 Borneo. I ㅇ Cambodia.

Synonyms tifata Fruhstorfer I9I4: ô Sumatra ; type B.M.

batis Fruhstorfer I9I4: ô Sumatra; type B.M. Like typical fulgida: ? wrong label or variety.

zohar Fruhstorfer I9I4: ô Borneo ; type B.M.

tenea Fruhstorfer I9I4: ô E. Java ; type B.M.

(c) of $\mathrm{F} 20 \mathrm{~mm}$., above, as fulgida. Unh the central and discal markings in space $7 \mathrm{much}$ enlarged.

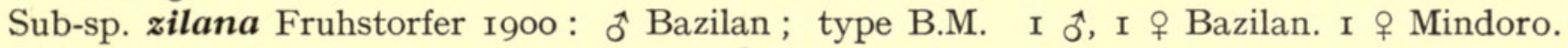

3a (Ic). Unh discal band in spaces 7,6 broad, overlapping end-cell spot and the discal spot in space 5 .

3 (4). $\mathrm{H}$ single short tail at end of vein 2, as in fulgida. 0 F $21 \mathrm{~mm}$., above as fulgida. Below, darker, generally as fulgida except for the discal band unh: also the tornal metallic scaling is more extensive than in any other species. Clasp of genitalia with end broadly rounded instead of pointed as in fulgida.

bungo nov. : đิ Ñias, Kalimbungo: I. Z. Kanniegieter, January, I896; type B.M. 2 ๙ Nias.

4 (3). $\mathrm{H}$ long tail at end of vein 2 and a short, white-tipped tail at end of vein 3. Large, of $\mathrm{F} 25 \mathrm{~mm}$. Generally as fulgida but purple colouring of $q$ restricted. Fig. Seitz I $50 d$.

kühni Röber 1887: 소 Bangkei ; type B.M. 3 ô, I q Bangkei.

Synonyms imperiosa Fruhstorfer I9I4: Celebes. Fig. Seitz I62a. lompana Ribbe 1926: đo Bonthain, Celebes.

5 (rb). $\mathrm{H}$ no tail, short tooth at end of vein 2.

anniella. Three sub-species. Fig. Corbet 86 and $108 \mathrm{~g}$.

(a) ô F I9 mm. ; brilliant dark purple-blue, no border : + shining blue (sometimes purple). with broad borders. Unh, basal and central markings obscured by the dark ground.

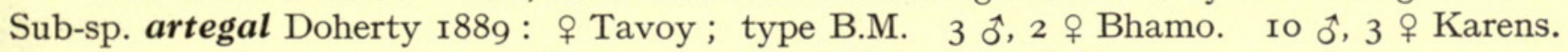

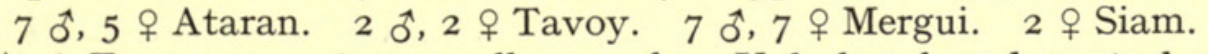

(b) ô $\mathrm{F} 22 \mathrm{~mm}$. क generally purple. Unh basal and central markings more or less conspicuous.

Sub-sp. anniella Hewitson I862: đat Singapore; type B.M. 2 \& Peninsular Siam. 8 d,

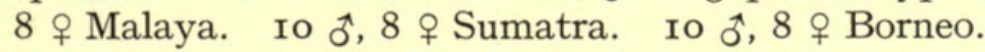

Synonyms triangularis Bethune-Baker 1903, as Staudinger MS.

husaina Fruhstorfer I914: ô Sumatra ; type B.M.

(c) Differences not clearly described by author.

Sub-sp. malangana Toxopeus I927: ô Java. None in B.M.

6 (ra). $\mathrm{H}$ rounded at tornus, vein $\mathrm{Ib}$ shorter than vein 2.

$6 \mathrm{~b}$ (I Ia). Unf conspicuous quadrate white spot mid space I b.

6c(Io). Tailed.

6d (9). Tail long, $3 \mathrm{~mm}$.

6e (8). Unh basal third more or less variegated.

ENTOM. 5,3 . 
6 (7). Unh without tornal metallic scaling. कै $\mathrm{F} 2 \mathrm{I} \mathrm{mm}$., dark purple, border $2 \mathrm{~mm}$. o blue with broad borders. Unh variegated grey and brown, markings blurred.

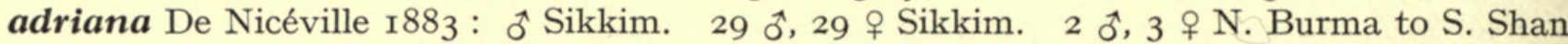

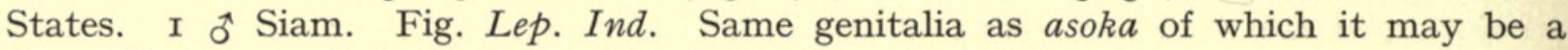
dimorph or an ecological sub-species : it is not a seasonal form.

7 (6). Unh with tornal metallic scaling and clearly defined whitish markings on the dark brown ground. Above, as adviana, but border upf in $\widehat{0}$ narrower, $1 \mathrm{~mm}$. Fig. Corbet I IO g.

asoka De Nicéville I883: ô Sikkim. Fig. Seitz I50B f. 24 ô, 24 ㅇ Sikkim. 2 우 Assam. I3 우 N. Burma to S. Shan States. I ㅇ Yunnan. 3 st, 4 아 Hong Kong.

Synonyms chola Moore I884: ô Sikkim; type B.M.

vaya Fruhstorfer I9I4: o Hong Kong; type B.M.

8 (6e). Unh basal third plain dark brown, marked as apidanus. Unf narrow white bar in cell and the dark discal band very broad. ㅇ light blue colouring much restricted.

arca De Nicéville I893: \& Celebes : figured. None in B.M.

9 (6d). $\mathrm{H}$ tail short, I mm. Unh with tornal metallic scaling. 0 $\mathrm{F} 22 \mathrm{~mm}$., shining dark blue, border I $\mathrm{mm}$. at apex, $\frac{1}{2} \mathrm{~mm}$. elsewhere. 우 purple with broad borders. Fig. Seitz I5oe.

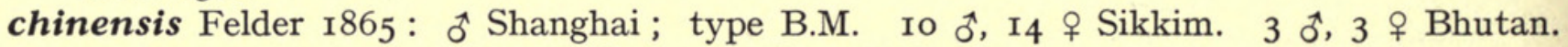
I 7 oै, I 7 우 Assam. I to W. China. I ô Shanghai.

Synonyms moellevi De Nicéville I883: ô Assam.

lazula Moore I884: ô Sikkim ; type B.M.

10(6c). H no tail. Unh no tornal metallic scaling. Similar genitalia to chinensis and differs therefrom as adriana differs from asoka. Fig. Corbet 88 and II I g.

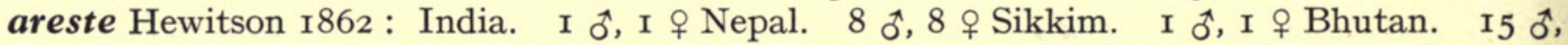
I5 ㅇ Assam. II $\hat{\jmath}$, I4 $q$ N. Burma to Ataran. I $\hat{o}$ Malaya. Coll. Höne (Leipzig) contains $68 \hat{\sigma}, 45$ from Chekiang and I $\hat{\sigma}, \mathrm{I}$ f from Kwang Tung : only I $\widehat{o}$ of chinensis from Chekiang, as well as an apparent hybrid between the 2 (?) species.

Synonyms patuna Moore: $ᄋ$ Nepal; type B.M.

arestina Evans I925: ô N. Shan States: type B.M.

11a (6b). Unf no conspicuous quadrate white spot mid space $\mathrm{Ib}$.

I Ib (I3). Tailed.

II (I2). $\mathrm{H}$ tail long, $3 \mathrm{~mm}$.

apidanus. Seven sub-species. Fig. Corbet 87 and $109 \mathrm{~g}$.

(a) ô $\mathrm{F} 20 \mathrm{~mm}$., dark shining blue, border $\mathrm{I} \frac{1}{2}$ to $\mathrm{I} \mathrm{mm}$.; + pale blue, border broad. Unh central pale area contrasting conspicuously with the basal and sub-tornal dark areas ; tornal metallic scaling vestigial. Back of uncus centrally concave instead of rounded.

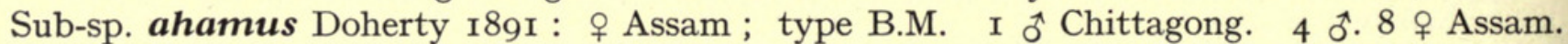

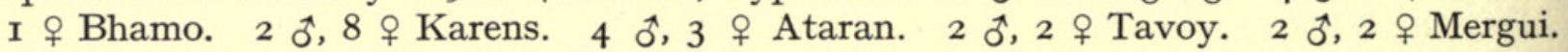
2 ㅊ, 2 우 Siam. I ơ “ Sumatra ".

(b) Duller, darker blue : $ᄋ$ more purple. Below, more uniform, like apidanus.

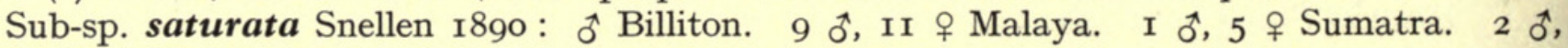
2 오 Banka. $\quad$ I 2 ô, 18 우 Borneo.

Synonyms kartaphilus Fruhstorfer I914: $0^{\uparrow}$ Malaya; type B.M. berossus and viribus Fruhstorfer I9I4: both $\sigma^{t}$ Borneo ; types B.M.

(c) Below, looking very different from saturata, plain brown unh, no violet washed pale central area and tornal metallic scaling more extensive : $q$ above, purple-blue area more extensive.

Sub-sp. phalakron Fruhstorfer I9I4: ô Sumatra ; type B.M. 4 ô, II 아 NE. Sumatra.

Synonyms ambigua, anabas, astrophila, anthracophila Toxopeus : Sumatra. 
(d) i purple-blue area more extensive. Below, like phalakron, rather than saturata, but has more sheen and more extensive metallic scaling.

Sub-sp. xisuthrus Fruhstorfer I9I4: 우 Nias ; type B.M. $3 \hat{0}, 9$ 우 Nias.

(e) As saturata, but + blue. Very variable.

Sub-sp. apidanus Cramer I777: ô Surinam (recte Java apud Staudinger, I889). I6 \$ే,

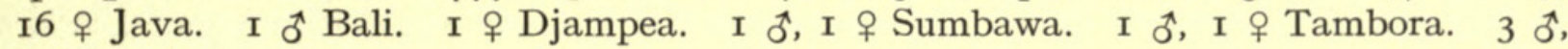
7 ㅇ Lombok.

Synonyms dorimond Stoll I790: Cape of Good Hope (recte Java apud Seitz, 1928).

cames and antipaxus Fruhstorfer I9I4: both ô Java; type B.M. alter Toxopeus I929: Java.

(f) Like apidanus, but larger. $0 * \mathrm{~F} 24 \mathrm{~mm}$.

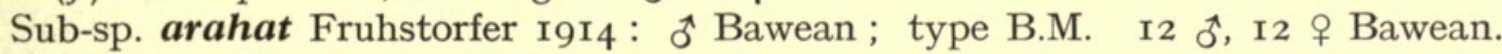

(g) \& purple above. Unh central pale area as conspicuous as in ahamus.

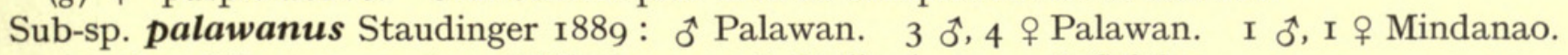

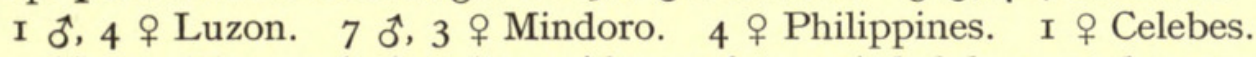

Note.-The variation in apidanus forms (phalakron and saturata) flying together recalls the adriana-asoka and chinensis-aveste relationships.

12 (II). H tail short, I mm. Uncus end triangular. $\hat{\sigma} \mathrm{F}$ I9 mm. Above, as apidanus, duller blue : $ᄋ$ purple with very broad borders : uph cell only purple. Below, very variable, but unf dark discal band very broad, as in arca: red areas at base costa F and $\mathrm{H}$ often very conspicuous : unh pale central area narrower and more sharply marked.

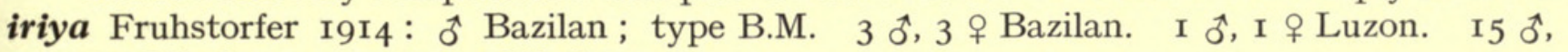

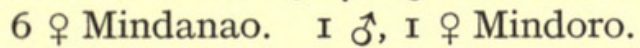

13 (I I b). H no tail, termen quite smooth and on unh narrowly white-edged.

morphina. Two sub-species. Fig. Corbet 89 and II 2 g.

(a) ô F $25 \mathrm{~mm}$., brilliant shining dark blue, border a thread. ㅇ paler purple-blue, border 4 to $\mathrm{I} \frac{1}{2} \mathrm{~mm}$. Unh basal quarter black, outer third darkened, central pale brown area with faint markings.

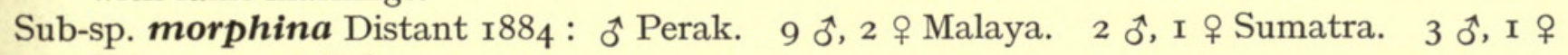
Borneo. I ㅇ Palawan.

(b) Smaller, ơ F $23 \mathrm{~mm}$., duller form.

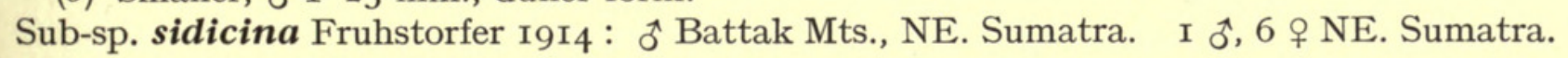

\section{APPENDIX}

\section{Amblypodia Horsfield I829 v. Arhopala Boisduval 1832}

Horsfield (1829) (Cat. Lep. E.I.C., page 87), under " Genus Thecla" describes the larva, either as in Pl. 4, figs. 3 and 4 (sub-genus Amblypodia apidanus and helus), or as in Pl. 4, fig. 2 (Thecla xenophon). At the end of page 88 he separates Amblypodia from Thecla on the basis of the antennae, clubbed in Thecla, gradual in Amblypodia. After describing the various species of Thecla ("strictae sic dicta"), he describes on page 98 Sub-genus Amblypodia on the basis of the antennae and the larvae referring to $\mathrm{Pl} .4$, figs. 3 and 4 . He divides the species of $A m b l y$ podia into 5 sections: No. I narada. No. 2 vivarna. No. 3 apidanus, centaurus, helus, eumolphus. No. 4 sugriva. No. 5 vulcanus etc. On page II I he says he considers the third section to be typical of the sub-genus Amblypodia.

Westwood (1852) (Gen. Diurn Lep. 2: 477) lists the species of Amblypodia, placing Arhopala as a synonym. He says that the types of the genus are the large Indian Amblypodias, centaurus, apidanus, helus, anthelus etc. He commences his list of 32 species with Horsfield's section 3, following with sections $\mathrm{I}, 2,4,5$, adding several species not included by Horsfield.

Boisduval (1870) (Lep. Guatemala: I4) specifies, without comment, narada as the type of Amblypodia.

ENTOM. 5, 3 . 
Scudder (1875) (Proc. Am. Ac. Arts \& Sci. 10 : 108) rejects Boisduval's type selection because of Westwood's previous limitation and he selects apidanus as the type.

Moore (I88I), Distant (I885), De Nicéville (1890), Bethune-Baker (1903), Bingham (1907) and Swinhoe (I9II) - all regarded narada as the type of Amblypodia.

Riley (I922) (Entomologist $55:$ 25) pointed out that Horsfield had considered his third section to be typical of his genus and consequently Boisduval's selection of narada from the first section was incorrect and that Scudder's selection of apidanus must be adopted. He created Horsfieldia, type navada. Seitz (I926) and Evans (I925 and I932) followed Riley's lead.

Corbet (I940) (Proc. R. ent. Soc. Lond. (B) 9:4) wrote- "It is considered that Horsfield's assertion that he considered his third section (comprising apidanus Cramer and 3 other species) as typical of his sub-genus Amblypodia I829 does not constitute a type selection, so that the first valid type selection for Amblypodia was that by Boisduval (1870), who specified narada Hsf. Mr. N. D. Riley is in agreement with this interpretation of the rules of the International Commission for Zoological Nomenclature". In his subsequent work Corbet used Arhopala Boisduval for all the species included in this review.

Corbet is correct in saying that Horsfield made no " type selection ", for under the International Rules of Zoological Nomenclature as they currently exist and are interpreted, since Horsfield did not specify any single species as typical of his Amblypodia, any subsequent author was free to select any one of the five species Horsfield originally included. It is unfortunate in many ways that Boisduval, when selecting a type species in I870, did not choose one of the two species (apidanus and helus) which fitted the description of Amblypodia so much better than did the other three species, for by doing so, much subsequent argument could have been avoided. However, as things stand, navada must be accepted as the type species of Amblypodia and the irregular but understandable action taken by Riley in 1922 set aside. The species included in the genus Amblypodia, in this sense, are not dealt with in this review and the genus is therefore excluded from consideration. Fortunately the species which first Scudder and later Riley incorrectly selected as they type species of Amblypodia, namely apidanus, is also the type species of Flos Doherty (I889) so the group of species which it typifies is not left without a generic name.

A really unfortunate outcome of my revision of the Arhopala group and its sub-division into definable genera, has been the restriction of the exceedingly well-known name Arhopala to a small Papuan group of 5 species of which phryxus is the type, leaving Narathura Moore as the generic name of the great bulk of the species hitherto referred to Arhopala.

\section{Narathura eridanus viola Röber}

Bethune-Baker (1903) listed on page 46 Amblypodia viola Röber as a synonym of Arhopala padus Felder. Then on page $5^{\mathrm{I}}$ he describes and figures as a new species Avhopala viola Semper (non viola Röb.) based on I $\sigma^{\star}$ and 2 o from Mindanao, which Staudinger had sent him for examination. It has been ascertained from Dr. E. M. Hering of the Berlin Museum that the specimens were destroyed in the war. The figures do not agree very well with the few specimens in the B.M. over the label sub-sp. dilutior Staudinger from the Philippines, but until more material becomes available, the coining of a name does not seem necessary.

\section{Identity of Arhopala kounga Bethune Baker}

The $\delta$ and $q$ of this species were described and figured by Bethune-Baker in 1896 as from Borneo. In 1903 he placed kounga o as a synonym of azinis De Nicéville and remarked that kounga $\sigma^{*}$ " is a curious form of aroa", in dealing with which species he makes no mention of kounga. Corbet (I94I) used the name kounga for the $\sigma^{*}$ described by Bethune-Baker and created a number of sub-species, beginning with ralanda from Burma.

It is considered Bethune-Baker's 1903 action restricted kounga to the $q$ and the name is used in this review for the Bornean sub-species of azinis. ralanda replaces kounga as the specific name for Corbet's "kounga" series, whereof the Bornean sub-species (kounga of Corbet nec Bethune-Baker) is ridleyi Corbet. 


\section{Identity of Amblypodia atrax}

Hewitson (1862) (Cat. Lyc. B.M. : 13) described atrax $\hat{o}$ and $q$ from India in coll. B.M. He figured the $o$ and remarked that the $\hat{\sigma}$ might belong to a different species. The $\hat{\sigma}$ is labelled "E. Indies" and the $ᄋ$ "Bengal". The $\widehat{o}$ (recte aida De Nicéville) occurs only from midBurma to Malaya and Indo-China. The o (recte atrax) is a common species of the plains of India, extending to mid-Burma.

Moore (1865) (P.Z. S. : 774) records atrax from Calcutta and thus became the first selector. In 1884 he cites atrax (quoting Hewitson's figure), as the type of his genus Satadra.

De Nicéville (I889) describes aida from mid-Burma and figures the $\hat{\jmath}$, which $=$ the B.M. specimen of Hewitson's $\widehat{o}$ atrax. In 1890 he follows Moore in using atrax for Hewitson's o and remarks that Hewitson had undoubtedly mixed up 2 species. In $189 \mathrm{I}$ he described and figured $\delta$ and $o$ alemon from N. Burma : the $\sigma^{*}$ is a specimen of atrax, while the "o" is a $\sigma^{*}$ of the species described as alax by Evans (1932).

Bethune-Baker (1903), wrongly over-riding the principle of the first selector, insists that Hewitson's $\sigma^{t}$ must be taken as the type of atrax and he describes the species represented by Hewitson's o atrax as hewitsoni. He considers aida to be a strongly marked form of his mindanensis and alemon he thinks comes near to his hewitsoni, replacing it in certain districts of Burma.

Swinhoe (I9Iо) (Lep. Ind.) followed Bethune-Baker, describing and figuring as different species, aida, atrax, alemon, mindanensis and hewitsoni : his figure for the of alemon is correct.

Evans (1925) (Identification Ind. Butt.) followed Bethune-Baker, but put aida and mindanensis as synonyms of atrax. In 1932 (2nd edition) he put hewitsoni as synonym of alemon and described alax as the species taken by De Nicéville to be the + of his alemon.

Corbet (I94I) generally followed Bethune-Baker, putting aida as a synonym of atrax, mindanensis as a synonym of rafflesi and hewitsoni as a synonym of alemon.

It is considered that Bethune-Baker was wrong in over-riding Moore's selection of Hewitson's o as the type of atrax. An attempt has been made in this review to straighten out the tangle by regarding atrax (= alemon and hewitsoni), alax, mindanensis and aida as species.

\section{Identity of Arhopala pseudomuta Staudinger}

Distant (1885) (Rhop. Malay.) described and figured a species he called Narathura amphimuta Felder.

Staudinger (1889) correctly pointed out that Distant's species was not the amphimuta of Felder and he renamed it pseudomuta.

De Nicéville (1890), in ignorance of Staudinger's action, acted similarly, calling Distant's species rafflesii. In I 895 he sunk his name to Staudinger's pseudomuta.

Bethune-Baker (1903) stated that pseudomuta is quite a distinct species from rafflesii and he figures what he calls pseudomuta.

Swinhoe and Corbet follow Bethune-Baker.

Bethune-Baker's figure of Paeudomuta portrays a species entirely different from that figured by Distant and is here renamed delta (A2I). vafflesii is correctly placed as a synonym of pseudomuta.

\section{Identity of Papilio centaurus}

Fabricius (I775) described this species as blue with a fuscous edge : from New Holland : in Mus. Banks.

Horsfield (1829) (Cat. Lep. E.I.C. 2 : I02) recorded centaurus from Java and stated that the type was in Mus. Banks.

Doubleday (1847) (List Lep. B.M. $2: 24$ ) recorded centaurus from Queensland and created pseudocentaurus for the centaurus of Horsfield from Java etc. Westwood (1852) (Gen. Diurn. Lep. $2: 478$ ) follows suit.

Horsfield \& Moore (1857) (Cat. Lep. E. I.C. : 40) record centaurus from Sikkim, Assam and pseudocentaurus from Java. 
Felder (1860) (Wiener Ent. Monat. $4: 395)$ creates nakula for the Sumatran and Malaccan form of centaurus from the Indian continent.

Butler (1869) (Cat. Lep. Fab. in B.M. : I79) states that the type of centaurus is in the Banks Collection and that it agrees with Felder's figure in the Reise Novara of his nakula. This determination was accepted by all authors.

Corbet (I94I) (Proc. R. ent. Soc. Lond. (B) 10 : roo) stated that "The specimen in the Banks Collection, which has hitherto been regarded as the type of centaurus is one of 2 males (without locality labels) which agree with Felder's nakula, were probably obtained by Koenig in Malaya and there is every reason for supposing that neither specimen was in the Banks Collection when Fabricius described centaurus. Moreover, the original description applies to a 9 . The original description fits best the + of Arhopala eupolis Miskin and it is a reasonable assumption that the type was obtained by Banks in N. Queensland ".

It is incorrect to say that Felder's description must apply to a 9 and there is no evidence to support the assumption that the specimens now in the Banks Collection were not those seen by Fabricius. Many of the localities recorded in the early part of the last century have been found to be incorrect. Apart from Doubleday, who makes no mention of the Banksian specimens, all authors have regarded centaurus as coming from the Oriental region and all entomologists whom I have consulted, agree that there is no justification for any departure from the conclusions reached by Butler in 1869 .

\section{REFERENCES}

For publications prior to I90o, references will be found in the more important works, marked below with a dagger $(\dagger)$.

$\dagger$ Bethune-Baker. 1903. A Revision of the Amblypodia group. Trans. Zool. Soc. London 17.

I903. Entom. Monthly Mag. 39.

1904. Ann. Mag. Nat. Hist. 7/14.

Corbet. I94I. Proc. R. ent. Soc. Lond. (B) $10:$ I49.

- I946. Trans. R. ent. Soc. Lond. $96: 73$.

1948. Proc. R. ent. Soc. Lond. (B) $17: 93$.

$\dagger$ De Nicéville. I89o. Butterfies of India, Burma and Ceylon 3.

Doherty i889. J. Asiat. Soc. Bengal 58/2.

Evans. I9I2 \& I9I4. J. Bombay Nat. Hist. Soc. 21 \& 23.

— I925. Ibid. 30; published 1926 as Identification of Indian Butterflies.

1932. Identification of Indian Butterflies. 2nd ed.

FruHSTORFER. I899. Stettiner Ent. Zeit. 60.

- I900. Berlin Ent. Zeit. $\mathbf{4 5}$.

I9I3 \& I9I4. Iris, 27 \& 28.

Joicey \& Talbot. I9i6. Trans. ent. Soc. London.

— 1917. Ann. Mag. Nat. Hist. 8/20.

I922. Bull. Hill Mus. 1.

Kato. I930. Zephyrus 2.

Matsumura. igio. Ent. Zeit. 23.

— I926. Ins. Matsumura 1.

Moulton. I9II-I2. J. Straits Branch R. Asiat. Soc. 60.

Ollenbach. I921. J. Bombay Nat. Hist. Soc. 28.

Piepers \& Snellen. I9I8. Rhop. Java: Lycaenidae.

RibBe. I926. Ent. Mitt. 15.

RILEy. I920. Entomologist, 53.

- 1923. Spolia Ceylanica 12.

Riley \& Godfrey. I92I. J. Nat. Hist. Soc. Siam. 4.

RöBER. I931. Int. Ent. Zeit. 24. 
Rothschild. I915. Lep. B.O.U. and Wollaston expedition to New Guinea.

Seitz. I926. Macrolepidoptera 9.

Sonan. 1945. Tr. Nat. Hist. Soc. Formosa. 30.

Strand. I9I2. Arch. für. Nat. 78, A II.

†Swinhoe. I9Iо. Lepidoptera Indica 8. 1917. Ann. Mag. Nat. Hist. 8/19.

Toxopeus. I929. Tijd voor Ent. 72.

- 1930. De soort als functie.

Tytler. I9I5. J. Bombay Nat. Hist. Soc. 24.

- I926. Ibid. $\mathbf{3 1}$.

Waterhouse. I932. What Butterfly is That.

- I942. Rec. Australian Museum 21. 
aberrans, $\mathrm{O}_{4}$

aboe, $I_{7}$

abseus, $C_{2}$

ace, $F_{7}$

acerba, $H_{\text {I } 2}$

Acesina, $O$

acestes, $G_{22}$

acetes, $G 8$

achelous, $A_{7}$

acron, $L_{\mathbf{I}}$

acta, G20

adala, $I_{7}$

adalitas, $I_{7}$

adatha, $F_{2}$

adherbal, $\mathrm{H}_{4}$

admete, $L_{2}$

adonias, $G$ I 5

adorea, $F_{5}$

adriana, $P 6$

adulans, $I_{7}$

aedias, $A$ I 8

aeeta, $I_{1} 3$

aexone, $H_{1} 4$

afranius, $E_{\mathbf{I}}$

agaba, $I_{4}$

agamemnon, $F_{4}$

agelastus, $I$ I 6

agesias, $B_{24}$

agesilaus, $B$ I I

aglais, $H_{\mathrm{I}}$

agnis, $A$ I 8

agrata, $F_{9}$

ahamus, $P$ II

aida, $F_{25}$

ajusa, $G_{\mathbf{I}}$

alaconia, $I$ Io

alax, $F_{\text {I9 }}$

albopunctata, $F_{20}$

alce, $G_{\mathbf{I}}$

alcestis, $G_{\mathbf{I}}$

alea, $F_{\mathrm{I}} 6$

alemon, $F_{\mathrm{I}} 8$

alesia, $I 9$

aleta, I6

alica, $B 9$

alitaeus, $F_{21}$

alkisthenes, $H_{1} 3$

allata, $A 22$

almansor, $P_{\mathbf{I}}$

aloana, I ro alter, $P_{\text {I I }}$

ambigua, $P_{\text {II }}$

amantes, GI I

amatrix, GII

amazona, $H_{\mathbf{I}}$

Amblypodia, $P$

amha, $P_{\mathbf{I}}$

ammon, 08

ammonides, 06 .

amphea, $C_{2}$

amphimuta, $B$ I 5

amphis, $H_{12}$

amydon, $H_{12}$

amytis, $H_{12}$

anabas, $P$ II

anamuta, $B_{20}$

anarte, $A_{5}$

andamanica $L_{4}$

ander, $\mathrm{H}_{\mathrm{I}} \mathrm{O}$

androtion, $\mathrm{H}_{\mathrm{I} 2}$

anella, $C_{\mathrm{I}}$

anicius, $\mathrm{H}_{9}$

anila, $B 25$

anniella, $P_{5}$

annulata, $A 9$

antharita, $G 2$

anthea, $A$ I

anthelius, $N_{\mathrm{I}}$

anthelus, $A$ I

anthore, $N_{I}$

anthracophila, $P_{\text {I I }}$

antimuta, $K 6$

antipaxus, $P$ I I

antis, $\mathrm{O}_{7}$

antura, $F 6$

anunda, $A_{\text {I }}$

apella, $G_{\text {I I }}$

apha, $F_{4}$

aphadantas, $F_{2}$

apharida, $F_{2}$

aphobus, $\mathrm{H}_{2}$

apidanus, $P$ I I

appianus, $H_{4}$

arahat, $P_{\text {I I }}$

arama, $F_{5}$

arata, $F_{7}$

araxes, $\mathrm{H}_{2}$

arca, $P 8$

ardea, $I_{7}$

areste, $P$ ro arestina, $P$ Io

argentea, $D_{3}$

Arhopala, $N$

aria, $A 23$

ariana, $F_{27}$

arianaga, $F_{27}$

ariavana, $F_{27}$

aricia, $A_{23}$

ariel, $\mathrm{O}_{7}$

arisba, $\mathrm{O}_{5}$

aristomachus, $G_{15}$

aroa, $F_{\text {I } 3}$

aronya, $D_{2}$

arops, $F_{I 3}$

arsenius, $I_{15}$

artegal, $P_{5}$

arta, $N_{3}$

aruana, $F_{2}$

arvina, $I_{7}$

asakurae, $\mathrm{O}_{5}$

asatha, $P_{\mathrm{I}}$

asia, $B$ I 5

asinarus, $I_{\mathrm{I}} 8$

asma, $G_{5}$

asoka, $\mathrm{P7}_{7}$

asopia, $I_{1} 7$

asopus, $\mathrm{H}_{2}$

astrophila, $P$ I I

atarana, $A 22$

ate, $E_{2}$

athada, $F_{4}$

athara, $G_{\mathbf{I}}$

atosia, $A_{23}$

atrax, $F_{\text {I }} 8$

Aurea, $M$

aurea, $M_{\text {I }}$

aurelia, $F_{\text {Io }}$

auxesia, $A_{2}$

auzea $A_{5}$

avatha, $K_{7}$

avathina, $B$ го

axina, $N_{4}$

axiothea, $N_{5}$

aytonia, $\mathrm{GI}_{5}$

azata, $A$ I 6

azenia, $L_{\text {I }}$

azinis, $F 8$

babsi, $L_{4}$

baluensis, $B$ I 2 
barami, I2

basiviridis, $G_{4} 4$

batis, $P_{2}$

bazaloides, Gio

bazalus, $G_{\mathrm{I} 3}$

bella, GI9

belphoebe, $B 2$ I

berossus, $P_{\text {II }}$

bicolora, $G_{9}$

binghami, $F_{9}$

birmana, $\mathrm{O}_{5}$

biru, $G_{14}$

borneensis, $M$ I

bosnika, $H_{12}$

bosnikiana, $G_{\mathbf{I}}$

bowringi, 06

brahma, $K_{4}$

brookei, $\mathrm{F}_{9}$

brooksiana, $A 8$

buddha, $I 6$

bungo, $P_{3}$

bupola, GI5

buruensis, $F_{\text {I } 5}$

busa, $B_{4}$

buxtoni, $F_{20}$

caeca, $M_{4}$

caelestis, $G_{\text {I }}$

caesarion, $G_{I} 5$

caesetius, $G_{\text {I }} 5$

calaureia, $N_{I}$

camdana, $A$ I 3

camdeo, $A$ I 4

cames, $P_{\text {II }}$

canaraica, FI6

canulia, $L_{4}$

capeta, $P_{\mathbf{I}}$

cardoni, $K_{3}$

carolina, $\mathrm{NI}$

catori, $\mathrm{BI}_{4}$

centaurus, $H_{\mathrm{I}}$

centenitus, $H_{\mathrm{I}}$

centra, $\mathrm{HI}_{2}$

cervidius, $H$ I

chamaeleona, $G_{1} 8$

chinensis, $P_{9}$

chola, $\mathrm{P}_{7}$

chota, $A$ I2

chrysoana, $\mathrm{HI}_{4}$

chunsu, 06

cidona, $H_{12}$

clarissa, $D_{3}$

cleander, $F_{2}$

comica, J6 conjuncta $A$ r 9

constanceae, $F_{\text {II }}$

contra, $F_{23}$

cooperi, I6

corestes, G22

corinda, $G_{22}$

corthatha, $\mathrm{O}_{5}$

coruscans, $H_{\text {I }}$

courvoisieri, $L_{3}$

cowani, $B 2$ I

cupido, $G_{3}$

curiosa, $J_{5}$

cyronthe, $H_{\mathrm{I} 2}$

daganda, $B_{4}$

dajagaka, $B$ I9

dama, $F_{27}$

Darasana, $A$

dascia, $\mathrm{O}_{5}$

davaona, $K_{5}$

davisonii, $K 6$

delta, $A 2$ I

democritus, $F_{20}$

denta, $F_{24}$

detrita, $F_{\text {I } 5}$

deva, $B 2$

diardi, $P$ I

diluta, $A$ I 2

dilutior, $A_{4}$

dispar, $A$ I 2

disparilis, $L_{3}$

dodonaea, $J_{4}$

dohertyi, $A_{20}$

dorimond, PII

droa, $E_{\mathbf{I}}$

drucei, $F_{5}$

duessa, $\mathrm{K}_{2}$

eichhorni, $H$ ro

elegabulus, GI 8

elfeta, $A_{4}$

elioti, $B$ I 8

elira, 06

elis, $G_{1} 5$

ellisi, $\mathrm{O}_{4}$

elopura, $F_{27}$

elsiei, $B$ I

empesta, $K_{4}$

enoma, $I_{1} 8$

epiala, $B \mathbf{I}$

epibata, $F_{23}$

epimete, $K_{2}$

epimuta, $B$ I

erebina, $A_{9}$ eridanus, $A_{4}$

esava, $F_{\text {I } 3}$

esra, $N_{I}$

etuna, $I$ I 2

eucolpis, $L_{2}$

eumolphus, $G_{15}$

eupolis, $\mathrm{H}_{2}$

eurisus, $\mathrm{H}_{2}$

eurysthenes, GI4

evandra, $A 22$

evansi, $F_{15}$

everetti, I I5

farquhari, $G_{\text {I } 5}$

Flos, $P$

formosana, $O$ I

fracta, $A$ I 2

fruhstorferi, $A$ I

fulgida, $P_{2}$

fulla, $L_{4}$

fundania, $F_{5}$

gana, I6

gander, $H$ ro

ganesa, $O_{\text {I }}$

gazella, $H$ ro

georgias, F6

gesa, $B$ I I

gilolensis, $E_{\mathrm{I}}$

gloria, $B_{4}$

grahami, $A$ I

grandiosa, $\mathrm{H}_{2}$

grynea, $G_{\text {I } 5}$

gunongensis, $B_{3}$

hagius, $A$ I 8

halma, $G_{4}$

halmaheira, $G_{7}$

hammon. $\mathrm{O}_{3}$

havea, $I_{\text {I I }}$

havilandi, $F_{2} 8$

heliagabulus, $G$ I 8

helianthes, $\mathrm{N}_{2}$

helius, $N_{\mathrm{I}}$

hellada, $A$ I 7

hellenore, $G$ I6

helus, $N_{\text {I }}$

herana, $\mathrm{H}_{\mathrm{I}} 4$

hercules, EI

herculina, EI

herodianus, $G_{14}$

hesba, $B$ I 7

hewitsoni, $F_{1} 8$

hilda, $B_{3}$

hirava, $I$ I 
horishana, $J \mathbf{I}$

horsfieldi, GI4

husaina, $P_{5}$

hyacinthus, G2

hylander, $H 6$

hypomuta, $B 2$

ignara, $L_{4}$

ijauensis, $A_{3}$

impar, $A$ I

imperiosa, $\mathrm{P}_{4}$

incerta, $F_{2}$

indicus, $C_{2}$

indra, $B 7$

inornata, $K_{4}$

intaca, $L_{4}$

interniplaga, $N_{I}$

Iois, $N$

iriya, $P$ I2

irma, $G 6$

irregularis, $C_{3}$

itama, $A_{4}$

jabadia, $A$ I

jahara, $A 23$

japonica, $J 2$

jobina, $F_{2}$

johoreana, $A$ ro

jona, $H$ I 2

kalima, $A$ ro

karennia, $A$ I I

karnyi, $F_{I 2}$

kartaphilus, $P$ I I

khamti, $F_{I} 7$

kinabala, $B 23$

kiriwinii, $H_{\text {I I }}$

kitjila, $G 8$

klossi, $B$ I6

kota, $F_{2} 8$

kotoshona, J2

kounga, $F 8$

kühni, $P_{4}$

kurzi, $B 5$

labuana, $I_{1} 2$

lammas, $A$ I9

lana, $K_{7}$

lanka, $G$ ıо

lata, $H_{3}$

latimarginata, $\mathrm{NI}_{\mathrm{I}}$

lazula, $P_{9}$

leander, $H$ Io

learmondii, $J 6$

leo, EI

leokrates, GI4 leonidas, $E_{\mathbf{I}}$

leontodamas, $E_{\mathbf{I}}$

leptines, $H_{12}$

lewara, $A_{4}$

linta, $K \mathbf{I}$

lompana, $P_{4}$

loomisi, $O_{\text {I }}$

louisa, EI

lurida, $A 23$

lycaenaria, $F_{20}$

mackwoodi, $C_{2}$

madytus, $H 8$

majestatis, $A_{\text {I }}$

major, $B$ I 3

malu, $A 8$

malangana, $P_{5}$

malayana, $A 23$

malayica, $F_{5}$

maranda, $B_{4}$

maxwelli, $G_{\text {I } 5}$

maya, $B$ I 6

maymoica, $\mathrm{O}_{5}$

meander, $\mathrm{H}_{9}$

media, $I$ Iо

meeki, $H$ ıо

mendava, $\mathrm{O}_{3}$

merguiana, $B_{4}$

meritatas, $A$ I 8

metamuta, $B_{3}$

micale, $H$ I 2

milleri, $F_{\text {I } 2}$

milleriana, $B \mathrm{I}_{4}$

mindanensis, $F_{23}$

minnetta, $N$ I

minor, $F_{2}$

mira, $F_{21}$

mirabella, $F_{21}$

moelleri, $P 9$

molta, $F_{\text {I } 2}$

monava, 06

moolaiana, $B \mathrm{I} 6$

moorei, $B_{4}$

morphicolor, $A_{5}$

morphina, $P_{13}$

muta, $B_{4}$

myrtale, $F_{21}$

myrtha, $F_{2} 6$

myrzala, $A$ I 9

myrzalina, $B 22$

nabala, $B 23$

nakula, $H_{\mathrm{I}}$

Narathura, $A$

natanda, $H_{\text {I4 }}$ nava, $C_{2}$

nebenius, $G$ I3

neon, $B$ ro

neva, $G_{3}$

newara, $J \mathbf{I}$

nicevillei, $F_{3}$

Nilasera, $A$

nobilior, $G_{\mathbf{I}}$

nobilis, $G \mathbf{I}$

norda, $B$ I 3

novaeguineae, $H_{\text {I } 2}$

oberthüri, I Iо

obina, $H_{12}$

obscurata, EI

ocrida, $I 8$

oenea, $F_{I 7}$

oenotria, $A$ I 8

oghatina, $C_{2}$

olinda, $F_{20}$

onetor, $\mathrm{H}_{2}$

opalina, $A$ I 5

ophiala, $C_{2}$

ophir, $F_{25}$

ormistoni, $I_{3}$

oryuzana, $\mathrm{O}_{5}$

overdijkinki, G2I

ovomaculata, B24

ozana, $A$ I 7

padus, $A_{4}$

pagaiensis, $B$ I6

pagia, $I_{\mathbf{I}}$

palawanus, $P$ I I

pallida, $A$ I8

Panchala, $O$

pandora, $A 22$

pangeran, $A$ I 8

panta, $F_{21}$

panthera, $A$ I 3

paralea, $I_{5}$

paraganesa, $\mathrm{O}_{3}$

paramuta, $J \mathbf{I}$

pardenas, $F_{21}$

pastorella, $B$ I6

patuna, $P$ ro

penanga, $I_{2}$

pendleburyi, $A$ r 2

periander, $\mathrm{H}_{9}$

perimuta, $K_{\mathbf{I}}$

perissa, $I$ I 6

phaenops, $F_{I 5}$

phalaerus, EI

phalakron, PII 
phanda, $F_{14}$

philander, $H$ ro

philippa, $B$ I I

philtron, $\mathrm{H}_{2}$

phryxus, $N_{I}$

pirama, $H_{\mathrm{I}}$

pirithous, $H_{\mathrm{I}}$

plateni, $F 6$

polita, $A_{4}$

potidaea, $N$ I

prasiä, $L_{4}$

pratinas, $G_{13}$

pratti, $H_{\text {I }}$

pryeri, $F_{\text {I } 3}$

psama, $F_{21}$

pseudo-centaurus, $H_{\mathrm{I}}$

pseudomuta, $F_{27}$

purpura, G6

quadra, $B$ I $_{5}$

querceti, $J 3$

quercoides, $F_{\mathbf{I}}$

rafflesii, $F_{27}$

rajah, $M 2$

ralanda, $F_{\mathrm{I} 2}$

rama, $J_{3}$

ramosa, $J 3$

regia, $F_{2}$

regia, $K_{\mathrm{I}}$

regina, $K_{\mathrm{I}}$

restricta, $G_{1} 8$

ribbei, $H_{12}$

ridleyi, $F_{\text {I } 2}$

rileyi, $G_{1} 8$

riuna, $H_{\mathrm{I} 2}$

roona, $I_{1} 4$

sacharja, $I_{9}$

salvia, $A_{2}$

sandakani, $F_{15}$

sangira, $\mathrm{D}_{4}$

sanherib, GI6

santa, $L_{4}$

santava, $B_{4}$

sarawaca, $O 8$

Satadra, $A$

saturata, $P$ I I

saturatior, $A$ I

sceva, $B 6$

sebonga, $A$ I 4

selta, $F_{\text {I I }}$

selymbria, $H_{1} 2$

seminigra, $O \mathrm{I}$ semperi, $A$ I3

serpa, $G_{\text {I4 }}$

shelfordi, $B 2$

siabra, $B 8$

siberuta, $I 6$

sidicina, $P_{1} 3$

silhetensis, $F_{5}$

similis, $B 25$

simonea, $A_{3}$

singhapura, $P_{2}$

singla, $G$ I 2

sintanga, $F_{22}$

siroes, $G$ I6

soda, $G_{3}$

sophax, $N_{\text {I }}$

sophilus, $E_{\mathrm{I}}$

sophrosyne, $H_{\text {I }} 5$

sosias, $L_{4}$

sostrata, $F_{2}$

sotades, $A$ I

soter, $A$ I 8

sphendale, $A$ I 5

sphetys, $A$ I 8

staudingeri, GI 7

stinga, $M_{3}$

strophe, $\mathrm{N}_{5}$

stymphelus, $E_{\text {I }}$

styx, $\mathrm{H}_{7}$

subfasciata, $A_{3}$

subfasciata, $L_{4}$

sublustris, FI4

sudesta, $L_{2}$

suedas, $K_{2}$

suffusa, $A 22$

superba, $H_{1} 2$

tagore, $G_{15}$

talauta, $\mathrm{H}_{2}$

tameanga, G20

tamyrus, $N_{\text {I }}$

tana, $K 6$

tebäensis, $H_{1} 2$

teesta, $G_{1} 3$

telephus, $E_{\mathrm{I}}$

tembaga, $M_{\mathrm{I}}$

tenea, $P_{2}$

tephlis, $G 9$

termerion, $F_{I_{5}}$

teuthrone, $\mathrm{NI}_{\mathrm{I}}$

thamyras, $\mathrm{NI}$

theba, $D$ I

tifata, $P_{2}$

timana, $K 6$

tindali, $\mathrm{H}_{2}$ tounguva, $I_{\mathrm{I}} 8$

triangularis, $P_{5}$

trima, $B_{4}$

trionoea, $A 6$

tristis, $A_{9}$

trogon, $M_{2}$

tropaea, $B_{4}$

turbata, $G_{\text {I } 3}$

tyrannus, $E_{\text {I }}$

uchidae, $\mathrm{O}_{5}$

udapa, $A 23$

unda, $G_{2}$ I

valika, $F_{21}$

vandenberghi, $F 6$

varro, $A$ I I

vaya, $P_{7}$

vellanus, $G_{\text {I } 4}$

verelius, $\mathrm{H}_{2}$

viardi, $P$ I

vihara, $I$ I

viola, $A_{4}$

violacea, $J 3$

viribus, $P$ I I

viridissima, $G$ I6

viviana, $F_{21}$

waigeoensis, $L_{2}$

wallacei, $B_{4}$

wanda, $\mathrm{H}_{5}$

waterstradti, $B_{4}$

watsoni, $O$ I

weelii, $\mathrm{O}_{2}$

whiteheadi, $I 6$

wildei, $G_{3}$

wildeyana, $I$ I I

wilemani, $F_{4}$

wimberleyi, $I_{9}$

woodii, I2

xenon, $B$ Io

xisuthrus, $P_{\text {I I }}$

yajuna, $B$ I 6

yendava, $A$ I 8

zalinda, $G_{\text {I } 3}$

zambra, $F 6$

zelea, $N_{\text {I }}$

zephyretta, $\mathrm{O}_{3}$

zeta, II 4

zilana, $P_{2}$

zilensis, $F_{23}$

zohar, $\mathrm{P}_{2}$

zylda, $B$ I 8 


\section{$2 \mathrm{BHL}$ Biodiversity Heritage Library}

Evans, William Harry. 1957. "A revision of the Arhopala group of Oriental Lycaenidae (Lepidoptera: Rhopalocera)." Bulletin of the British Museum (Natural History) Entomology 5, 85-141. https://doi.org/10.5962/bhl.part.1508.

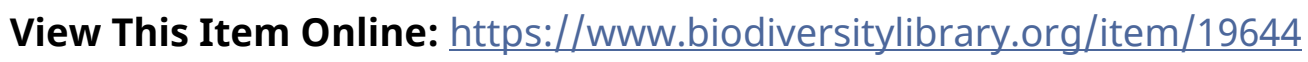

DOI: https://doi.org/10.5962/bhl.part.1508

Permalink: https://www.biodiversitylibrary.org/partpdf/1508

\section{Holding Institution}

Natural History Museum Library, London

\section{Sponsored by}

Natural History Museum Library, London

\section{Copyright \& Reuse}

Copyright Status: In copyright. Digitized with the permission of the rights holder.

Rights Holder: The Trustees of the Natural History Museum, London

License: http://creativecommons.org/licenses/by-nc-sa/4.0/

Rights: http://biodiversitylibrary.org/permissions

This document was created from content at the Biodiversity Heritage Library, the world's largest open access digital library for biodiversity literature and archives. Visit BHL at https://www.biodiversitylibrary.org. 